\title{
Our world in words : the business implications of word use in online conversations
}

Citation for published version (APA):

Ludwig, S. (2012). Our world in words : the business implications of word use in online conversations.

[Doctoral Thesis, Maastricht University]. Prost Druck GmbH. https://doi.org/10.26481/dis.20121221sl

Document status and date:

Published: 01/01/2012

DOI:

10.26481/dis.20121221sl

Document Version:

Publisher's PDF, also known as Version of record

\section{Please check the document version of this publication:}

- A submitted manuscript is the version of the article upon submission and before peer-review. There can be important differences between the submitted version and the official published version of record.

People interested in the research are advised to contact the author for the final version of the publication, or visit the DOI to the publisher's website.

- The final author version and the galley proof are versions of the publication after peer review.

- The final published version features the final layout of the paper including the volume, issue and page numbers.

Link to publication

\footnotetext{
General rights rights.

- You may freely distribute the URL identifying the publication in the public portal. please follow below link for the End User Agreement:

www.umlib.nl/taverne-license

Take down policy

If you believe that this document breaches copyright please contact us at:

repository@maastrichtuniversity.nl

providing details and we will investigate your claim.
}

Copyright and moral rights for the publications made accessible in the public portal are retained by the authors and/or other copyright owners and it is a condition of accessing publications that users recognise and abide by the legal requirements associated with these

- Users may download and print one copy of any publication from the public portal for the purpose of private study or research.

- You may not further distribute the material or use it for any profit-making activity or commercial gain

If the publication is distributed under the terms of Article $25 \mathrm{fa}$ of the Dutch Copyright Act, indicated by the "Taverne" license above, 
online communicationam

members' perceptions and partu

should Our World bees

reaping Our World the bention

effective. An important reason is thater panies collaboration by neglecting $m$

communication accom

reflect their con

cial integra

embers' com

uses text mining to extract 'm Juistic properties members' pos communities. Two mixed multilevel members' linguistic style tches signal their community identification and impact their participat, the expanded view on organizational identifi are considered, by examining the trend.an Whereas a stronger trend reversals in members community level, a great individual members' development where decisions onl we studying th influence ol chang
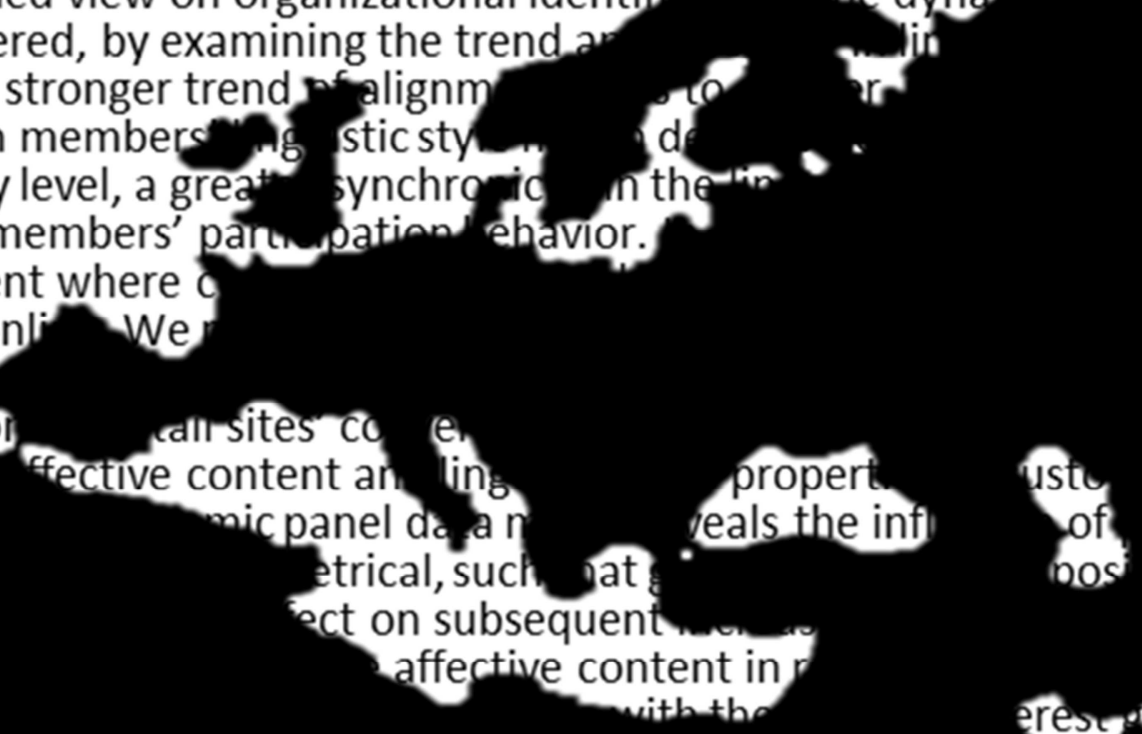

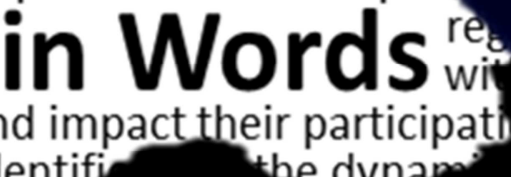

\section{The Business Implications of Word Use in Online Conversations}





\section{Our World in Words}

THE BUSINESS IMPLICATIONS OF WORD USE

IN ONLINE CONVERSATIONS

Copyright 2012 by Stephan Ludwig

All rights reserved. No part of this publication may be reprinted or utilized in any form or by any electronic, mechanical or other means, no known, or hereafter invented, including photocopying and recording, or in any information storage or retrieval system, without written permission from the copyright owner. 


\section{Our World in Words}

THE BUSINESS IMPLICATIONS OF WORD USE

IN ONLINE CONVERSATIONS

\section{PROEFSCHRIFT}

Ter verkrijgingvan de graad van doctor aan de Universiteit Maastricht op gezag van de Rector Magnificus, Prof. dr. L. L. P. Soete volgens het besluit van het College van Decanen, in het openbaar te verdedigen

Op Vrijdag 21 December 2012 om 10 uur.

Door

Stephan Ludwig 


\section{Promotores}

Prof. dr. Ko de Ruyter

Prof. dr. Martin Wetzels

Prof. dr. Gerard Pfann

\section{Copromotor}

Dr. Elisabeth Brueggen

\section{Beoordelingscommissie}

Prof. dr. Jos Lemmink (voorzitter)

Prof. dr. Willemijn van Dolen, Universiteit van Amsterdam

Prof. dr. Stan van Hoesel 
The only true wisdom

is in knowing

you know nothing.

- Socrates (470 BC-399 BC) 


\section{ACKNOWLEDGEMENTS}

In the end, it is not only the work one puts in nor the skills one acquires that will lead to the successful completion of a dissertation, but the people that surround and support you.

It sure took me some time to realize, that answering the question "So what's your theoretical contribution" is not only necessary, but also a lot of fun. I would like to thank my promoter Ko de Ruyter for being the conduit for academic enthusiasm in my $\mathrm{PhD}$ process. His continued guidance and support were invaluable to this dissertation. Moreover, I would like to thank my promoter Martin Wetzels for his methodological guidance, advice and support throughout these four years. No matter what the challenge was, the support was always strong with me. And because all good things come in threes, I am also grateful for the enthusiasm and guidance of my third promoter Gerard Pfann. It was thanks to his great support and infinite patience that I learned the necessary steps of dynamic panel data analysis to complete the empirical endeavors of my dissertation. Thank you all for your continued support and guidance. I strongly believe that it is your complementary diversity in backgrounds and knowledge that made this dissertation.

Staying with "diverse yet complementary", a somewhat unique aspect of my $\mathrm{PhD}$ process is that it was fully sponsored by InSites Consulting. Throughout my process, I had the advantage of being able to discuss my work not only with my academic advisors but also with InSites' market research experts. It was an invaluable learning exercise to me to continuously align the academic thought and rigor with the practical relevance and inspirational drive which characterizes work at InSites every day. This is why I would like to acknowledge the skilled and tireless support of each and everyone at InSites. I am especially indebted to the current and previous members of the ForwaRD Lab, Dr. Niels Schillewaert, Tom de Ruyck, Annelies Verhaege, Elias Veris, Daniel Soto and Dr. Mike Friedman. Thanks to you, I got to experience and contribute to the evolution of research communities into a true corporate 
spearhead as well as the advancement of text-mining as a key means to generate customer insights. InSites, thank you!

Furthermore, I would like to thank Jos Lemmink, Willemijn van Dolen and Stan van Hoesel for their valuable feedback on my dissertation. I deeply appreciate your time and efforts in revising my chapters.

Special thanks go to my colleagues at the marketing department who enabled me to work in a stimulating, supportive and collegial atmosphere. I am especially grateful for the down to earth, non-competitive and friendly atmosphere amongst the PhDs which I believe is unique to this group - keep it up! Thanks also goes to Pascalle, Eefje and Nicole who supported me in all administrative questions and always made the secretariat an entertaining place. Thanks to Clemens, Jacqueline, Jan, Jessica, Roos and Theo. The room F 1.04 was always a fun and inspiring office. I am also grateful to Hannes and Matthias for their efforts and support, especially during these final stages of my PhD. Thanks are due to my co-authors, especially Dominik Mahr and Mike Friedman; it sure was not only productive and inspirational to work with you, but also a great deal of fun.

I would like to thank my parents Ute and Edgar and my brother Martin who, despite of the many kilometers that part us, were there for me every time it counted. Thank you for supporting my life- and career choices at every step of the way, for always reminding me that life is most importantly about living and for making physical distance negligible.

Last, but certainly not least, I would like to thank Julia for her love and support. Without you I would never have come to Europe in the first place. It was you who carried me through this $\mathrm{PhD}$ and who stood by me at all times. The greatest thing about this life is that $\mathrm{I}$ get to spend it with you.

Thank you all. 


\section{TABLE OF CONTENTS}

\section{INTRODUCTION}

Prelude 1

Practical Relevance 3

Text mining Content and Function words 8

$\begin{array}{ll}\text { Theoretical Considerations } & 11\end{array}$

Research Questions 15

\section{TAKE THEIR WORD FOR IT}

Introduction 18

Conceptual Background 21

Hypotheses Development 25

Individual LSM 25

Individual LSM patterns 26

Group-level LSM 29

Empirical Study $\quad 31$

Setting 31

Data and Measures $\quad 32$

Pre-study 42

Data Analysis $\quad 42$

Results 44

Discussion and Conclusion $\quad 47$

Theoretical Implications $\quad 47$

Limitations and Further Research 51

Managerial Implications 53

\section{MORE THAN WORDS}

Introduction $\quad 55$

Conceptual Backround $\quad 59$

Hypotheses Development 65

Affective Content 65

Linguistic Style Match 67

Joint Impact of Affective Content and LSM 68 
Empirical Study $\quad 70$

Setting $\quad 70$

Data and Measures 72

Data Analysis $\quad 78$

Results $\quad 81$

Discussion and Conclusion $\quad 88$

Theoretical Implications $\quad 88$

Limitations and Further Research 92

Managerial Implications $\quad 94$

\section{CONCLUSION}

Synopsis 97

Further Research Suggestions 101

Managerial Implications 104

Final Thought 106

$\begin{array}{ll}\text { REFERENCES } & 107\end{array}$

$\begin{array}{ll}\text { APPENDIX } & 122\end{array}$

$\begin{array}{ll}\text { SUMMARY } & 124\end{array}$

SAMENVATTING 126

RESEARCH @ InSites Consulting 128 


\section{1 \\ INTRODUCTION}

\section{Prelude}

The words we use in our daily lives reveal important aspects of our social and psychological worlds. Any time we talk to new people, we can share our views and opinions. Yet, beyond sharing content, the style in which we communicate is a way to present ourselves to our audience and judge them by the way they talk with us.

Online conversations are no different. When we read an email, blog or product review, just as when we meet a new person in real life, we consider what they write to learn their story. We also reflect on their writing style to judge whether we like and trust them.

Imagine you are looking to buy a Book on the Hip Hop and Reggae music styles for one of your friends via the online retailer Amazon.com. To get a better idea of the book's quality, you read the following two product reviews posted by previous customers:

Customer 1: "This is book rocks, really awesome stuff- you need to get it right away!"

Customer 2: "This book is very poorly written; it is also missing significant information and seems incomplete in general. I would suggest looking for an alternative."

Clearly the opinions of these customers diverge, where customer 1 talks about an awesome book, customer 2 uses adjectives like poor and incomplete to describe it. Yet whose' opinion are you likely to trust, before you spend those 100 Euros to buy the music book? To 
answer this question you no longer consider the reviews' contents, but their writing styles. You have no way of knowing who these people are, yet you already have a picture of them in your mind based on the way they write. Depending on how well their writing style matches your own, or matches someone who you believe may be knowledgeable about Hip Hop and Reggae, will let you decide whom to trust. Now imagine these are not reviews for a music book but instead for a book on business statistics. Not only may this change which review you trust, it also means you are no longer buying the book, not because of what the reviews say about the books but because of how they are written.

"Language is the currency of most human social processes" (Chung et al. 2007, p. 343). We use words to describe the content of our feelings and thoughts, but our particular word usage style also reveals parts of our personality and backgrounds. Despite this central role of language, few investigations in the social sciences have actually studied peoples' word usages in the real world and the resulting implications. The reason, of course, is that until the very end of the 20th century, the analysis of text was labor intensive, expensive and involved complex coding. The purpose of my research is to suggest that social scientists in general and marketers in particular, by using automated text mining methods, can explore real life language use and its implications in new and rich ways, on a scale never imagined. 


\section{Practical Relevance}

\section{The promise of online customer conversations}

The past decade has witnessed an incredible increase in the volume and importance of online conversations in people's daily lives. Touching almost all ages, ethnicities and geographies; the spectacular rise of sites like Facebook and Twitter is revolutionizing the way

people communicate and interact with friends, family, colleagues and, perhaps most revolutionary of all, complete strangers. Just as they are used to establish and maintain interpersonal relationships, online conversations are used by customers to scrutinize, discuss and evaluate products and services.

Indeed Facebook is the third biggest country in the world, counting over 500 million inhabitants, 60 percent of whom directly comment on products and services in their posts (Incite 2011; Levy 2010). Moreover, there are 200 million tweets posted daily, 19 percent of which discuss brands, products and services (Jansen et al. 2009). Similarly, online retailers like Amazon.com receive thousands of new customer reviews scrutinizing their products and services on a daily basis.

The rise of online conversations has toppled traditional one-directional, firm-tocustomer communication formats and has caused companies to re-invent their business models to remain competitive. One result of this development is that companies increasingly facilitate and encourage customer conversations on their own online sites and communities.

Online retailers provide examples of how to successfully integrate customer conversations into their business practices (e.g. Amazon.com and Barnes\&Nobles.com). Initially focusing on business-to-customer relationships between itself and its customers, Amazon realized customers' need for sharing and obtaining unbiased, peer information regarding products and services. Enabling any customer to write product and service reviews 
has been key to Amazon's exponential growth over the past years. Similarly, Klaka, Social Media Marketing Manager at Conrad (2009, p. 1) states: "We introduced reviews because we were convinced that our customers' opinions would help others with their buying decisions," and happily confirms "The sales data tells us our assumptions were correct." Indeed, 98 percent of online shoppers read online customer reviews before making a purchase online (Freedman, 2008) and a report by ComScore (2007) shows 24 per cent of Internet users access such reviews before paying for a service delivered offline. Furthermore, a Deloitte market study (2007) shows, 69 percent of those who read customer reviews share them with people in their social circle, thus magnifying their impact. Accordingly, research confirms the positive effect such feedback mechanisms can have on buyers' trust in sellers (Pavlou and Dimoka 2006) and, provided they are positive, such reviews can have a positive influence on products'sales (e.g. Archak et al. 2011; Chevalier and Mayzlin 2006; Clemons et al. 2006)).

The majority of Fortune 1000 companies has also recognized the increased popularity of online conversations amongst customers and tries to benefit from the trend by introducing so-called user-communities. Such communities "constitute an online social structure woven from continuous interactions among individuals focused around shared interests and common practices, as well as usage of the same tools and products" (Dahlander and Frederiksen 2012, p. 989). In general, members and their conversations in these user-communities are considered a desirable means for adding value along the entire innovation process (Nambisan and Baron 2009) but community members can also provide product and service support to fellow customers (Schau et al. 2009).

Popular examples include Dell's online user-community called Dell IdeaStorm: Where Your Ideas Reign. This user-community solicits customers to submit and discuss their experiences and improvement suggestions for Dell's products and services. LEGO's Design by $M E$ has transformed the company's innovation business model. By downloading free 
software provided by LEGO, users can design their own sets which are subsequently made available for purchase. Through this user-community, LEGO has boosted the amount of sets it produces, from 200 to over a million per year (Pulman-Jones 2012). The car manufacturer Audi initiated a user-community called "'Virtual Lab,'” where 1,662 car enthusiasts develop ideas for future infotainment systems and discuss product configurations (Füller et al. 2006).

Despite these successful examples of how businesses utilize customers' online conversations, for the most part businesses find themselves overwhelmed, even scared, of the exponential growth quantity, speed and reach of seemingly unmanageable text-based conversations about them (Lee and Bradlow 2011; Singh et al. 2011), and sound principles for analyzing and using such conversations are not yet firmly established.

\section{The problem (it's) in words}

The unstructured, text-based nature of online customer conversations renders traditional methods to detect customer perceptions (such as preference data or satisfaction surveys) obsolete. Yet it is these perceptions which are crucial to comprehend the meaning and implications of online conversations and to react accordingly.

While it is great to have customers advocating your products online, pity the product or retailer that customers do not like. A Nielsen (2010) survey shows 41 percent of customers are willing to share negative product experiences online via Twitter or by writing a review. Some customers even create entire Web sites or blogs to punish brands' product and service failures. Take ihatestarbucks.com as an example. Importantly, companies' failure to react to such negative conversations can cause severe financial and reputational damages, or as puts it, we now live "in a world where one angry tweet can torpedo a brand" (Bernoff and Schadler 2010, p. 95). Consider, for example, the bicycle lock producer Kryptonite. On September 12, 2004, an anonymous customer posted that the unbreakable, U-shaped Kryptonite lock could 
be easily opened with a ballpoint pen. Within days, the news was shared in blogs and chat rooms. The fury in customers' online conversations forced Kryptonite to call back all affected locks on September 22 (Duan et al. 2008).

Even in settings where quantifiable rating scales are presented next to text-based customer reviews, these rating scales fail to succinctly capture the sentiment and impact of the text-based conversations. For example, despite mildly positive quality ratings (e.g., 6.2 out of 10 on imbd.com, $67 \%$ freshness score on the Rotten Tomatoes movie review site), the motion picture Bruno fell $\$ 20$ million short of box office expectations, more in line with rich narrative reviews that expressed audience members' disappointment (Corliss 2009).

Similarly, though user-communities can be a significant source of value, research shows the extent to which such value can be realized critically depend on the social integration of members' into the community (Joon et al. 2007). Yet, the socialization perceptions of members in these communities remains largely unknown, as community managers have no way of knowing how their members feel about their community involvement (Moran and Gossieaux 2010). Failure to monitor and manage members' socialization perceptions has been posited to be a primary reason for the vast majority of usercommunities that fail (Moran and Gossieaux 2010). For example, in a recent study, Spaulding (2009) illustrates how $75 \%$ of user-communities fail to acquire and sustain participation and are more like ghost towns than thriving communities. Similarly, 91.2 percent of user-communities on MSN have fewer than 25 members, and count between 1 and 20 posts in total (Farnham 2002).

Simply put, the sheer volume of online conversations and their unstructured, textbased nature renders traditional research methods, such as cross-sectional and longitudinal surveys obsolete in gauging customer perceptions. Text mining has been suggested as a solution. By automatically scanning unstructured text for user-specified key words, this 
method proves useful to distill underlying meaning from text-based data (Kambil et al. 2005). This dissertation uses text mining to investigate different aspects of word usage in people's online conversations, the drivers of this word use and their behavioral consequences. The next section will elaborate on how text mining works and what should be mined to extract meaning from online conversations. 


\section{Text mining content- and function words}

Computer-automated approaches to analyze text are generally referred to as computeraided text analysis (e.g. (Duriau et al. 2007; Pollach 2012; Short et al. 2010) or text mining (Lee and Bradlow 2011; Singh et al. 2011). Text mining generally uses word count strategies to derive underlying meanings from textual accounts. The process of text mining is divided into three steps, (1) structuring any form of written texts into a database, (2) extracting word usage patterns within these textual accounts, and finally (3) using quantitative analysis to make inferences from texts to context in an objective and systematic manner (e.g. Neuendorf 2002; Pennebaker et al. 2003; Pollach 2012). Research questions typically investigate the presence or intensity of words in texts signifying research relevant concepts (for example the presence/strength of positive and/or negative sentiments by the count of emotion words), or the co-occurrence of two concepts (Krippendorff 2004).

The central premise of text mining is based on the assumption that the frequency with which particular words and concepts occur in a text is (1) a measure of their relative importance, attention, or emphasis (Krippendorff 2004) and (2) conveys psychologically relevant information over and above the words' literal meaning (Pennebaker et al. 2003). Although there has been some debate between language researchers concerning this assumption, most researchers see unique advantages in automatically analyzing word use, since this cannot be achieved efficiently through manual coding (Hart 2001).

Two approaches to text mining analysis can be distinguished, depending on the source of the word lists (generally referred to as text mining dictionaries) used to extract text-based measures. Researchers can either make use of existing dictionaries or compile a dictionary specifically for a particular study (Pollach 2012). Arguably, self-constructed dictionaries are more suitable to explorative research. For example, they have been used to give an overview of the justifications for manager compensations in corporate statements (Porac et al. 1999), or 
to explore metaphors for teamwork used in interviews (Gibson and Zellmer-Bruhn 2001). Conversely, to study categories of organizational values (Kabanoff et al. 1995), the social relation between conversants (Ireland and Pennebaker 2010), or the emotional tone of newspapers (Humphreys 2010), researchers have drawn on existing, predefined dictionaries.

In our studies we use predefined and externally validated dictionaries, an arguably more deductive approach, to derive our measures. Specifically, we utilize the Linguistic Inquiry and Word Count (LIWC) dictionaries, to deduce our theoretical constructs from the text-based online conversations. The LIWC dictionaries, rather than being study-specific, represent collections of words that have been pre-classified, by independent raters, from the entire range of vocabulary in the English language. Furthermore, these dictionaries have been the subject of extensive testing and analysis in order to ensure that they give important and valid information, irrespective of the specific study context (for details on the process and specific findings, please see Pennebaker et al. 2007). We use the LIWC dictionaries for extracting function word categories (articles, prepositions, pronouns including first person singular, first person plural, etc.) and word categories for psychological processes (positive and negative emotion, cognitive processes such as use of causation words). The robustness and usefulness of these dictionaries has already been demonstrated in multiple scientific disciplines (Pennebaker et al. 2007) and across diverse forms of online content, such as blogs (Cohn et al. 2004), web forums (Dino et al. 2009), instant messaging (Slatcher and Pennebaker 2006), newspaper articles (Humphreys 2010) and online group negotiation settings (Huffaker et al. 2011).

Importantly, my research critically distinguishes itself from previous research across business disciplines applying text mining, by considering not only content words but also function words. The few notable research studies in business research which have applied text mining approaches have solely focused on words that suggested specific content themes, 
predominantly sentiment (Das et al. 2005; Humphreys 2010). These research studies considered - what people are talking about - by mining the use of nouns, verbs, adjectives and adverbs, commonly referred to by linguistics as content words (Tausczik and Pennebaker 2010, p. 29).

Yet linguistics and social psychologists highlight the fact that, there is much more to communication than content (Allport 1961). The communication style is seen as equally important - i.e. how people put their words together to create a message. Consider the example in the prelude to this dissertation, in which the two customers express their views on a book. Not only do the reviews' contents diverge, the styles in which they are written hint at other relevant information. Reviewer 1 expresses herself in a very colloquial and informal style, while Reviewer 2 is almost overly stiff and formal. The two reviewers differ in their linguistic styles, or at word level - their function word usage (comprising pronouns, prepositions, articles, conjunctions, and auxiliary verbs). Whereas the average native English speaker has an impressive vocabulary of well over 100,000 words, less than 400 are function words (Pennebaker et al. 2007). This deceptively trivial percentage (less than 0.04\%) accounts for over half of the words people use in their daily conversations (Rochon et al. 2000). Function words have been shown to have a powerful impact on the reader and, at the same time, reflect a great deal about the writer.

Using both these linguistic word categories, we conducted automated text mining analysis on the population of user-community posts (in study 1) and customer reviews (in study 2) to identify not only what people write but also how they write. 


\section{Theoretical Considerations}

The ways in which people use words convey substantial information about who they are, their relationship to their audience, and their intentions (Pennebaker et al. 2003). In addition, word use is 'metacommunicative' (Bateson 1972), inviting the audience not only to decide whether or not to agree with the viewpoints presented but also inducing them to create mental perceptions about the communicator (Fairclough 1992). Words use in online conversations, in this perspective, are not simply a means to share realities but to actually create them (Gergen and Thatchenkery 2004). Following research in linguistics and social psychology, this dissertation distinguishes between content and function words in online conversations. We investigate how word use relates to a conversant's perceptions and how word use influences their own and their audience's behavior.

First, we consider the implications of word use for the conversant's own perceptions and behavior. Given the relative anonymity of online user-communities, which are void of most social cues, text-based online conversations are the predominant means by which members understand and construct their community realities. It is commonly known that the successful social integration of members into the user-community is crucial for sustaining their participation efforts. Word usage and the development thereof may be unobtrusive conduits to members' integration perceptions and participation behavior. Therefore, drawing on communication accommodation theory, we investigate how word usage styles can be used to assess the socialization and behavior of user-community members.

Second, we investigate the implications of conversants' word use for the behavior of their audience. The sheer volume of online conversations often leads customers to process information heuristically. Feldman and Lynch (1988) posit that the relative weight of heuristic inferences, as decision inputs, depends on two context-dependent facets namely their relative accessibility and diagnosticity compared with alternative inputs. The particular use of content 
and function words may define the relative accessibility and diagnosticity of online conversations and in turn their impact on the audience. To investigate this, we draw on research into the influence of affect on consumer decision making (Pham, et.al. 2008) and communication accommodation (Giles and Coupland 1991). We examine the impact of both affective word cues and function word usage styles on the audience's purchase decision making within online retail settings.

\section{Communication Accommodation Theory}

Our first study is grounded in communication accommodation theory (CAT). Studying interactions between conversants, Giles and Coupland (1991) explained individual variations in speaking styles by developing communication accommodation theory. Originally developed as speech accommodation theory, Giles and Coupland renamed their theory Communication Accommodation Theory in 1991 to account for the fact that interactants not only make communicative adjustments via speech characteristics but also other communicative behaviors (e.g., nonverbal behaviors and discourse patterns). The key premise of CAT is that conversants adapt their speech and communication patterns to become "more like their interactant in a bid to decrease social distance, seek or signal approval, and thereby accommodate" (Giles et al. 2007, p. 142). If you have ever found yourself matching the vocabulary, speed or posture of the person you are talking to, you have experienced a firsthand illustration of Communication Accommodation Theory. Accordingly, conversants can adopt one of two main accommodation processes. They can match their communicative behavior to the interactant(s) in order to reduce social differences and create a "positive image" in the minds of others (McCroskey and Richmond 2000, p. 279). Conversely, they can diverge by accentuating differences in communicative behavior, signaling an attempt to distance themselves from their interactants. Building on these processes research finds 
evidence of communication accommodation through matching word choices, sentence or utterance length, or even mimicking nonverbal cues (Miller 2005). Reasons for people to converge include their desire to be liked or socially accepted, or to increase identification with their interactant(s) (Miller 2005). Several researchers have recently highlighted that, given the relative anonymity and absence of non-verbal cues in computer mediated communication, accommodation manifests itself through convergence (vs. divergence) in writing styles, or the degree of linguistic style match (Ireland and Pennebaker 2010). Consequentially, we study how communication accommodation, measured by the degree of linguistic style match, can be used to assess members' level of identification and participation behavior in online usercommunities

\section{The Accisibility-Diagnosticity Framework}

Feldman and Lynch (1988) accessibility- diagnosticity framework is central to our second study. Their framework posits that "an earlier response will be used as an input to a subsequent response if the former is accessible and if it is perceived to be more diagnostic than other accessible inputs" (Feldman and Lynch 1988, p.431). Where the term accessibility refers to the ease of retrieving input information, diagnosticity refers to the sufficiency of this information to arrive at a satisfactory decision concerning the task at hand. In the customer review context of our second study, where the sheer volume of reviews often leads consumers to process information heuristically, the likelihood that a review would be used in the purchase decision making is dependent upon (1) the ease with which the viewpoint, or product experience is accessible; and (2) the perceived diagnosticity of the viewpoints suggested. Drawing from research on affect in consumer decision making, we posit that affective content words serve as readily accessible cues used by readers to approximate the product experience. Moreover, we suggest that the relative diagnosticity of reviews depends 
partially on the extremity to which affective content words are used but also (drawing on communication accommodation research outlined above) the degree to which the reviews' linguistic styles match the conventional style of reviewers within a particular product genre. 


\section{Research Questions}

This background suggests that in online text-based conversations, content and style convey critical implications regarding the conversants' and audience's perceptions and behavior. The central research problem of this dissertation is to address the outlined gaps in the marketing literature on assessing the meaning and impact of online text-based communication. Two quantitative studies have been conducted, encompassing 6 key research questions, to provide theoretical and managerial insight. The first, contributes to the emerging but limited body of research on the symbolic role of communication style in user-communities. It explores the implications of function word usages and the temporal development thereof, at the individual and group-level, for user-community members' perceptions and participation behavior. The second study, contributes to contemporary research on customer reviews, extracting customer review texts linguistic content and style properties, to demonstrate their dynamic influence on conversion rates in online retail sites.

Chapter 2: "Take their Word for it": The Symbolic Role of Linguistic Style Matches in User-Communities

While user-communities are increasingly becoming an essential element of companies' business processes, reaping the benefits of such social systems does not always prove to be effective. An important reason is that companies fail to continuously stimulate members' collaboration by neglecting members' social integration in these communities. Following communication accommodation theory, members' communication style alignment may symbolically reflect their community identification and impact subsequent participation behavior. This research study uses text mining to extract linguistic style properties of 74,246 members' posts across 37 user-communities and estimates two mixed multilevel poisson regression models to address the following research questions: 
$\mathbf{R Q}_{1}$ : Following communication accommodation theory, do members' linguistic style matches with the conventional community style signal their community identification and impact their participation quantity and quality?

$\mathbf{R Q}_{2}$ : Drawing on the expanded view of organizational identification, do shape patterns in the temporal development of linguistic style matches (trends and reversals) reliably and distinctly predict participation quantity and quality?

$\mathbf{R Q}_{3}$ : At a community level, does a greater synchronicity in the linguistic style across all community members foster individual members' participation quantity and quality?

Chapter 3: "More than Words": The Influence of Affective Content and Linguistic Style Matches in Online Reviews on Conversion Rates

Customers increasingly rely on other consumers' reviews to make purchase decisions online. New insights into the customer review phenomenon can be derived from studying the linguistic content and style properties of verbatim customer reviews to examine their influence online retail sites' conversion rates. This research study employs text mining to extract changes in affective content and linguistic style properties of customer book reviews on Amazon.com. For 17 consecutive weeks we recorded product and retail site related information for a total of 591 books and 18,682 customer reviews. We estimate a generalized method of moments (GMM) model to empirically investigate the following research questions:

$\mathbf{R Q}_{1}$ : Is there a nonlinear influence of extreme positive and negative changes in customer reviews affective content on conversion rate dynamics?

$\mathbf{R Q}_{2}$ : How do changes in linguistic style matching between a product review and the interest group's linguistic style impact conversion rate dynamics? 
$\mathbf{R Q}_{3}$ : How do positive changes in affective cues and increasing congruence with the product interest group's typical linguistic style conjointly influence conversion rate dynamics?

In chapters 2 and 3, we address each question and detail my research into them. Finally, chapter 4 concludes by summarizing the main findings about the meaning and implications of communication style in online collectives. Drawing on my findings, the conceptual implications are discussed; suggestions for further research presented and ideas for managers are offered. 


\section{TAKE THEIR WORD FOR IT: THE SYMBOLIC ROLE OF LINGUISTIC STYLE MATCHES IN USER-COMMUNITIES1}

\section{Introduction}

An increasing number of companies assume that user communities can be leveraged to provide access to their end users' insights and resources (Dahlander and Frederiksen 2012). However, the benefits of this assumption have not always been realized; at least half newly established user communities fail to sustain members' participation and collaboration (Ransbotham and Kane 2011). With virtually no barriers to switching to various alternative user communities (Iriberri and Leroy 2009), members' social integration and identification with the community is the key reason they stay and participate (Kohler et al. 2011). Yet the socialization of newcomers in these communities remains largely under the radar; community managers have relied predominantly on post and visit counts as indicators of members' integration and ongoing participation (Moran and Gossieaux 2010). An almost exclusive focus on such quantitative, surface-level parameters ignores how text posts serve as conduits that signal identification and help new members interpret and reveal "how things are done around here" (versus observation of formal procedures and isolated practices) (Herring 2001).

Using text posts, users contribute their ideas and views, such that these posts serve as in vivo tests, providing information about consensual behavior and the extent to which

\footnotetext{
${ }^{1}$ Stephan Ludwig, Ko de Ruyter, Dominik Mahr, Martin Wetzels, Elisabeth Brueggen, "Take Their Word For It": The Symbolic Role of Linguistic Style Matches in User-Communities, under review at MIS Quarterly (revise and resubmit)
} 
members agree to it (Fayard and DeSanctis 2010). Although user communities thrive on diversity in members' ideas and views (Di Gangi et al. 2010), patterns of subtle similarities in the way members converse may indicate an active process of social integration, which drives members' ongoing participation. New managerial insights on members' social integration and participation in user communities thus can emerge from their communication styles.

Accordingly, this study incorporates emerging, cross-disciplinary theorizing that views communication is a symbolic action (Heracleous and Marshak 2004). The basic premise of this paradigm is that the act of communication transcends information content by conveying conversants' underlying intentions (Fayard and DeSanctis 2010). In the body of research referred to as communication accommodation theory (CAT) (Giles 2009a), a focal communicative process pertains to how conversants align with a consensual style of interaction. Accumulating evidence indicates that in computer-mediated, text-based communication, linguistic style matches (LSMs) among conversants signal social identification perceptions (Ireland and Pennebaker 2010) and influence cooperative behavior (Huffaker et al. 2011). However, this evidence and recent theorizing in CAT, is primarily limited to communication dyads and cross-sectional designs. It remains uncertain whether these findings generalize to members' alignment with the style of interactive, ongoing online collectives, such as user communities that continuously exchange and discuss ideas among multiple members. That is, does LSM in a user community context reflect a process of social identification (Ireland and Pennebaker 2010)? Furthermore, it is not clear how LSM, as a process, develops over time and whether diverging temporal patterns in LSM distinctly foster community members' participation behavior. Finally, communication research thus far has focused on text or a member posting text in one community but neglected the societal context in which the text is nested (Hardy et al. 2005). Thus, it is uncertain how differences between communities with regard to linguistic style practices influence the individual members' 
allocation of their efforts (Brockman and Morgan 2006). This study contributes to an emerging but limited body of research on the symbolic role of communication styles in user communities by addressing three critical issues.

First, it extends CAT by conceptualizing LSM in text-based user communities as symbolic action that signals member identification with the community and predicts their participation efforts in the community. We disentangle LSM's effect on two key community member performance parameters: (1) participation quantity (post frequency) and (2) participation quality (substantiated development of arguments). Both are critical for sustaining the value and appeal of the user communities to its members and hosts (Ransbotham and Kane 2011). Second, in accordance with the inherently dynamic process of members' social integration into organizations (Levine and Moreland 1994), this study considers the temporal development, or gestalt, of LSMs. We suggest two distinct temporal patterns in members' LSMs (trend and reversals) and detail their distinct influence on members' participation efforts. Third, for the plethora of user communities, which suffer from a relative paucity of contextual implications for communication, it seems both managerially and conceptually relevant to examine between-community differences in members' LSM cohesiveness and their effects on individual members' contribution behavior. 


\section{Conceptual Background}

The central premise of communication accommodation theory (CAT) is that symbolic actions, inherent to communication styles, form the basis for linguistic style adaptions. Conversation partners thus adapt their communication style to become "more like their fellow interactants in a bid to decrease social distance, seek or signal approval, and thereby accommodate" (Giles et al. 2007, p 142). By referring to an object, conversants develop a shared conceptualization or conceptual pact that they can refer to in subsequent discussions, resulting in lexical entrainment (Brennan and Clark 1996). In line with this definition, CAT suggests that people consciously or subconsciously accommodate their dialogue partners to develop closer relationships and signal empathy, credibility, and a common social identity (Giles et al. 2007). Across communication formats, conversants can accommodate one another by mimicking verbal behaviors, such as matching word choices and utterance length, or nonverbal behavior, such as facial expressions or posture (Ireland and Pennebaker 2010).

With the rise of social media, user communities have become a more widely embraced communication format (Ransbotham and Kane 2011). They enable relationships among a group of members and collective goal attainment. In the absence of face-to-face contacts and other explicit member information, the words used in text-based posts become the only symbols available ((Kohler et al. 2011; Ma and Agarwal 2007). Accordingly, people's degree of accommodation in linguistic style may be particularly relevant in computer-mediated communication settings, to assess conversants' social identification and subsequent behaviors.

To derive linguistic styles and the proximity between two or more writing styles, researchers in communication science and linguistics highlight the use of "function words," which indicate sentinel structure within texts (Tausczik and Pennebaker 2010). Function words comprise categories such as pronouns, prepositions, articles, conjunctions, or auxiliary 
verbs; are used subconsciously; and constitute $55 \%$ of daily word usage. In contrast with nonfunction words (e.g., nouns, verbs, adjectives), which convey content, function words set the tone for social interactions and are key to understanding the relationships among speakers, objects, and other people (Chung and Pennebaker 2007). In line with CAT, the similar use of function words, and thus a greater LSM, represents a symbolic move toward stronger social identification and/or psychological synchrony (Ireland and Pennebaker 2010). Thus, LSM fosters understanding and decreases perceived social distance. For example, for couples on a first date, LSMs predict subsequent relationship viability; Huffaker et al. (2011) show that in online negotiations, greater matches in function word usage increase interpersonal rapport and agreement between potential coalition partners. Therefore, LSM is a sensitive, unobtrusive symbol of conversant affinity, diagnostic of behavioral outcomes regardless of the interaction environment, perceived quality, length, or objective (Niederhoffer and Pennebaker 2002).

Beyond an individual-level communicative alignment, verbal mimicry represents a key indicator for collective alignment (Kozlowski and Ilgen 2006) that can influence group performance (Brockman and Morgan 2006). Yet this communication style assimilation is distinct from so-called markers of community (Muniz and O'Guinn 2001), such as codified rituals and traditions, formal procedures, and isolated events. Communities may develop a distinctive collective communication style to achieve a sense of oneness or consciousness (Fayard and DeSanctis 2010). Members switch between communication styles to align or distance themselves from a particular collective (Gumperz 1996). Thus, we conceptualize an individual member's alignment with a common communicative style as a symbolic action, reflecting his or her identification with a community, which could affect subsequent participation efforts (Wasko and Faraj 2005).

In contrast with existing cross-sectional research, contemporary conceptualizations of members' socialization into groups consider alignment a dynamic, evolutionary process 
(Levine and Moreland 1994). For example, Elsbach and Bhattacharya (2001) demonstrate that employees fluctuate in their levels of identification with their organization. Similarly, Herring (2001) shows that people's communication patterns, rather than being stable, evolve over time. Therefore, different patterns of LSM within a community can emerge as a grouping principle and differentially signal members' identification with the collective. Previous research has shown that two properties of temporal development- the rate of change and the number of reversals in a trend-explain behavioral dynamics across scientific disciplines (DeKinder and Kohli 2008; Jokisaari and Nurmi 2009). Accordingly, it seems necessary to adopt a temporal dynamic perspective that focuses on interdependent communication incidents of members, across time and communities, to disentangle the parameters of temporal development in members' linguistic style. More precisely, we deduce LSM trends (degree of convergence toward or divergence from a collective style) and the number of reversals in these trends (changes from convergence to divergence, and vice versa) to probe their impact on members' participation quantity and quality in user communities.

Researchers have suggested that participation quantity and quality both are crucial for the effectiveness and viability of an online collective (Ransbotham and Kane 2011). Participation quantity refers to the number of a member's posts, where a higher number increases the likelihood that the member raises topics that attract a larger audience and reciprocal participation (Wasko and Faraj 2005). Conversely, lack of sufficient participation quantity may make a community unappealing for members and lead online collectives to become more like ghost towns, deserted of virtual life (Ransbotham and Kane 2011). Although important, participation quantity still may be insufficient for sustaining the community if posts hold undeveloped statements and opinions (Hansen and Haas 2001). In this vein, participation quality refers to members' efforts to develop their communication, which leads to better group discussion outcomes (Gouran 1990). This conceptualization 
corresponds with communicative argumentation quality research, which demonstrates that the development of reasoning, rather than its strength, predicts decision outcomes (Seibold et al. 2010). Thus, a community member contributing posts with more developed arguments achieves higher participation quality, which enhances the appeal of participation for others (Seibold and Meyers 2007). By focusing on this measure of argumentation development, we can compare members' participation quality across communities, irrespective of their content. Members' on-going participation in terms of quantity and quality, crucial for online communities, can only be ascertained through the successful socialization of members into the community (Wasko and Faraj 2005). We develop hypotheses that reflect these relationships. 


\section{Hypotheses Development}

\section{Individual LSM}

In user communities, members' alterations in their linguistic style, to more closely match the community's dominant style, represent symbolic acts that signal their level of social identification and give rise to their subsequent participation efforts. Research on faceto-face interactions reveals conversants' tendency to accommodate one another by adapting verbal and nonverbal behaviors (Giles 2009a); other research shows that in computermediated contexts, such communication style accommodations are manifest through interactants' assimilations in linguistic styles (Ireland and Pennebaker 2010). Research on communication accommodation further shows that LSMs elicit understanding and perceptions of a common social identity, but they decrease perceptions of social distance among partners (Giles et al. 2007). Whereas the aforementioned studies exclusively examine communication dyads, the symbolic act integral to conversants' language use also may represent social identification in groups of conversants. This position is rooted in research on both organizational discourse (e.g. Hardy et al. 2005) and information systems (Fayard and DeSanctis 2010). Fayard and deSanctis (2010), in a study of online communities, illustrate the impact of common language use on members' feelings of "we"-ness. They argue that the shared identification by members online is displayed through the enactment of a consistent discursive practice (e.g., common ways to phrase greetings and closings). Furthermore, the presence of such communication conventions can lead to the development of a set of expected behaviors. Similarly, Hardy et al. (2005) propose that the discursive construction of a collective identity through communication influences the importance that members attach to issues being discussed, as well as their willingness to invest time and energy in addressing them. Thus, the degree to which a member's linguistic style matches the overall community 
style should reflect his or her level of identification with the group and influence his or her participation.

$H_{1}:$ A member's linguistic style match is positively related to subsequent (a) participation quantity and (b) participation quality.

\section{Individual LSM Patterns}

Current literature on communication accommodation and LSM typically examines accommodation and its implications at one time or derives a single, aggregated accommodation level across all conversational intervals (Giles 2009a; Ireland and Pennebaker 2010). Similarly, user community literature almost exclusively relates community perceptions to participation likelihood at a single point in time (Faraj et al. 2011). But rather than being passively formed and stationary, members' community identifications evolve over time and are characterized by constant and active negotiation and contestation within a particular collective (Elsbach and Bhattacharya 2001; Postmes et al. 2000). The importance of considering within-individual temporal patterns for predicting people's perceptions and behaviors has frequently been emphasized in communication (Chidambaram 1996; DeSanctis and Monge 1999) and organizational turnover (Kammeyer-Mueller et al. 2005) research. In particular, reducing temporal trajectories to mean-level differences obscures members' different adjustment trajectories, which can account for additional variance in member behavior (DeSanctis and Monge 1999). To establish how a user community "grows on" its new members, we consider the temporal development of new members' socialization processes, which foster their subsequent participation behavior (Koh et al. 2007; Levine and Moreland 1994). Drawing on the extended view of organizational identification (Elsbach and Bhattacharya 2001), we also assess whether differences in members' community 
identification development, as manifested in their LSM patterns, relate differentially to participation efforts.

Researchers denote three forms of identification: identification, disidentification, and ambivalent/neutral identification (Elsbach and Bhattacharya 2001; Kreiner and Ashforth 2004).These forms constitute ways people can define themselves through attachments. In contrast with identification, disidentification acknowledges that members derive a sense of self by distancing (rather than aligning) themselves from a particular collective's attributes or principles (Elsbach and Bhattacharya 2001). Furthermore, members may have mixed, rather than one-sided, views regarding their fit with a collective. Ambivalent identification enables members to define themselves as the same as the collective at one time but different from it at other moments (Kreiner and Ashforth 2004).

Members who disidentify actively and increasingly separate themselves and their behavior from the collective (Kreiner and Ashforth 2004). Disidentification consists of a pattern of increasing disconnect between aspects of the collective and a person's selfconception (Elsbach and Bhattacharya 2001). Considering the symbolic role of LSMs, such trends should become manifest themselves in members' linguistic style convergence or divergence with the community style. Beyond an average level, trends in members' LSMs can signal whether these members increasingly adapt the linguistic style of the community and contribute to the collective identity or if they are departing from the established discursive practices and disregarding the (implicit) rules of engagement. In communication dyads, people who make adjustments in their communication style across conversational intervals display more interest in establishing common ground perceptions than conversants who do not (Ireland and Pennebaker 2010). Furthermore, recent research on the socialization of newcomers has highlighted that, beyond general trend considerations, studying the rate at which such trends occur yields finer-grained insights into temporal developments (Jokisaari 
and Nurmi 2009). Accordingly, we consider the rate of members' LSM trends, such that faster convergence (divergence) should signal greater identification (disidentification) and thereby increase (decrease) people's participation efforts.

H2: The greater the rate of convergence (divergence) in members' linguistic style matches, the higher (lower) their subsequent (a) participation quantity and (b) participation quality.

In addition to solely identifying or disidentifying, members in a collective may be ambivalent about their identification (Elsbach and Bhattacharya 2001). Particularly in collectives that are rather loosely structured, members can simultaneously identify and disidentify with the organization (or aspects of it), maintaining an overall state of ambivalence (Kreiner and Ashforth 2004). Similarly, in user communities, members may be inclined to immerse themselves in some discussion topics but completely avoid others. Such mixed feelings cause members to feel torn between identification and disidentification (Kreiner and Ashforth 2004), which should lead them to reverse the direction of their LSM trend repeatedly. The total reversals in members' communication style thus reflect consistency (or lack thereof) in a member's identification behavior. Fayard and deSanctis (2010) show that online community members who do not consistently participate in the "language game" (i.e., the shared communication style) are less likely to continue the expected behaviors. Similarly, Kreiner and Ashforth (2004) suggest that to the degree organization members experience ambivalent identification, they use up valuable cognitive resources that otherwise could be spent on organizational goals; they also appear reluctant to go beyond the required level of job performance. Thus, members with a relatively high degree of reversals in LSM development should be less motivated to continue to provide high-quality argumentation and participate.

$H_{3}$ : Increasing amounts of reversals in members' LSM relate negatively to (a) participation quantity and (b) participation quality. 


\section{Group-Level LSM}

The impact of measures taken to stimulate members to participate and actively contribute varies considerably across user communities (Iriberri and Leroy 2009). Although the drivers of success are many and often case specific (Faraj et al. 2011), active communities generally are characterized by synergistic social processes and shared understanding among members regarding their goals and behaviors (Moran and Gossieaux 2010). In communities of practice, shared patterns of coordinated behavior (i.e., high synchronicity) result in greater levels of interaction and shared focus among members, whereas diverging patterns are detrimental to the overall community performance (Dennis et al. 2008). Specifically, such high synchronicity in communicative behavior is associated with improved collaborations in online group settings, with reduced cognitive effort to encode and decode messages and thus improved response times in discussions (Kock 2004). The degree to which communicative behavior in user communities are "in sync" likely leads to differential success in stimulating overall community performance. All virtual communities exhibit discursive practices that provide scripts for action, but there are also clear differences among communities. Fayard and deSanctis (2010) describe two online forums in which the community sponsor or a small number of active members early on significantly shape the communication, creating the community atmosphere and encouraging a sense of we-ness (Fayard and DeSanctis 2010). In both cases, a distinct style emerges from initial interactions. The dominant participants appear to enact a language game that is strong enough to allow other participants to enter the forum easily and participate actively. In contrast, in communities without such established common communication styles, it is difficult for members to identify and adopt the appropriate linguistic style. Thus, the collaboration process is hampered, which also impedes members' ability to participate actively. User communities exhibiting high levels of LSM across 
members should reflect a more prominent collective identity, which affects member participation and contribution effort.

$H_{4}$ : Community-level cohesiveness in members' LSM relates positively to individual members' (a) participation quantity and (b) participation quality. 


\section{Empirical Study}

\section{Setting}

The study sample includes 37 similarly structured user communities. Such communities "constitute an online social structure woven from continuous interactions among individuals focused around shared interests and common practices, as well as usage of the same tools and products" ((Dahlander and Frederiksen 2012, p. 989). All the user communities were hosted by the same market research consultancy, which aimed to facilitate cocreation with users spanning the financial, fast-moving consumer goods, telecommunication, and television industries between 2009 and 2011. We chose this setting for several reasons. First, members' community participation is, as with most user communities, purely intrinsically motivated, in that no financial rewards are given (Dholakia et al. 2004). Second, to motivate and sustain participation in such collectives, it is crucial for members to develop a sense of community identification (Kohler et al. 2011). Third, as with most online communities, nonverbal social cues and personal member information are not available, with text-based posts serving as the sole means by which to develop and assess social identification (Herring 2001). Fourth, the homogeneity across the user communities' setup, duration, structure, and purpose supports both within- and between-community comparisons. Each community consists of 150-300 members, all invited to participate because of their interest in and affiliation with the facilitating company and its products or services. Because this study's focus is on members' communication as symbolic action, we eliminated all members who did not participate (post) from the sample (lurkers), which resulted in a final sample of 2,208 members across all 37 communities who made a total of 74,246 posts. On average, there were 60 active members per community and 33 posts per member. 


\section{Data and Measures}

A distinct language style in an online community develops in the first few interactions (Fayard and DeSanctis 2010). Therefore, we divided the observation period into an “initiation" period $\left(\mathrm{t}_{1}\right)$, encompassing a member's first two weeks in a community (Farzan et al. 2012), and an active participation period, covering the subsequent eight weeks of membership $\left(\mathrm{t}_{2}\right)$.

Dependent Variables. The absolute count of posts (participation quantity) by each member in period $t_{2}$ indicated the participation quantity per member measure:

PQuant $_{t 2, i}=\sum_{N=1}^{N}\left(\right.$ Posts $\left._{t 2, i}\right)$

where i stands for individuals; $\mathrm{t}_{2}$ indicates the time period after the initial two-week initiation period; $\mathrm{n}$ to $\mathrm{N}$ denotes the entire range of posts by the member; PQuant is participation quantity; and Posts is the occurrence of a post.

Furthermore, because of the importance of substantiated and well-developed arguments in effective group discussions (Seibold and Meyers 2007), we consider argumentative development, generically conceptualized as quality, in posts. To construct this measure, we followed Cohn, Mehl and Pennebaker (2004) and text-mined all community posts across the 37 communities to determine the use of causal words (e.g., because, cause, effect) and other words suggestive of cognitive processing (e.g., realize, understand). We constructed a composite measure of the text-mined cognitive effort (CE) for each post (p) by summing the total amount $(\mathrm{N})$ of cognitive words and causal words used:

$$
C E_{p}=\sum_{N=1}^{N}\left(\text { Cognitive Words } s_{p}\right)+\sum_{N=1}^{N}\left(\text { Causal Words } s_{p}\right)
$$


To verify the accuracy of this approach for capturing argument development, we drew a random subset of 6,000 community posts. Three independent coders content analyzed and classified the subset of posts according to the quality of how insights are shared using the thought-listing technique commonly employed used to assess the quality of cognitive responses (Cacioppo and Petty 1981). In line with prior research using this technique, the coders considered every stated and reasoned idea, regardless of whether they were grammatically correct, as a unit. The intercoder agreement was assessed using the Krippendorff's $\alpha$ measure, which found matching argument count incidences of $93 \%$ (well above the critical threshold of .80). To verify the level of congruence between the count of arguments by the three manual coders and the text-mined cognitive effort per post, we computed a Pearson product-moment correlation coefficient. The correlation coefficient of .72, which prompts strong confidence in the viability of the text mining approach. The average, text-mined count of cognitive effort words per post during period $t_{2}$ calculated for each user community member yielded the second dependent variable, namely, the average argument development quality a member exerted in his or her posts:

PQual $_{t 2, i}=\sum_{N=1}^{N}\left(C E_{t 2, p, i}\right)$

where PQual signifies argument development quality, $\mathrm{i}$ is the individual, $\mathrm{t}_{2}$ denotes the time period after initiation, $\mathrm{n}$ to $\mathrm{N}$ refers to the entire range of posts by the member, and $\mathrm{CE}_{\mathrm{p}}$ is the cognitive effort per post, as derived through Equation 2.

Independent Variables. As mentioned previously, a distinct language style in an online forum develops during the first few interactions (Fayard and DeSanctis 2010). Therefore, we assessed the independent variables in this study according to communication behaviors in the first two weeks $\left(\mathrm{t}_{1}\right)$ only. Observing communication during the initiation period $t_{1}$ and linking it to participation behavior during the observation period $t_{2}$ also ensures 
stronger greater causality implications, because the predictor variables precede the outcome behaviors. In line with recent research on LSM (Gonzales et al. 2010; Ireland and Pennebaker 2010), we operationalized LSM as a measure of the degree to which two or more conversants produce similar rates of function words.

First, we text-mined, for each user community post (p), the total word count of nine function word categories (which comprise all 469 function words in English): (1) auxiliary verbs (e.g., to be, to have), (2) articles (e.g., an, the), (3) common adverbs (e.g., hardly, often), (4) personal pronouns (e.g., I, they, we), (5) impersonal pronouns (e.g., it, those), (6) prepositions (e.g., for, after, with), (7) negations (e.g., not, never), (8) conjunctions (e.g., and, but), and (9) quantifiers (e.g., many, few) (Ireland and Pennebaker 2010). We constructed a measure of the function word usage intensity (FWCi) for each category (j) separately, by dividing the total amount $(\mathrm{N})$ of words belonging to the particular function word category by the total number of words $(\mathrm{N})$ within the post $(\mathrm{p})$ :

$F W C_{j, i, p}=\frac{\left(\sum\left(F W C_{j, N, p}\right)\right)}{\sum\left(\operatorname{Words}_{N, p}\right)}$

Second, we determined the specific community-level function word category usage intensity $\left(\mathrm{FWC}_{\mathrm{ci}}\right)$ for each category $(\mathrm{j})$ across all the posts that were present before post $(\mathrm{p})$ was submitted. That is, to derive the community's usage style of a particular function word category before the post, we took the cumulative average of that function word category's usage e intensity across all posts before post $\mathrm{p}$ or $(\mathrm{p}-1)$ :

$F W C_{j, c i, p}=\frac{\left(\sum_{p=1}^{p-1}\left(F W C_{j, i, p}\right)\right)}{p-1}$

Third, the LSM for each user-community post $\left(\mathrm{LSM}_{\mathrm{p}}\right)$ can be derived next by calculating separate LSM scores for each function word category (j) using the following formula: 
$L S M_{j, p}=1-\frac{\left(\left|F W C_{j, N, p}-F W C_{j, i, p}\right|\right)}{\left(\left|F W C_{j, N, p}+F W C_{j, i, p}+0.0001\right|\right)}$

In this formula, $L S M_{j, p}$ is the percentage of overlap between the usage intensity of function word category (j) used in post (p) and the cumulative average usage intensity of the same category by all community posts thus far. In the denominator, we added .0001 to prevent empty sets. Finally, we established the overall LSM for each post across all nine functional word categories by averaging the nine separate LSM ratios.

we used two levels to describe the dynamics of communicative behaviors: member-level aspects of communicative behavior (average, trend, and reversals) and overall communitylevel cohesiveness in communicative behavior. Following our theoretical development, each of these parameters highlights unique aspects of members' communicative trajectories in the sample. First, the within-member LSM mean is the general level of LSM across all posts of member $i$ in the first two weeks $\left(t_{1}\right)$. It is computed by taking the mean LSM across all posts of member $\mathrm{i}$ in $\mathrm{t}_{1}$, which yields a composite LSM percentage, bounded by 0 and 1 for each of the 2261 members, for which higher numbers represent greater overall stylistic similarity between a member and the community in $t_{1}$ (cf. Gonzales et al. 2010). We therefore use it to signify a member-specific average level of LSM across all posts in the first two weeks $\left(\mathrm{t}_{1}\right)$.

Second, a member's LSM trend is established by regressing the sequential post incidences by member (i) on the respective LSM of each of his or her posts using the least squares method. All post incidences of a member are numbered consecutively, so that posts made later receive higher numbers. We then regressed the LSM of member $i$ on the post incidents of member $i$. The beta-coefficient $\left(\beta_{1}\right)$ of the post incidence variable in the equation, $\mathrm{LSM}_{\mathrm{i}}=\beta_{0+}$ $\beta 1$ POSTINCIDENCE for member $i$, signifies the rate of change in his or her LSM trend over time (Jokisaari and Nurmi 2009). A rate of change near zero represents a stable LSM trend 
throughout the initial period of a person's community membership. The more positive the coefficient, the greater the assimilations in linguistic style by that member.

Third, we measured the frequency of change in a member's LSM across subsequent posts by counting the number of slope changes (that exceed one standard deviation) compared with the number of posts (DeKinder and Kohli 2008). We did not count slope changes smaller than one standard deviation, because they only reflect minor alterations in an otherwise stable communication style.

Fourth, to establish community-level cohesiveness in communicative style (i.e., indicate the degree of equality in communication styles within a community), we used the coefficient of variation adjusted for group size, as suggested by Harrison and Klein (2007). The majority of research on collective settings has examined group behavior similarities by using direct consensus models (i.e., taking the group average as the preferred mode of aggregation). Yet recent research shows that such group-level similarities are more appropriately assessed by considering within-group variability or dispersion-composition models, which better reflect multilevel phenomena (Cole et al. 2011). In recognition of these new insights, we constructed the measure of cohesiveness in communication style within communities as one minus the within-group variability of LSM.

To empirically justify this multilevel perspective and validate the aggregation procedure, we calculated the within-group agreement measure $r_{w g}$ for single-item measures, as James, Demaree, and Wolf (1984) suggest. Because this measure is designed for scale variables only, we discretionized the original ratio measure of LSM into a scale consisting of 10 categories and estimated the rectangular distribution. The mean of the $r_{w g}$ coefficients, which indicates the homogeneity of LSM within communities, is .87. These findings demonstrate that the common communication style of individual LSMs within communities are highly consistent. 
We illustrate the individual-level LSM parameters using a community discussion excerpt from one of the user communities in the data set (Table 1). 


\section{TABLE 1}

\section{Sample conversations in a user community: Recipe discussions}

\begin{tabular}{|c|c|c|}
\hline Member & Text & $\begin{array}{l}\text { LSM of } \\
\text { member }\end{array}$ \\
\hline User 1: & $\begin{array}{l}\text { Hi, my family love cake - particularly a nice light victoria sponge. I use [...], it makes the } \\
\text { cake really moist. My Mum taught me this when I was a nipper. }\end{array}$ & 0.69 \\
\hline User 2: & $\begin{array}{l}\text { Well me and my hubby used to go eat in }[\ldots . .] \text { I kept thinking i used to make that many } \\
\text { years ago, so i set about it didn't tell hubby. Just put at front of him, well he loved it, said } \\
\text { it is better than }[\ldots] \text { its good but fattening }\end{array}$ & 0.71 \\
\hline User 3: & $\begin{array}{l}\text { Lost weight at }[\ldots] \text { and devised a lot of convenient low fat / fat free recipes when I was } \\
\text { on the plan. The ideal way to make }[\ldots] \text { is to use }[\ldots] \text {, season appropriately, no fat other } \\
\text { than the substances in the milk. }\end{array}$ & 0.32 \\
\hline \multirow[t]{2}{*}{ User 2: } & $\begin{array}{l}\text { Thanks [..] I am going to look out for some of that - I do like [...] but I have to lose quite } \\
\text { some weight so this is just the job! Have you discovered [...] It really does fill me up } \\
\text { honest and it tastes wonderful too! }\end{array}$ & 0.57 \\
\hline & {$[\ldots]$} & \\
\hline User 4: & $\begin{array}{l}\text { I LOVE [..] Hollondaise sauce but you can't buy it in England. I stocked up big time } \\
\text { when I was working in the US but it's all gone now - all gobble up and my family are } \\
\text { suffering withdrawl!! [...] Now I need to make my mock hollandaise every time we have } \\
\text { cauliflower with our dinner! }\end{array}$ & 0.73 \\
\hline User 5: & $\begin{array}{l}\mathrm{Hi}[\ldots] \text { if you like Mock Hollandaise sauce for Cauliflower without the }[\ldots] \text { this one may } \\
\text { be for you. Just use any White sauce recipe and add the nutmeg, lemon juice and egg } \\
\text { yolk this makes all the difference and done really quickly. }\end{array}$ & 0.62 \\
\hline \multirow[t]{2}{*}{ User 3: } & $\begin{array}{l}\text { Talking about }[\ldots], \text { I also like the range of }[\ldots] . \text { I use the ITALIAN GARLIC one all the } \\
\text { time, so easy to shake and add }[\ldots] \text { using this one mixed up with butter is very easy to do } \\
\text { and is ready in a flash }\end{array}$ & 0.56 \\
\hline & {$[\ldots]$} & \\
\hline User 3: & $\begin{array}{l}\text { When roasting a joint of beef use }[\ldots] \text {. Learned this years ago working as a waitress at a } \\
\text { night club that had a top notch restaurant. The chef was Croatian and his food was } \\
\text { devine! }\end{array}$ & 0.34 \\
\hline User 6: & $\begin{array}{l}\text { Hi everyone, for an interesting twist I have a tip for you, use peanut butter as a topping } \\
\text { on a beefburger. It sounds odd but tastes really good! I saw this on [...] and thought I'd } \\
\text { give it a try and have used up many jars of peanut butter since! }\end{array}$ & 0.72 \\
\hline
\end{tabular}

Note: These excerpts are taken from one of the user communities in the data set. Multiple users commented and exchanged recipes and tips for cooking and baking. For privacy reasons, we removed user names, brands, and product names and parts of the texts. 
Multiple users commented and exchanged recipes and tips for cooking and baking; for purposes of illustration, we focus on User 3. Although the posted content varies, users' expressions (linguistic style) are relatively similar, with a warm and personal tone. Consider User 3: Her LSM scores are .12, .56, and .34 across her three posts, compared against the cumulative communication style of the overall community (which includes more posts than listed here). Her second post matched the community linguistic style best in terms of function words. Her first post is highly divergent from the conventional communication style in that user community. Note further that (considering only these three posts), User 3's overall rate of change would be negative, and her linguistic style would drift away from the community style. Finally, across these three post incidences, one change (reversal) appears in User 3's LSM trend; that is, there is a trend toward a greater LSM from her first to the second post, but this trend reverses with her third post.

Control Variables. In addition to communication style, several member- and grouprelated aspects of user communities affect members' participation quantity and quality. Members' participation history can help predict their future participation (Moran and Gossieaux 2010). To capture differences in members' general disposition to participate in a user community, we controlled for their participation quantity $\left(\operatorname{PQuan}_{\mathrm{t} 1}\right)$, quality $\left(\mathrm{PQual}_{\mathrm{t} 1}\right)$, and number of page views within the community (Pviews $\mathrm{t}_{\mathrm{t}}$ ) during their first two weeks of membership. Previous research has suggested that all these variables influence participation efforts (Koh et al. 2007; Ma and Agarwal 2007). Because participation quality is a count measure, we needed to control for the average word length (Plength) of a member's posts as well. Furthermore, at community level, we controlled for the community size (CSize), which is the total amount of members. Moreover, we controlled for community-level qualities, which may affect the influence of community members' identification on their participation. Specifically, we consider overall participation quantity $\left(\mathrm{CPQuan} \mathrm{t}_{\mathrm{t} 1}\right)$ and quality $\left(\mathrm{CPQual}_{\mathrm{t} 1}\right)$ by 
all members of a particular community. Table 2 outlines the descriptive statistics and correlations; the correlations between participation quantity, participation quality, and our communication style variables of interest are all in the expected directions. 
TABLE 2

Descriptive Statistics and Correlations

\begin{tabular}{|c|c|c|c|c|c|c|c|c|c|c|c|c|c|c|c|}
\hline & Mean & $\begin{array}{l}\text { Std. } \\
\text { Dev. }\end{array}$ & 1 & 2 & 3 & 4 & 5 & 6 & 7 & 8 & 9 & 10 & 11 & 12 & 13 \\
\hline \multicolumn{16}{|c|}{ Member-level variables } \\
\hline 1. PQuant ${ }_{\mathrm{t} 2}$ & 14.79 & 23.86 & 1.00 & & & & & & & & & & & & \\
\hline 2. $P Q u a l_{12}$ & 1.84 & 0.054 & 0.02 & 1.00 & & & & & & & & & & & \\
\hline 3. $\mathrm{LSMM}_{\mathrm{t} 1}$ & 0.63 & 0.172 & 0.35 & 0.25 & 1.00 & & & & & & & & & & \\
\hline 4. $\mathrm{LSMT}_{\mathrm{t} 1}$ & -0.02 & 0.093 & 0.12 & 0.09 & 0.01 & 1.00 & & & & & & & & & \\
\hline 5. $\mathrm{LSMR}_{\mathrm{t} 1}$ & 0.27 & 0.276 & -0.16 & -0.14 & -0.15 & -0.03 & 1.00 & & & & & & & & \\
\hline 6. PQuant $t_{t 1}$ & 10.19 & 14.655 & 0.47 & 0.43 & 0.10 & 0.09 & -0.14 & 1.00 & & & & & & & \\
\hline 7. PQual $_{\mathrm{t} 1}$ & 0.051 & 0.054 & -0.03 & 0.08 & 0.18 & 0.01 & -0.24 & 0.01 & 1.00 & & & & & & \\
\hline 8. PView $_{\mathrm{t} 1}$ & 615 & 223.39 & 0.26 & 0.20 & -0.02 & 0.01 & -0.03 & -0.03 & -0.05 & 1.00 & & & & & \\
\hline 9. Plength & 41.99 & 10.481 & -0.06 & 0.29 & 0.29 & -0.01 & -0.29 & -0.05 & 0.20 & 0.03 & 1.00 & & & & \\
\hline \multicolumn{16}{|c|}{ Community-level variables } \\
\hline 10. $\mathrm{CLSM}_{\mathrm{t} 1}$ & 0.91 & 0.146 & 0.14 & 0.27 & 0.17 & 0.02 & 0.02 & 0.18 & 0.13 & -0.03 & -0.01 & 1.00 & & & \\
\hline 11. Csize & 178 & 33.430 & 0.12 & 0.11 & -0.02 & -0.08 & 0.10 & -0.06 & -0.06 & -0.01 & -0.08 & 0.19 & 1.00 & & \\
\hline 12.CPQuant $\mathrm{t}_{\mathrm{t}}$ & 9.03 & 6.436 & 0.03 & 0.01 & 0.13 & -0.01 & 0.13 & 0.42 & -0.01 & 0.03 & -0.01 & 0.15 & -0.09 & 1.00 & \\
\hline 13. CPQual ${ }_{\mathrm{t} 1}$ & 0.05 & 0.044 & -0.12 & 0.62 & 0.01 & -0.02 & -0.03 & -0.07 & 0.54 & -0.01 & 0.21 & 0.14 & -0.24 & -0.01 & 1.00 \\
\hline
\end{tabular}

*for all variables $\mathrm{N}=2208$. 


\section{Prestudy}

We conducted a prestudy to assess the validity of LSM empirically as a symbol for members' social identification. Of the five seven-point Likert scales that Algesheimer et al. (Algesheimer et al. 2005) developed to measure community identification, we used the four that were most applicable in this context: "I am very attached to the community," "Other community members and I share the same objectives," "I see myself as a part of the community," and "The friendships I have with other community members mean a lot to me." We sent online surveys twice (including one follow-up survey) by e-mail to all members of a subset of 18 communities, 8-12 weeks after they had begun their community participation. We introduced the questions as part of a general opinion survey regarding their community experience. Of the 3,211 community members, 622 completed the survey (response rate $=$ 19.37\%). The scale items were internally consistent (coefficient $\alpha=.74$ ). We considered the correlation between members' community identification on their overall degree of LSM (established from their posts). The results of the Pearson-product correlation coefficient showed a significant correlation between members' LSM ratio and their community identification $(.715, p<.01)$. On the basis of this prestudy result, we are confident that the degree of members' LSM is a significant positive symbol of their community identification.

\section{Data Analysis}

To capture the influence of the explanatory variables, at the member and community levels, on members' subsequent behavior, we specified two multilevel Poisson models, often referred to as hierarchical linear models (HLMs). The Poisson HLM approach accounts for member interdependencies and simultaneously allows for investigations of cross-level effects (Long 1997). With multiple members nested in each user community, the HLM modeling 
approach also controls appropriately for the possibility that communication behaviors from members in the same community may be more similar than they are for members in another community; it can estimate relationships that are nested across levels. We estimated how much variance in members' participation quantity and argument quality resides within members or between communities by computing the median incidence rate ratios (IRRs; (Long 1997). With regard to participation quantity, the estimated median IRR is 1.454 , which implies that half of the time, the ratio of expected participation quantity will range from .68 $(1 / 1.454=.68)$ to 1.454 , and the other half of the time, it will lie outside that range. Similarly, the median IRR for participation quality is estimated at 1.376, and thus, the expectation should lie in the range between .726 and 1.376 in $50 \%$ of the cases. This finding provides convincing evidence that community characteristics can have a direct influence on members' participation quantity and argument quality. We next specified two multilevel Poisson regression models to estimate the effects of the antecedent member- and community-level variables at $t_{1}$ (and time-fixed variables) on participation quantity and quality at $t_{2}$. We used STATA12 to estimate the models, beginning with two null (intercept only) models for participation quantity and argument quality. We introduced the individual-level variables and covariates in Model 1a for participation quantity and Model 1b for argument quality. Finally, we added the group-level variables and covariates to estimate the full models for participation quantity (Model 2a):

PQuant $_{\mathrm{t} 2 \mathrm{ij}}=\beta_{0 \mathrm{j}}+\beta_{1} \mathrm{LSMM}_{\mathrm{t} 1, \mathrm{ij}}+\beta_{2} \mathrm{LSMT}_{\mathrm{t} 1 \mathrm{ij}}+\beta_{3} \operatorname{LSMR}_{\mathrm{t} 1, \mathrm{ij}}+\beta_{4} \mathrm{LSMC}_{\mathrm{t} 1, \mathrm{j}}+\beta_{5} \operatorname{MLCOV}_{\mathrm{t} 1, \mathrm{ij}}+$ $\beta_{6} \operatorname{CLCOV}_{\mathrm{j}}+\zeta_{0 \mathrm{j}}$

and participation quality (Model 2b):

$\operatorname{PQual}_{\mathrm{t} 2 \mathrm{ij}}=\beta_{0 \mathrm{j}}+\beta_{1} \mathrm{LSMM}_{\mathrm{t} 1, \mathrm{ij}}+\beta_{2} \mathrm{LSMT}_{\mathrm{t} 1, \mathrm{ij}}+\beta_{3} \mathrm{LSMR}_{\mathrm{t} 1, \mathrm{ij}}+\beta_{4} \mathrm{LSMC}_{\mathrm{t} 1, \mathrm{j}}+\beta_{5} \operatorname{MLCOV}_{\mathrm{t} 1, \mathrm{ij}}+$ $\beta_{6} \mathrm{CLCOV}_{\mathrm{j}}+\zeta_{0 \mathrm{j}}$ 
where

- $\mathrm{i}$ is the individual member, $\mathrm{j}$ indicates the communities, and PQuant $\mathrm{t}_{2}$ and PQual ${ }_{\mathrm{t} 2}$ stand for the participation quantity and participation quality, respectively, in period $t_{2}$.

- For the hypothesized effects, $\mathrm{LSMM}_{\mathrm{t} 1}$ is the average degree of LSM, $\mathrm{LSMT}_{\mathrm{t} 1}$ is the rate of change in LSM trend, and $\mathrm{LSMR}_{\mathrm{t} 1}$ is the frequency of reversals in LSM in a member's posts in period $t_{1}$.

- $\mathrm{LSMC}_{\mathrm{t} 1}$ is the group-level cohesiveness in members' LSM at the community level in period $t_{1}$.

- The covariates at the individual level, $\mathrm{MLCOV}_{\mathrm{t} 1}$, are participation quantity (PQuant $\left.{ }_{\mathrm{t} 1}\right)$, quality $\left(\mathrm{PQual}_{\mathrm{t} 1}\right)$, page views $\left(\mathrm{PView}_{\mathrm{t} 1}\right)$, and average post length $\left(\mathrm{Plength}_{\mathrm{t} 1}\right)$; at the group level, we control for $\mathrm{CLCOV}_{\mathrm{j}}$, including community size (CSize) and community-level qualities: overall participation quantity (CPQuant $\left.\mathrm{t}_{11}\right)$ and quality (CPQual $\left.{ }_{t 1}\right)$ of the community.

- $\varepsilon$ is the individual-level error variance, and $\zeta$ is the random variance for intercept.

We assume an independent correlation matrix. The correlation matrix in Table 2 and the variance inflation factor scores indicate that there is no potential threat of multicollinearity $\left(\right.$ Model 2a VIF $\operatorname{MAX}=1.24 ;$ Model $\left.2 \mathrm{~b} \mathrm{VIF}_{\mathrm{MAX}}=1.97\right)$. To improve interpretability, we standardized all predictor variables in the models.

We used full maximum likelihood estimation to estimate the parameters and compare the model fits across nested models (Raudenbush and Bryk 2002). Using chi-square difference tests, we confirmed that the member- and community-level explanatory variables added explanatory power to the final model (see Table 3, Models $2 \mathrm{a}$ and $2 \mathrm{~b}$ ). We took all the standardized estimates analyzed next from these final models; the parameter estimates provide support for the majority of the hypotheses. 


\section{Results}

The results reveal a significant, positive impact of members' LSM in the early period $\left(\mathrm{t}_{1}\right)$ on their community membership participation $\left(\beta_{\mathrm{LSMM}}=.233, p<.001\right.$; quality $\beta_{\mathrm{LSMM}}=$ $.331, p<.001)$ in the subsequent membership period $\left(\mathrm{t}_{2}\right)$. Thus, we can confirm $\mathrm{H}_{1}$; the IRRs indicate that a one standard deviation increase in LSMM is associated with increases of $26 \%$ $(\mathrm{IRR}=1.26, \mathrm{CI}(95 \%) 1.228-1.298)$ in participation quantity and $39 \%(\mathrm{IRR}=1.39, \mathrm{CI}$ (95\%) $1.291-1.499)$ in participation quality. Both shape parameters, capturing the temporal development in linguistic style over members' initial membership period, have significant effects on subsequent participation quantity. A faster accommodation rate by members toward a stronger LSM in $t_{1}$ has a significant positive effect on participation quantity $\left(\beta_{\text {LSMT }}=.061\right.$, $p<.001)$ and quality $\left(\beta_{\text {LSMT }}=.172, p<.001\right)$ at $t_{2}$, in support of $\mathrm{H}_{2}$. Conversely, reversals and frequent alterations in members' LSMs toward the community style have a significant negative impact on their participation quantity $\left(\beta_{\mathrm{LSMR}}=-.071, p<.001\right)$ but no significant impact on argument quality at $t_{2}$, in support of $\mathrm{H}_{3 \mathrm{a}}$ but not $\mathrm{H}_{3 \mathrm{~b}}$. Overall, the results support the claim that the temporal development of members' communication style can explain subsequent behavior. A trend increase by one standard deviation correlates to a $6 \%$ increase in participation quantity and an $18 \%$ increase in quality. A one standard deviation increase in LSM reversals decreases participation quantity by $7 \%$. Furthermore, in support of $\mathrm{H}_{4 \mathrm{a}}$, the community-level effect of communication style cohesiveness in communities in $t_{1}$ has a significant positive impact on both participation quantity $\left(\beta_{\text {LSMC }}=1.045, p<.001\right)$ and argument quality $\left(\beta_{\mathrm{LSMC}}=.456, p<.001\right)$. As the IRR indicates, a one standard deviation increase in the cohesiveness of the communities' linguistic style (i.e., all members use a more synchronized linguistic style) enhances individual members' participation quantity by $147 \%$ and their participation quality by $103 \%$ (Long 1997). This highlights the criticality of community-level context aspects for members' behaviors. The member-level control variables 
are all significant predictors of subsequent participation quantity, but only members' participation quality in $\mathrm{t}_{1}$ significantly affects participation quality in $\mathrm{t}_{2}\left(\beta_{\mathrm{PQualt} 1}=.232, p<\right.$ .001). None of the community-level covariates significantly affects members' subsequent participation quantity. However, community size significantly reduces members'subsequent participation quality $\left(\beta_{\mathrm{CSize}}=-.274, p<.01\right)$, and a community in which all members develop their arguments more in their posts significantly and positively influences the subsequent participation quality of the individual members $\left(\beta_{\mathrm{CPQualt} 1}=-.363, p<.001\right)$. 
TABLE 3

Multilevel Poisson Regression Analysis

\begin{tabular}{|c|c|c|c|c|c|c|}
\hline \multirow[b]{2}{*}{ Constructs } & \multicolumn{3}{|c|}{ Participation Quantity $_{\mathfrak{t}}$} & \multicolumn{3}{|c|}{ 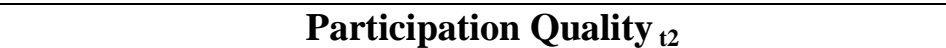 } \\
\hline & Model 1a & Model 2a & IRR (95\% CI) & Model 1b & Model 2b & IRR $(95 \%$ CI $)$ \\
\hline \multicolumn{7}{|c|}{ Member-level variables } \\
\hline $\mathrm{LSMM}_{\mathrm{t} 1}$ & $0.707 * *$ & $0.233 * *$ & $1.26(1.228-1.298)$ & $0.630 * *$ & $0.331 * *$ & $1.392(1.291-1.499)$ \\
\hline $\mathrm{LSMT}_{\mathrm{t} 1}$ & $0.089 * *$ & $0.061 * *$ & $1.062(1.049-1.076)$ & $0.203 * *$ & $0.172 * *$ & $1.188(1.141-1.237)$ \\
\hline $\mathrm{LSMR}_{\mathrm{t} 1}$ & $-0.037 * *$ & $-0.071 * *$ & $0.931(0.916-0.945)$ & -0.024 & -0.013 & $0.983(0.941-1.030)$ \\
\hline PQuant $_{\mathrm{t} 1}$ & $0.352 * *$ & $0.307 * *$ & $1.359(1.349-1.368)$ & 0.022 & -0.031 & $0.968(0.929-1.009)$ \\
\hline PQual $_{t 1}$ & $0.078 * *$ & $0.068 * *$ & $1.071(1.040-1.102)$ & $0.272 * *$ & $0.232 * *$ & $1.261(1.189-1.337)$ \\
\hline PView $_{\mathrm{t} 1}$ & $0.116^{* *}$ & $0.113 * *$ & $1.119(1.112-1.126)$ & -0.023 & -0.034 & $0.964(0.921-1.012)$ \\
\hline Plength $_{\mathrm{t} 1}$ & $-0.024 * *$ & $-0.011 * *$ & $0.989(0.987-0.991)$ & $0.008 * *$ & $0.016 * *$ & $1.017(1.012-1.021)$ \\
\hline \multicolumn{7}{|c|}{ Community-level variables } \\
\hline $\mathrm{CLSM}_{\mathrm{t} 1}$ & & $0.907 * *$ & $2.477(2.394-2.564)$ & & $0.719 * *$ & $2.032(1.836-2.293)$ \\
\hline Csize & & -0.204 & $0.814(0.628-1.056)$ & & $-0.274 * *$ & $0.739(0.616-0.936)$ \\
\hline CPQuant $_{\mathrm{t} 1}$ & & -0.192 & $0.825(0.674-1.009)$ & & -0.098 & $0.906(0.769-1.067)$ \\
\hline CPQual $_{\mathrm{t} 1}$ & & 0.116 & $1.049(0.835-1.318)$ & & $0.363 * *$ & $1.737(1.460-2.114)$ \\
\hline Intercept & $3.051 * *$ & $2.539 * *$ & & -0.1667 & $-0.378 * *$ & \\
\hline $\mathrm{N}$ (members) & 2208 & 2208 & & 2208 & 2208 & \\
\hline $\mathrm{N}$ (communities) & 37 & 37 & & 37 & 37 & \\
\hline Log likelihood & $-13,498,296$ & -12104.396 & & -3042.213 & -2932.289 & \\
\hline Wald $\chi 2(\mathrm{df})$ & $19634.35(7)$ & $21486.63 * *(11)$ & & $1231.19(7)$ & $1376.78(11)$ & \\
\hline Deviance(-2LL) & $26,996,592$ & $24,208,792$ & & $6,084,426$ & $5,864,578$ & \\
\hline
\end{tabular}

a $* p<.05$ and $* * p<.01$.

${ }^{\mathrm{b}}$ All regression coefficients are standardized.

${ }^{\mathrm{c}}$ For Models $2 \mathrm{a}$ and $2 \mathrm{~b}$, the LR test is significant $(p<.001)$, indicating a relative increase in model fit compared with Models $1 \mathrm{a}$ and $1 \mathrm{~b}$, respectively.

${ }^{\mathrm{d}} \mathrm{IRR}=$ incidence rate ratio; $\mathrm{CI}=$ confidence interval 


\section{Discussion and Conclusion}

\section{Theoretical Implications}

This study conceptualizes a user community member's LSM with the community's common communication style as symbolic action. In line with contemporary views on the role of language (e.g. Herring 2001), this study posits and empirically validates how linguistics serve not only to describe realities but also to symbolically reflect conversants' feelings and affect their subsequent behaviors. The symbolic action innate to communication style is the foundation of speech act theory (Searle 1975), rhetoric (Gill and Whedbee 1997), and social constructionism (Berger and Luckmann 1966). However, a relative paucity of research describes the signaling role of linguistic styles online (Fayard and DeSanctis 2010), which entail no nonverbal cues and thus distinct communication behaviors.

First, inspired by communication accommodation research in conversation dyads (Giles 2009a; Ireland and Pennebaker 2010), this study contributes to contemporary research on the role of communication in user communities by showing that the degree of members' LSM symbolically reflects their level of identification in large online groups (i.e., user communities). Previous research has shown that members' community identification critically influences their participation efforts (Kozlowski and Ilgen 2006; Wasko and Faraj 2005). Yet it has not considered how text-based communication may drive participation efforts, rather than being just its result (Fayard and DeSanctis 2010). Such a language-as-action perspective diverges from a traditional language-as-product view (Brennan and Clark 1996) and advances language beyond description, to become a means to construct reality.

Moreover, emerging research on CAT indicates that LSM is a subconscious, coordinative indicator of common ground formation, based on a member's identification and 
sense of belonging to a community. In contrast, the traditional view highlights common ground formation as a cognitive, intentional attempt by people to replicate mental models to ease their understanding and facilitate shared sense-making (Gonzales et al. 2010; Weick 1995). Although easing communication might be an important rationale for group alignment, the results study indicate a member's identification is the mechanism underlying LSM.

Second, research on communication accommodation has focused on conversants' perceptions and behaviors at a given time but neglected the dynamic nature of a person's identification with a group (Levine and Moreland 1994). The current study contributes by adopting a temporal perspective, viewing LSM trends and reversals as essential, distinct symbols in the ongoing socialization process through which user community members produce, reproduce, and change their community identification. In line with the expanded view of organizational identification (Elsbach and Bhattacharya 2001; Kreiner and Ashforth 2004), steeper trends in linguistic style alignment (distancing) signal members' accelerated identification (disidentification) with the user community. Accordingly, the findings show that positive, faster trends toward greater LSM enhance members' subsequent participation quantity and quality. Frequent changes in linguistic style accommodation trends suggest members' ambivalence regarding their identification with a community (Elsbach and Bhattacharya 2001). In line with research into such identification uncertainty (Kreiner and Ashforth 2004), the current study shows that members who often alter their degree of LSM are less likely to excel in subsequent participation quantity. Yet contrary to the hypothesized relationship, reversals in members' LSM are not significantly negatively related to their subsequent participation quality. We speculate that the hypothesized negative impact of ambivalent identification on the willingness to interact with other members (Meyerson and Scully 1995) might be offset by its advantages. As Stonequist (1937, p.155) argues, members with ambivalent identifications are fundamentally "outsiders within," who access the 
knowledge of an insider but hold the critical attitude of the outsider. Thus, their overall participation quantity decreases, but the quality of their argument development remains unaffected, with these members serving as acute, able critics (Meyerson and Scully 1995). Overall, we demonstrate empirically the substantive symbolic nature of two temporal parameters (trend and reversals) in linguistic style accommodation, while controlling for behavioral (e.g., passive reading behavior) and contextual (e.g., community quality, size) aspects (Faraj et al. 2011; Ma and Agarwal 2007).

Third, we contribute to research on communication by considering text not only as a data source but also as the societal context in which the text is nested (Fairclough 1992). We find that synchronicity in communicative behavior-or cohesiveness across community members' linguistic styles_adds substantively to the explanation of individual members' participation behavior. Such group cohesiveness appears to foster shared identification or a sense of we-ness among members, which further encourages members to invest themselves on behalf of the collective (Hardy et al. 2005). The significant explanatory power of the community-level characteristics (i.e., communication style, size, and participation quality and quality), which collectively explain $41 \%$ of variation in subsequent individual members' behavior, demonstrate the importance of contextualizing linguistics suggested in previous research (Fairclough 1992).

In corroboration with previous research, the current study offers additional insights on user community participation. Specifically, whereas previous research has stressed the criticality of frequent participation and the generation of good quality content (Ransbotham and Kane 2011), drawing on research on argumentation quality, we highlight the importance of argument development quality in group communication processes (Seibold et al. 2010). Well-formulated and -developed argumentations enhance the effectiveness and value of members' community participation (Hansen and Haas 2001; Ransbotham and Kane 2011), 
possibly even to the point of transcending the importance of the actual content strength of the argument itself (Seibold et al. 2010). Accordingly, we view participation quality as the degree to which members substantiate and develop their statements and arguments, which enables a better analysis of participation quality across communities that vary in their content.

To validate the quality measure and to demonstrate its content independence, we drew on existing research on the conversational argument coding scheme (CACS), which has proved its utility and validity in assessing interpersonal arguments (Seibold et al. 2010; Seibold and Meyers 2007). Among other content categories, the scheme includes diametrically opposite content categories, such as convergence-seeking activities (i.e., showing agreement and recognition) and disagreement-relevant intrusions (i.e., showing denial and questioning accuracy and truth).

We drew a random subset of 32 community discussion threads (979 community posts). Two trained coders independently coded each post using the CACS. The Pearson product-moment correlation with our text-mined participation quality and presence of agreement/convergence-seeking behavior (.691, $p<.001)$ and disagreement-relevant intrusions $(.549, p<.001)$ are positive and significant, indicating the measure's validity across content categories. This conceptualization might also explain the seemingly contradictory findings of previous research, which suggest that group cohesiveness impedes performance. For example, Brockman and Morgan (2006) note a negative influence of group cohesiveness, yet they conceptualize performance as the development of novel and different ideas. 


\section{Limitations and Further Research}

As does any form of academic inquiry, the current study suffers from several limitations, which can be used to identify fruitful lines for research. First, we derived the measure of linguistic style from a member's particular usage of functional words. Although this approach parallels previous research in linguistics and communication science, it does not account for the occurrence and impact of particular, community-specific vocabulary. There may be slang or other conventional words that are strongly embedded in the communication style of a particular community. Therefore, depending on availability of innovations in text analytic software, researchers may be able to capture the use of such style formats and assess their implications in member posts.

Second, we consider and empirically validate within-community congruence with one unique communication style. Although this approach is feasible for relatively small-scale user communities (not exceeding 200 active members), it may be more complicated to generalize these findings to larger or multifocused online communities, established around brands or for the purpose of peer-to-peer, after-sales support. For example, in such multifaceted environments, subgroups may form sub communication styles, which may differ from the dominant style and perhaps indicate factionalism or community decline. Further research might investigate the value of communication styles as signals of subgroups within a single collective and relate this prediction to the life span of the community. Such an analysis would be useful for examining whether and how LSM analysis can be used in conjunction with existing modes of social network analysis.

Third, this study considers communication style aspects alone as symbolic for members' social integration into a user community. Social integration signifies members' willingness to invest on behalf of the user community, but multiple case studies also 
recognize that members can be intentionally counterproductive or abolish proactive participation in communities (i.e., flaming). Such "flame wars" escalate over time and lead to detrimental effects on collaboration. Although flaming can stem from a variety of issues, including misunderstanding, frustration, or perceptions of unfairness, further research should seek text analytic approaches to detect flaming before it becomes detrimental to community collaboration. 


\section{Managerial Implications}

This study's findings offer several actionable implications for managers of user communities. Overall, user-community managers, who struggle to encourage and sustain members' participation efforts, should recognize that community posts may reveal more about a member's attitude and perception than what is literally said. By introducing LSM and assessments of temporal development, the current study offers managers an unobtrusive and automatic way to assess user community members' social identification and predict their subsequent participation, provided members give their consent. In the absence of extrinsic remuneration, social identification offers a primary, intrinsic motivator of ongoing participation efforts. Four key implications for practitioners thus follow from our study.

First, to assess new members' integration, community managers should derive and track the dominant communication style by text mining the common usage style of function words. Firms can install continuous monitoring tools to assess not only the overall level of members' LSMs but also the patterns of how members' communication styles evolve through their iterative posting incidences. With this information, a community manager can obtain a real-time update of the sense of belonging by each member and detect changes before they lower participation behavior. As Tom de Ruyck (2012), Research Director at InSites Consulting, states:

"Given the relative anonymity of user communities it is hard to find out how well our members feel part of the community which is of the utmost importance to us. Monitoring these LSM patterns, would enable us to unobtrusively monitor the happiness of our community members and try to help them before it is too late".

In many cases, a simple "thank you" or other symbolic acknowledgment at the right time may revive participation efforts. 
Second, managers could leverage the emergence of community-level cohesiveness in communication style to drive individual members' subsequent participation efforts. By monitoring the variability in members' communication styles, managers can assess the strength of their connection. When styles begin to diverge, it may be necessary to host community events, such as brandfests, to spark a feeling of we-ness (Algesheimer et al. 2005) and encourage members to participate in their community.

Third, companies often decide to sponsor or buy into an existing user community on the basis of the number of community members or posts (Ransbotham and Kane 2011). However, they might more fruitfully assess the cohesiveness in the communication style across members to estimate the level of participation they can expect in the future.

Fourth, the amount of cognitive words used in community posts is a reliable measure of the amount of in-depth thinking in which the poster engaged. Typically, user communities filter posts by their recency, contributor, or views, to help users manage the vast amount of information available (Ma and Agarwal 2007). Our current findings supply community managers and members with an impetus to seek posts that offer high quality argument development. Such a restructuring of posts can help members and managers sift through the informational clutter; according to structural priming research (Bock and Griffin 2000), it also may stimulate other members to contribute similarly. Furthermore, current community member status and recognition systems, which tend to be based on members' post quantity, could be complemented by assessments and rewards of members' well-developed and substantiated arguments. 


\section{More than Words: The Influence of Affective Content and Linguistic Style Matches in Online Reviews on Conversion Rates ${ }^{2}$}

\section{Introduction}

Customer reviews have become one of the most frequently accessed online information sources, as consumers appear to be weary of traditional, marketer-dominated information channels (Godes and Mayzlin 2004). Online shoppers confide 12 times more trust in peers' opinions than in marketer-initiated sources (eMarketer 2010), and according to a recent market study (ChannelAdvisor 2010), 92\% of online customers read and use verbatim review comments in their purchase decisions. Online retailers thus recognize the effectiveness of customer reviews for converting customer visits into sales; Roku, the market leader in innovative applications for digital media, attributes a $20 \%$ lift in its online conversion rates to the appearance of approximately 17,000 (both positive and negative) customer reviews on its website (Bronto.com 2011). Yet the sheer volume and lack of structure of qualitative information in customer reviews continues to present a formidable challenge (Cao et al. 2011; Singh et al. 2011). Most online retailers believe their performance is hampered because they cannot efficiently decipher or reliably assess how online customers use the informational cues from their online conversations at a manageable, product category level (Bonnet and Nandan 2011). A recent market study by Econsultancy (2011) even shows that $81 \%$ of online retail sites have "limited" or "no understanding" of why customers leave without purchasing. Thus,

2

Stephan Ludwig, Ko de Ruyter, Mike Friedman, Elisabeth Brueggen, Martin Wetzels, Gerard Pfann, "More than Words: The Influence of Affective Content and Linguistic Style Matches in Online Reviews on Conversion Rates", paper forthcoming at the Journal of Marketing (January 2013) 
there is a clear managerial need to develop insights into the influence of text-based customer reviews, to improve understanding of conversion behavior.

Current research on online reviews offers little guidance. Most studies focus nearly exclusively on "quantitative surrogates" of review contents (Mudambi and Schuff 2010, p.195), and in this emerging stream, the empirical support for the predictive influence of numerical quality diagnostics, such as review volume or star ratings, on sales remains equivocal (Chen et al. 2004; Chevalier and Mayzlin 2006; Dellarocas et al. 2007; Duan et al. 2008). Therefore, researchers are turning to the reviews' textual properties and assessing their impact on retail performance (Chevalier and Mayzlin 2006). In particular, affective cues provided in verbatim text (e.g. "I love the book" or "worst book I ever read") might influence respondents' attitudes (Cohen et al. 2008), and the heuristic nature of online information processing seems likely to allow for the affective content contained in review texts to drive behavior (Das et al. 2005; Jones et al. 2004). However, it is still unclear whether affective word cues serve as straightforward predictors of the collective impact of customer reviews on retail success, considering the limited evidence of nonlinear relationships between affective activation and product evaluations (Andrade 2005; Roehm and Roehm 2005). In particular, extreme (positive and negative) review content is prevalent and may threaten review diagnosticity (Streitfeld 2011). Beyond review content, recent theorizing in social psychology points to linguistic style, as manifested in an author's profile, as likely to shape the impact of information contained in reviews (Ireland and Pennebaker 2010). The inherent inseparability of content and style in reviews suggests that insights into linguistic style may extend beyond verbatim content to enhance understanding of their overall impact on customer decision making and thus retail performance.

In addition, reviews have long been related to sales (or its proxies), yet there is growing consensus that online conversion rate offers a better metric for gauging online retail 
performance (Gurley 2000; Moe and Fader 2004). Small gains in conversion rates have powerful implications for firm performance, through increasing revenue and decreasing marketing costs as a percentage of sales. The impact of user-generated content on performance metrics also should be assessed in a dynamic rather than static manner (Tirunillai and Tellis 2012), because conversion rate dynamics give a continuous indication of the potential business that retailers lose when customers leave the site without making a purchase. However, few efforts have explored the dynamics of customer conversion rates as a primary success metric (Moe and Fader 2004).

Considering these gaps and concerns, we aim to provide theoretical and managerial guidance on the influence of textual properties of consumer reviews on online retailers' conversion rates in three ways. First, we examine the collective impact of affective content from a dynamic perspective, by noting how changes in affective content influence changes in conversion rates over time. Little previous work on affect has featured longitudinal measures or analyses; to address this shortcoming, we study the impact of aggregate, weekly changes in the affective content of product reviews on shifts in product conversion rates. This novel approach to investigating affect in marketing is particularly important in the context of reviews, because new reviews typically take prominent spots on the product display page, so changes in affective content likely provide strong drivers of changes in product conversion rate. We focus on their nonlinear impact, taking into account extreme positive and negative changes. Research into manipulations of affective states and their influence on responses to various stimuli (e.g., ads, products; Cohen et al. 2008) usually focuses on mean-level differences across experimental conditions. While experimental manipulations provide suggestive evidence of nonlinear relationships between affect and consumer thought and behavior (such as Andrade (2005) and Roehm and Roehm (2005) who demonstrate nonlinear relationships between manipulated affect activation and product evaluations), a rigorous test 
of this notion requires studying the effect of affect across a range of values, rather than at specific points on a spectrum primed by experimental procedures.

Second, we add to recent research by noting the impact of linguistic style of customer reviews on online conversion rates. Human communication theory (e.g., Giles 2009b) posits that conversation style can elicit perceptions in conversational dyads. Furthermore, recent research has shown that synchronization in conversational style, or linguistic style match (LSM), irrespective of content, increases rapport, credibility, and shared perceptions between conversants (Ireland and Pennebaker 2010). Yet previous research on the impact of customer review texts focuses on content and ignores linguistic style as a potential diagnostic cue. Beyond the importance of recommender similarity perceptions, as suggested in prior research (Menon and Blount 2003), we posit that the degree to which reviewers accommodate the linguistic style of the product interest group may determine the influence of the reviews on changes in customers' conversion behavior.

Third, content and linguistic style are inherently inseparable and may reinforce the impact of a review (Chaiken and Maheswaran 1994; Menon and Blount 2003), and their collective impact demands more empirical examination. Verbatim comments assume a pivotal role as the primary means to establish source perceptions and indicate reviewers' product experience. We supplement prior research on customer reviews by assessing how changes in the reviews' affective content and style jointly relate to subsequent conversion rate dynamics. In customer review settings, such a joint impact highlights the need to study content and style collectively when assessing the impact of customer reviews on retail success. 


\section{Conceptual Background}

Feldman and Lynch (1988) posit that the relative weight of heuristic inferences, as decision inputs, depends on two context-dependent facets: their relative accessibility and their diagnosticity compared with alternative inputs. The sheer volume of online peer reviews often leads consumers to process information heuristically. We posit that, at an aggregate level this has a decisive influence on their online purchase decisions and website conversion rates (Jones et al. 2004). Existing research has accordingly focused on the diagnosticity of readily extractable, quantifiable customer review information cues, such as quality ratings (Chevalier and Mayzlin 2006), volume (Duan et al. 2008), and reviewer identity information (e.g., name, location; (Forman et al. 2008), as well as on product-related aspects such as product popularity (Zhu and Zhang 2010) and price (Yong 2006). However, empirical investigations into the influence of numerical cues (e.g., star ratings) on sales often provide mixed or inconclusive results, which suggests some doubts about their diagnosticity and predictive ability (Yong 2006). Chevalier and Mayzlin (2006) find that additional favorable review ratings on Amazon.com increase book sales, whereas incremental negative ratings decrease them. Yet, Chen, Wu, and Jungsun (2004) find no significant impact of positive ratings on sales, and Berger, Sorensen, and Rasumussen (2010) suggest that even negative ratings increase sales for products with lower awareness. In the movie industry, Dellarocas, Xiaoquan, and Awad (2007) indicate that numerical ratings relate positively to box office revenue, irrespective of the volume of reviews, whereas Duan, Gu, and Whinston (2008) and Yong (2006) find that review volume, not ratings, drives sales.

These mixed findings might stem from (1) methodological shortcomings, such as a cross-sectional context and inability to control for unobserved differences, including product quality (Zhu and Zhang 2010) or (2) the inability of numeric cues to do justice to the nuanced, fine-grained, and expressive nature of verbatim reviews (Cao et al. 2011; Pavlou and 
Dimoka 2006; Singh et al. 2011). Making use of recent advances in text analytics to systematically analyze large volumes of collections of customer review verbatims, and taking a dynamic perspective, which is more reflective of the rapid, continual changes in usergenerated content (Tirunillai and Tellis 2012), may clarify the impacts of review content on conversion rates (Chevalier and Mayzlin 2006; Mudambi and Schuff 2010).

Emerging research on text-based communication suggests that both content and style elements of verbatim reviews are relevant decision inputs that help determine relative diagnosticity and accessibility (Huffaker et al. 2011). This research distinguishes between linguistic content and style, where at a word level, "content words are generally nouns, regular verbs, and many adjectives and adverbs. They convey the content of a communication" (Tausczik and Pennebaker 2010, p. 29). Yet no content can be communicated without style words. As Tausczik and Pennebaker (2010, p. 29) state, "intertwined through these content words are style words, often referred to as function words. Style or function words are made up of pronouns, prepositions, articles, conjunctions, auxiliary verbs, and a few other esoteric categories". These categories identify not only what people convey (i.e., sentential meaning) but also how they write (sentential style), so both have diagnostic value that affects decisions (Bird et al. 2002).

Affective content words (e.g., conveying emotions like happiness, sadness, anger) reveal the intent of a text (Bird et al. 2002; Das et al. 2005). Affect in and of itself is not a linguistic property but refers to an "internal feeling state" (Cohen et al. 2008, p. 297) that is "consciously accessible as the simplest raw (non-reflective) feelings evident in moods and emotions" (Russell 2003, p. 148). The use of word cues may be the most effective way to make affect accessible (Ortony et al. 1987). In line with accumulating empirical support for treating feelings as information (Schwarz and Clore, (1996), we find a clear underlying rationale for mining affectively laden content words in relation to online customer reviews. At 
the individual level, affective content words should be particularly likely to influence consumers whose motivation to engage in detailed cognitive processing is low, those with limited access to processing resources (e.g., because they are distracted or under time pressure), when other bases of evaluation are ambiguous or unrevealing, and when consumers lack expertise in the target domain (Cohen et al. 2008; Greifender et al. 2011; Lau-Gesk and Meyers-Levy 2009). These conditions describe the online purchase process (Jones et al. 2004); because text-based affective content words provide rapidly accessible and diagnostic signals about targets (Cohen et al. 2008). We argue that, at the aggregate level, affective content will influence conversion rates. Regarding accessibility, Zajonc's (1980) welldocumented hypothesis on the primacy of affect in evaluative judgments indicates that affective cues are more accessible than factual or descriptive information. Pham et al. (2001) demonstrate that affective cues are registered more rapidly than cognitive assessments; the relative accessibility of affective cues also increases with their volume and evaluative clarity or intensity (Gorn et al. 2001). In addition to accessibility, affective cues provide decision inputs only if they are perceived as sufficiently diagnostic. Two facets of diagnosticity documented in prior literature seem relevant to (conversion) behavior: (1) perceived representativeness, which relates to the extent to which consumers believe that affective content reflects the target and whether the representation of the sender indicates qualifications to express his or her opinions, and (2) perceived validity, or whether affective cues appear consistent with other cues and across multiple sources (Gasper and Clore 1998). The anonymous nature of online review settings makes it difficult to establish sender qualifications, but extreme deviations in affective cues lower the value of feelings as information and elicit counterproductive effects by reducing diagnosticity (Andrade 2005). We investigate whether this extends to the aggregate level. 
In addition to affective content, the accessibility and diagnosticity of customer reviews and their impact on customer purchasing behavior likely relates to their linguistic style (i.e., the particular usage style of function words employed). Humans are highly attentive to the conveyance of messages (Giles and Smith 1979), and prior work in several scientific disciplines has demonstrated the importance of function words for determining conversational outcomes (Huffaker et al. 2011). There are only about 500 function words in the English language, but this deceptively small category comprises roughly $55 \%$ of people's daily word usage and provides insight into conversants' personalities (Bird et al. 2002). Consider three different descriptions of book experiences at Amazon.com:

Reviewer A: "One of my favorite series."

Reviewer B: "[...] The best in the world!! Loved it!"

Reviewer C: "A very fine finish to a thrilling trilogy."

All three reviews say essentially the same thing, but the reviewers' ways of expressing themselves (i.e., pronoun usage, conjunctions, and other function word dimensions) provide additional information. Reviewer A is positive but in a relatively restrained manner; Reviewer $\mathrm{B}$ is more overtly positive and uninhibited; Reviewer $\mathrm{C}$ is rather formal and stiff. Thus, in addition to affective content, review texts communicate specific linguistic styles that reveal aspects of the authors' personality. The LSM, or degree of synchronization between two conversants in terms of their use of function words, also has behavioral implications (Ireland and Pennebaker 2010).

Traditional conceptualizations of common ground in conversations posit that shared perspective taking depends on conversational content (Clark and Brennan 1991). However, recent research drawing on communication accommodation theory (Giles and Smith 1979) also suggests that common ground may be an automatic outcome of LSM, irrespective of content (Ireland and Pennebaker 2010). The use of similar function words-that is, high LSM 
between two conversation partners - represents a form of psychological synchrony (Ireland and Pennebaker 2010; Pickering and Garrod 2004). Linguistic style matching thus elicits understanding and perceptions of a common social identity but decreases perceptions of social distance in verbal and written communications (Chung et al. 2007). Ireland and Pennebaker (2010) find that for potential romantic couples on a first date, for example, the degree of match in their function words predicts their subsequent relationship initiation and stability. Furthermore, in online text-based negotiation settings, greater matches in function word usage increase interpersonal rapport and agreement among potential coalition partners (Huffaker et al. 2011). Convergence in communication styles is not exclusively a property of conversation dyads though; research on online collectives that qualitatively monitors online text-based conversations reveals the phenomenon of so-called language games (Fayard and DeSanctis 2010, p. 154), in which members adhere to the collective's style of conversing to demonstrate their affiliation. Customer review forums similarly are collectives of customers who share a common interest (e.g., product interest groups). As Forman, Ghose and Wiesenfeld (2008) have demonstrated, many features of Amazon.com are designed to increase the salience of reviewers' membership in and identification with the community. Forman et al. highlight that reviewers typically post and read reviews for a particular product type, such as science-fiction or political books. Thus within Amazon, there exist sub-groups sharing common interests, whose members are likely to have repeated encounters with one another. This necessitates studying the impact of customer reviews at the aggregate sub-group level of product interest group.

The three review comments we highlighted describe the same science fiction book The Reckoning on Amazon.com. Although readers process function words subconsciously, the relative match of each review with the pervasive communication style of the sci-fi book 
interest group varies. In our example, Reviewer A reveals a much greater LSM with the product interest group than Reviewer C, which likely affects each review's diagnosticity.

Finally, the relevance of LSM in review settings is evident in research on the criticality of source characteristics in persuasion contexts (Pornpitakpan 2004). Experimental evidence highlights the perceptual and subjective nature of diagnosticity in heuristic consumer decision-making situations (Chaiken and Maheswaran 1994), which often invoke messenger bias (Menon and Blount 2003). Communicators perceived as highly similar also seem more representative, capable, and qualified to pass judgment than communicators who are perceived as less similar (Brown et al. 2009). In an online customer review context, readers often have little but the review text to use to form their perceptions of the review's diagnosticity, so linguistic styles may serve as identity-descriptive information that, as a heuristic cue, shapes consumers' evaluations of the review and thus of the product. According to research on the diagnosticity of message source and content, an intricate interplay exists between affective content of a message and source cues (Pornpitakpan 2004). People who receive tailored messages from a similar source exhibit high levels of trust and tend to comply (Campbell et al. 1999). Czapiski and Lewicka (1979) also conclude that source credibility affects the weight an audience grants to positive and negative information in a message. We anticipate that LSM influences the perceived representativeness of the sender and influences the effectiveness of affective content conveyed in reviews. We next develop specific hypotheses about the dynamic influences of affective content and LSM on online retail site conversion behavior. 


\title{
Hypotheses Development
}

\begin{abstract}
Affective Content
Affect drives evaluation and decision making (Lench et al. 2011). Evidence from previous studies that use experimental manipulations to prime affective states suggests that exposure to affective cues influences evaluations and/or judgments of attitude objects, such as brands and products: Positive (negative) affective cues lead to more positive (negative) evaluations and judgments (e.g. Lau-Gesk and Meyers-Levy 2009). Simply reading a text with affective content may be sufficient to influence thoughts and behaviors (Lau-Gesk and Meyers-Levy 2009; Lench et al. 2011). Previous theory and research thus suggest that affective cues elicit automatic affective responses, which require few processing resources, emerge rapidly, and guide attitudes and actions (Baumeister et al. 2007; Cohen et al. 2008). The transfer of affect from such diagnostic cues and the corresponding automatic responses may be best understood according to a positive-negative continuum (Baumeister et al. 2007; Russell 2003), so research examining the content of online text applies this approach to understand links between the mood of online messages and stock markets (Das et al. 2005) or changes in the affective content of blog posts before and after September 11, 2001 (Cohn et al. 2004). We use text analytics to capture positive and negative affective content and determine how changes in the affective tone of product reviews alter conversion rate dynamics at the collective level.
\end{abstract}

We examine both linear and quadratic effects in the relationship between changes in affective content and changes in conversion rate at aggregate levels. The linear relationship tests the notion from the affect transfer and priming literature that predominantly negative (positive) reviews over time increase the negative (positive) affect conveyed through reviews, leading to reduced (increased) product conversion rates. We test this relationship to 
corroborate previous research and to demonstrate the ability of text analytic techniques to detect theoretically meaningful, well-established relationships.

However, we also consider the quadratic relationship between affective content change and conversion rate change. When new reviews are exceedingly positive (negative), increases in positive (negative) affective content fall out of balance with the global (i.e. aggregate) affective impression conveyed by all other existing reviews. If such steep changes in affective content occur, consumers' suspicion may be aroused, leading them to correct for the influence of affect when making their product evaluations and choices (Petty et al. 2003). Scandals prompted when interested parties write glowing reviews of their own offerings (or harshly critique competitors',(Streitfeld 2011) have resulted in heightened public awareness of the existence of fake or planted reviews on e-commerce sites. Thus, new product reviews with an extreme imbalance of positive or negative affective content likely initiate consumer wariness and corrections to the influence of these affective cues (Petty et al. 2003). This line of reasoning suggests that small or modest changes toward more positive affective content should result in larger increases in conversion rate, while steep changes in positive affective tone should result in more moderate increases in conversion rate. Conversely, small or modest changes toward more negative affective content should result in larger decreases in conversion rate, while steep changes toward more negative affective content should result in more moderate decreases in conversion rate. Accordingly, we posit:

$\mathrm{H}_{1 \mathrm{~A}}$ : There is a quadratic relationship between changes in aggregate positive affective content in a product's reviews and changes in conversion rate. At the extremes of positive affect change, each additional increase should have a smaller impact on conversion rate change.

$\mathrm{H}_{1 \mathrm{~B}}$ : There is a quadratic relationship between changes in aggregate negative affective content in a product's reviews and changes in conversion rate. At the extremes of 
negative affect change, each additional increase should have a smaller impact on conversion rate change.

\section{Linguistic Style Match}

Social psychology and communication research show that the manner or style in which a person communicates not only reveals personality but also elicits relational perceptions in the communication partner (Pennebaker 2011). According to communication accommodation theory (CAT) (Giles and Smith 1979), greater degrees of synchronization in communication styles (e.g., voice, posture, gestures) in conversation dyads lead participants to perceive a common social identity, decrease their perceptions of social distance, and elicit more approval and trust (Pickering and Garrod 2004). Even in text-based (nonverbal) communication, dyadic LSM (i.e., similarities in the use of function words) transcend the actual content of the conversation to establish common ground perceptions (Ireland and Pennebaker 2010). Although LSMs and their implications have not been studied in group settings, members of online collectives, who share a common interest, tend to develop and adhere to a unique style of "in-group" communication (Fayard and DeSanctis 2010). In online customer reviews, the review "authors" are likely to read other reviews about their product of interest (e.g., science fiction books) and write reviews for an audience that shares this interest (Forman et al. 2008). Therefore, within the product interest groups, voracious readers and writers of reviews likely come to associate a certain linguistic style with that interest group and non-consciously mimic it in their own writing. According to CAT, reviewers' adjustments to group-specific linguistic styles should elicit perceptions of shared identity and rapport among the reading collective (Giles 2009b). Such perceived rapport provides readily accessible diagnostic information, which directly influences consumer judgments and behaviors if they process information heuristically, as is the case for online information searches (Chaiken and Maheswaran 1994; 
Jones et al. 2004). New reviews with a high LSM score help readers establish rapport with the reviewer, which stimulates them to rely on source cues to form attitudes, perhaps even to the exclusion of message content (Pornpitakpan 2004). Thus, an increase in reviews that match the linguistic style of the particular interest group should enhance conversion rates. In other words, if new reviews change the linguistic style such that there is a closer match with the interest group's linguistic style, we would expect a positive change in conversion rates. Therefore, we hypothesize

$\mathrm{H}_{2}$ : A positive change in linguistic style matching between a product review and the interest group's linguistic style results in positive changes in conversion rates.

\section{Joint Impact of Affective Content and LSM}

The inherent inseparability of content and style in customer reviews almost dictates an investigation of their joint effect, and previous research confirms an interplay between perceived source attributes (e.g., physical attractiveness) and message elements (e.g., sidedness) with distinct explanatory power (beyond their individual effects) for recommendation persuasiveness (Pornpitakpan 2004). For example, when Feldman (1984) presented high school students with nutrition messages attributed to a high, medium, or lowsimilarity sources, greater perceived similarity increased participants' likelihood to adopt the promoted nutrition behavior and attitudes. Noriega and Blair (2008) also show that the choice of language determines the effectiveness of advertising messages among bilingual consumers. Because we posit that LSM elicits similarity perceptions, the increasing match between the review and the product interest group's linguistic styles should make that review more appealing, as well as grant greater importance to changes in its content. Thus, a combination of positive changes in affective content and increasing degrees of LSM should exert a greater impact on conversion rate changes. Specifically, we posit positive effects on conversion rate 
changes when positive changes in affective content combine with positive changes in LSM in customer reviews:

H3: There is an interaction between affective content and LSM, such that positive changes in a product review's positive affective content coupled with positive changes in linguistic style matching lead to greater positive changes in conversion rates. 


\section{Empirical Study}

\section{Setting}

We gathered data using automated Java scripts to access and parse HTML and XML pages describing books available for sale on Amazon.com, the leading electronic retailer. We chose this research context because of the unique traceability features of customer review information and their influence on conversion behavior on retail sites. All information is publically accessible and updated frequently on the retailer's webpage. Therefore, in addition to the information conveyed through the customer reviews, we could collect and control for other product and review-related information, such as price, review volume, review helpfulness, and advertising, all of which may affect consumers' purchase decisions. During the data collection, Amazon.com made customers' conversion behavior publicly available (Bray and Martin 2011), so we also could establish direct links between customer reviews and retail performance dynamics. Similar data about the conversion rates of websites could be obtained from software packages designed to track or retrace online visitor behavior. Finally, online customer reviews, conversion behavior, and product-related information represent high-frequency data that can be collected repeatedly—a prerequisite for obtaining a sufficient number of observations for dynamic panel data analysis.

Our initial sample included 641 unique books across all subgenres, released between April 15 and May 5, 2010, which received at least one customer review during the observation period. We selected only books launched in this time period to ensure that the sample books were in approximately the same stage in their product life cycle. To explore how changes in customer reviews influence the conversion behavior dynamics of visiting customers, we retrieved conversion rates and customer reviews, along with general product and price information, at weekly intervals for 17 consecutive weeks. To preserve any 
causality implications, we collected dynamic product and customer review information from Saturdays to Thursdays and conversion rate information (our outcome measure) on Fridays. However, we eliminated 36 books that were unavailable for purchase (out of stock) for some period of time during the data collection. The final sample thus consisted of 591 books and 18,682 customer reviews. In a second stage, two independent coders assigned the books to subgenres using Amazon's official genre classification (Krippendorf's alpha for the original coding was 95\%; discrepancies between coders were resolved through discussion). The final sample included books across all subgenres (see Table 1), including 49\% nonfiction books. 
TABLE 1

Final Sample

\begin{tabular}{lcclcc}
\hline \multicolumn{2}{c}{ Nonfiction } & \multicolumn{3}{c}{ Fiction } \\
\hline Subgenre & \#Books & \#Reviews & Subgenre & \#Books & \#Reviews \\
\hline Art & 20 & 141 & Fiction \& Literature & 56 & 1931 \\
History & 22 & 582 & Graphic Novel & 27 & 191 \\
Education & 19 & 725 & Horror & 10 & 796 \\
Craft, Hobbies \& Travel & 14 & 204 & Mystery \& Crime & 68 & 2199 \\
Cooking & 30 & 561 & Romance & 15 & 549 \\
Technology & 11 & 323 & Sci-Fi & 96 & 4337 \\
Business & 24 & 638 & Thriller & 25 & 1113 \\
Biography & 31 & 1163 & Western & 8 & 574 \\
Sports & 17 & 362 & & & \\
Science & 22 & 331 & & & \\
Religion & 26 & 382 & & & \\
Political\& Current Events & 34 & 1180 & & & \\
Philosophy & 11 & 99 & & & \\
Family & 16 & 483 & & & \\
Humor & 3 & 91 & & & \\
\hline
\end{tabular}

\section{Data and Measures}

We obtained conversion behavior data from the conversion rate information provided by Amazon.com, namely, the "What Do Customers Ultimately Buy After Viewing This Item" information, which listed the percentage of customers who bought the product featured on the retail page (Bray and Martin 2011).

To assess the affective content and LSM of the review texts, we then conducted a content analysis of the reviews' qualitative text comments. Content analysis is an increasingly popular method to study user-generated posts online (Singh et al. 2011). To transform text comments into quantitative data, content analysis uses automated, systematic procedures that ensure the objectivity, reproducibility, and reliability of the data analysis (Chung et al. 2007). Preparing the data for automated text analysis entails archiving the review texts and converting them into text files, a process that produced several review text files for each product $($ minimum $=1$, maximum $=503)$. 
Next, the customer review texts were automatically analyzed using the linguistic inquiry and word count (LIWC) program (Pennebaker et al. 2007). Originally developed to analyze emotional writing, LIWC dictionaries offer strong, reliable convergence between the dimensions they extract and content ratings performed by human coders (Pennebaker et al. 2007). Their validity also has been confirmed in more than 100 studies that applied this methodology to various texts, including online content such as blogs (Cohn et al. 2004) and instant messaging (Slatcher and Pennebaker 2006). The LIWC approach recently appeared in marketing to unearth sentiment in newspaper articles (Humphreys 2010). Using word counts for a given text, LIWC calculates the proportion of words that match predefined dictionaries.

We used two LIWC dictionaries related to affective content and function words. The automatic retrieval of the word count for affect-laden, positive (happiness) and negative (fear, anger, disgust, sadness) words in the review texts produced our measure of affective content. For example, "disappointing" would appear in the negative affect dictionary and be counted as 1 in the total amount of negative affective content words in the review. If the word "hate," which also belongs to the negative affect dictionary, appeared in the same review text, it would be counted, and the total score for negative affective content would be 2 . At the end of the content analysis, LIWC calculates the total number of times the dictionary words appear in a review, divided by the total number of words in the review, to determine the percentage of the text that falls into a particular linguistic category. We aggregated all review scores for the same product to derive a mean level for each week, that is, an intensity percentage or summary score between -1 and 1 , depending on relative intensity of negative or positive affective content across all reviews for that product in a given week. Because review titles are particularly prominent, we mined and conducted separate calculations for title and text intensities similar to Cao, Duan and Gan (2011). The aggregation is as follows:

$$
\mathrm{AC}_{\mathrm{it}}=\left[\left(\left(\sum_{i=1}^{n} \mathrm{PA}_{\mathrm{itT}}-\sum_{i=1}^{n} \mathrm{NA}_{\mathrm{itT}}\right) / \sum_{i=1}^{n} \mathrm{~N}_{\mathrm{itT}}\right)+\left(\left(\sum_{i=1}^{n} \mathrm{PA}_{\mathrm{itB}}-\sum_{i=1}^{n} \mathrm{NA} \mathrm{itB}_{\mathrm{tB}}\right) / \sum_{i=1}^{n} \mathrm{~N}_{\mathrm{itB}}\right)\right] / 2,
$$


where $\mathrm{AC}_{\mathrm{it}}$ represents the overall intensity of affective content in reviews for product $\mathrm{i}$ in week $\mathrm{t} ; \sum_{i=1}^{n} \mathrm{PA}_{\mathrm{itT}}$ is the sum of positive affective content words (PA) in the title (T) across all reviews ( $\mathrm{j}$ to $\mathrm{n}$ ) posted on product (i) in week (t); $\sum_{i=1}^{n} \mathrm{NA}_{\mathrm{itT}}$ is the sum of negative affective content words in the title; and $\sum_{i=1}^{n} \mathrm{~N}_{\mathrm{itT}}$ represents the sum of all words used in the title. The subscript (B) denotes the body of the review text, and the calculations for affective content of the review body are the same as those for titles, but denoted by $\sum_{i=1}^{n} \mathrm{PA}_{\mathrm{itB}}$; $\sum_{i=1}^{n} \mathrm{NA}_{\mathrm{itB}}$, and $\sum_{i=1}^{n} \mathrm{~N}_{\mathrm{itB}}$, , respectively.

We next operationalized the degree of LSM between each review and the common linguistic style of the product interest group in three steps. First, book subgenres represent special product interest groups in the overall Amazon community, so we segmented reviews according to book genre (Forman et al. 2008). Research into collective settings has examined group similarities using direct consensus models, which take the group average as the preferred mode of aggregation (Bliese 2000). We construct the common linguistic style for reviews of a particular subgenre by averaging their usage intensity separately for every function word in the English language. To empirically justify this aggregation procedure, we calculated the intra-class correlation (ICC 1) coefficients for nine function word categories separately (Table 2 ). The ICC 1 coefficient provides a ratio of between-group to total variance and thereby captures both within and between-genre variation in the usage of function words. Our results empirically justify the data aggregation of individual linguistic styles in reviews to derive a common "genre" linguistic style; for all the function word variables, the ICC 1 values are significant (F-values, $p<.05)$, ranging from .62 to .94 . That is, each function word category possesses a sizable amount of between-genre variance, which is convincing evidence of reliable genre means for linguistic styles.

Second, having established a common usage intensity for each function word in a given book genre, we calculated separate LSM scores for each function word, using the 
following formula to derive the difference in usage intensity of a particular word (e.g., "his") between review $\mathrm{w}_{\mathrm{i}}$ and the average usage intensity of that same word in the subgenre of review LSM "his" reviewi $=1-\left(\mid \sum\right.$ “his"”/ $\sum \mathrm{N}_{\mathrm{i}}-\mu$ “his", $\left./ \mu \mathrm{N}_{\mathrm{j}} \mid\right)$,

where LSM"his" $i$ is the similarity in the usage intensity of the word "his" between a review and the general subgenre style; $\sum$ "his" ${ }_{i}$ denotes the count of the word "his" in review i; $\sum \mathrm{N}_{\mathrm{i}}$ refers to the total words in review $\mathrm{i} ; \mu^{\text {"his" }}{ }_{\mathrm{j}}$ is the average count of the word "his" in all reviews for the same subgenre $\mathrm{j}$; and $\mu \mathrm{N}_{\mathrm{j}}$ is the average words used in reviews in subgenre $\mathrm{j}$.

Third, in line with Ireland and Pennebaker (2010) we derived the overall LSM score of a particular review by taking the average LSM score across all function words. For example, if a review used "despite" four times in a text of 100 words, it would yield an intensity of .04. If the average intensity across all reviews for the same subgenre was .02, the LSM score for "despite" in that review would be .98 . After applying this approach for all function words, we averaged the LSM scores per review to yield a composite LSM score, bounded by 0 and 1; higher numbers represented greater stylistic similarity between a review and the subgenre style. Each review received a single LSM score. Similar to the affective content scores, all reviews for the same product in a particular week were aggregated at the mean level. Therefore, we obtained a measure of overall LSM for reviews published about a particular product in a given week. We conducted a pilot study (please see Appendix A) to confirm the validity of the LSM measure, in terms of actually eliciting social identification by the target audience and strengthening the impact of the reviews on purchase intentions. 
TABLE 2

Word Categories Used to Calculate Linguistic Style Match and Affective Content AFFECTIVE CONTENT

\begin{tabular}{ll}
\hline Category & Examples \\
\hline Positive affective content & Love, nice, sweet \\
Negative affective content & Ugly, dumb, hate \\
\hline \multicolumn{1}{c}{ LINGUISTIC STYLE MATCH } \\
\hline Category & Examples \\
\hline Personal pronouns & I, his, their \\
Impersonal pronouns & it, that, anything \\
Articles & a, an, the \\
Conjunctions & and, but, because \\
Prepositions & in, under, about \\
Auxiliary verbs & shall, be, was \\
High-frequency adverbs & very, rather, just \\
Negations & no, not, never \\
Quantifiers & much, few, lots \\
\hline
\end{tabular}

Notes: The text mining was conducted using the 2007 Linguistic Inquiry and Word Count Program by (Pennebaker et al. 2007) 
Control measures: We constructed our control variables from observed Amazon.com data. In addition to the traditional star rating measure, which offers a $1-5$ product quality rating per review, we controlled for the effects of increased review quantity posted in a particular week for each book. Review quantity is the count of reviews posted on the product site of product i during week t. Because price dynamics influence online purchase decision making (Xinxin and Hitt 2010), we also considered the impact of changes in discounts (percentage margin of the original price in week $t$ ). We include the helpfulness perceptions of reviewers, to control for potential differences in the "expertise" of reviewers. To derive these helpfulness perceptions, we divided the number of people who considered a review helpful by the total votes in response to the "was this review helpful to you?" question featured on Amazon.com for each review. Using the same measure, Mudambi and Schuff (2010) show the percentage of people who find a review helpful relates to the diagnosticity of the retail site. Noting important recent findings related to the impact of variance in purchase information on consumers' choices (Clemons et al. 2006), we also include measures of variability in star-rating and affective content; we decided to use the standard deviation, which reflects within-subject variability. Finally, we collected data about additional advertising of the books, but because there were virtually no such occurrences and the effect was highly insignificant, we did not include this variable in the final model. 


\section{Data Analysis}

To capture the influence of our explanatory variables on changes in product site conversion rates, we specified a dynamic panel data model. We assessed the impact of the preceding changes in the explanatory variables on subsequent changes in the product site's conversion rates, to reduce potential problems associated with autocorrelation and remove the impact of time-invariant unobservable factors. By studying the within-product changes rather than absolute levels, we could eliminate observed and unobserved differences between the books, which might influence conversion rates. Observed differences, such as the presence or absence of the "look inside" feature, may cause differences in conversion rates, because customers can view and read pages prior to purchase and thereby better assess the quality of a book. However, this feature does not change over time, so we removed (by statistically controlling for) it with the general method of moments (GMM) first-difference transformation. Unobservable product aspects that are constant over time, such as the inherent quality of books, may cause further unobserved differences in behavior. Past conversion behavior predicts future conversion behavior, and we want to test individual effects of our explanatory variables, so we included lagged and second-lagged differences of the dependent variables as controls, which enabled us to control for inertia and persistence in conversion rates. The initial condition was zero for all products; the launch date, as a first observation, produced a conversion rate of zero. We outline, in Table 3, the descriptive statistics and correlations; the level and change correlations between conversion rate and affective content in the review texts, linguistic similarity, and star ratings were all in the expected directions. 
TABLE 3

Descriptive Statistics and Correlation Matrix

\begin{tabular}{|c|c|c|c|c|c|c|c|c|c|c|c|c|c|}
\hline Variables & $\mathbf{N}$ & $\mathbf{M}$ & SD & 1 & 2 & 3 & 4 & 5 & 6 & 7 & 8 & 9 & 10 \\
\hline \multicolumn{14}{|c|}{ Levels of Variables } \\
\hline 1. Conversion rate & 4763 & .79 & .12 & 1.00 & & & & & & & & & \\
\hline 2. Conversion rate $(t-1)$ & 4763 & .79 & .12 & .93 & 1.00 & & & & & & & & \\
\hline 3. Affective Content & 4763 & .22 & .13 & .22 & .17 & 1.00 & & & & & & & \\
\hline 4. LSM & 4763 & .04 & .02 & .19 & .15 & .16 & 1.00 & & & & & & \\
\hline 5. Star Rating & 4763 & 4.21 & .64 & .18 & .14 & .46 & .13 & 1.00 & & & & & \\
\hline 6. Review Quantity & 4763 & 20.82 & 32.5 & .01 & .02 & -.03 & -.12 & -.05 & 1.00 & & & & \\
\hline 7. Helpfulness $(\mathrm{t}-1)$ & 4763 & 3.82 & 4.95 & .05 & .07 & .07 & .05 & -.21 & .29 & 1.00 & & & \\
\hline 8. Price Discount $(\mathrm{t}-1)$ & 4763 & .34 & .10 & .21 & .19 & .18 & -.01 & -.04 & .21 & .10 & 1.00 & & \\
\hline 9. Quality Rating Variation & 4763 & .87 & .52 & .07 & .03 & -.29 & -.14 & -.65 & .29 & .22 & .08 & 1.00 & \\
\hline 10. Affective Content Variation & 4763 & .24 & .13 & .06 & .03 & .14 & -.12 & -.12 & .21 & .07 & .02 & 0.31 & 1.00 \\
\hline \multicolumn{14}{|c|}{ Changes in Variables } \\
\hline 1. Conversion rate & 4763 & .01 & .03 & 1.00 & & & & & & & & & \\
\hline 2. Conversion rate $(\mathrm{t}-1)$ & 4763 & .01 & .03 & .21 & 1.00 & & & & & & & & \\
\hline 3. Affective Content & 4763 & .01 & .05 & .19 & .13 & 1.00 & & & & & & & \\
\hline 4. LSM & 4763 & .01 & .02 & .14 & .07 & .12 & 1.00 & & & & & & \\
\hline 5. Star Rating & 4763 & .01 & .10 & .01 & .00 & .19 & .03 & 1.00 & & & & & \\
\hline 6. Review Quantity & 4763 & 1.12 & 5.94 & -.01 & -.03 & -.03 & -.08 & .04 & 1.00 & & & & \\
\hline 7. Helpfulness $(\mathrm{t}-1)$ & 4763 & .06 & 6.83 & .05 & .06 & .10 & .03 & -.12 & .30 & 1.00 & & & \\
\hline 8. Price Discount $(\mathrm{t}-1)$ & 4763 & .01 & .10 & .07 & .02 & .01 & -.08 & -.06 & .12 & .08 & 1.00 & & \\
\hline 9. Star Rating Variation & 4763 & .01 & .66 & .02 & .01 & .12 & -.15 & -.46 & .27 & .12 & .19 & 1.00 & \\
\hline 10. Affective Content Variation & 4763 & .01 & .18 & .04 & .01 & .15 & -.14 & -.15 & .22 & .07 & .11 & .30 & 1.00 \\
\hline
\end{tabular}

Notes: Correlations in italics are significant at the $90 \%$ level. 


\section{Overall Model}

The overall model, transformed into first differences, is:

$\Delta C R_{i t}=\alpha_{1} \Delta C R_{i, t-1}+\alpha_{2} \Delta C R_{i, t-2}+\beta_{2} \Delta X_{i t}+\beta_{3} \Delta E_{i t-1}+\Delta u_{i t}$,

where:

$\Delta \mathrm{CR}_{\mathrm{it}}=\mathrm{CR}_{\mathrm{it}}-\mathrm{CR}_{\mathrm{it}-1}$ is the change in conversion behavior for book $\mathrm{i}$ from the previous week $(\mathrm{t}-1)$ to the current week $\mathrm{t}$.

$\Delta \mathrm{CR}_{\mathrm{i}, \mathrm{t}-1}$ and $\mathrm{CR}_{\mathrm{i}, \mathrm{t}-2}$ represent changes in the lagged conversion behavior for book $\mathrm{i}$ from the previous two periods, $(\mathrm{t}-1)$ and $(\mathrm{t}-2)$, respectively.

$\Delta \mathrm{X}_{\mathrm{it}}$ represents a matrix of changes in the explanatory variables in week $\mathrm{t}$ for product $\mathrm{i}$, including all substantive hypotheses variables, affective content, LSM, the LSM $\times$ affective content interaction term, and the affect content squared term, as well as all exogenous variables, such as star rating, star rating variation, affective content variation, review quantity, the interaction between review quantity and LSM, and the interaction between review quantity and affective content.

$\Delta \mathrm{E}_{\mathrm{it}-1}$ represents a matrix of changes in the endogenous explanatory variables, namely, $\mathrm{PD}_{\mathrm{it}-1}$ or the price discount of book $\mathrm{i}$ and $\mathrm{H}_{\mathrm{it}-1}$ or the helpfulness votes for all reviews of book i. Both variables are assumed to be endogenous. We also assume that $E\left[\Delta \mathrm{u}_{\mathrm{it}} \mid\right.$ $\left.\Omega_{\mathrm{t}}\right]=0$, where the expectation of change in the error term, given the information set at time $t$, is 0 , instrumented using the lagged value from the previous week $(t-1)$.

$\Delta \mathrm{u}_{\mathrm{it}}$ is the change in the random error term (we excluded fixed effect errors from the model by first differencing).

t denotes the week. Although $\mathrm{CR}_{\mathrm{i}}$ was always collected on the last day of the current week $(\mathrm{t}=$ Friday $)$, predictor variables were collected on the second-to-last day of the week $(\mathrm{t}$ $=$ Thursday), to preserve causal implications. 
Including the lagged dependent variable avoids a misspecified model, because current values of the dependent variable are influenced by the prior values. Including the lagged dependent variables implies that the usual fixed effects estimator is biased (Nickell 1981).

We predict the price discount and helpfulness of reviewers to be endogenous regressors and thus not strictly exogenous. First, on the basis of past conversion behavior, Amazon likely adjusts its price discount, such that past levels of conversion behavior and price discounts, though potentially orthogonal to current disturbances, depend on prior levels. Second, the amount of past conversions should influence the amount of visibility of reviews. In this sense, past changes in conversion behavior may influence the amount of helpfulness votes that reviews on that site accumulate in a subsequent week. Collectively, the traditional fixed effects estimators therefore must be biased. In addition, idiosyncratic disturbances may have individual-specific patterns of heteroscedasticity and serial correlation. Finally, our estimators were designed for general use across customer review settings, so we do not assume good instruments are available outside the immediate data set. The available instruments are internal and use the lags of the instrumented variables. Therefore, we used a GMM estimator (Arellano and Bond (1991). Specifically, we eliminated book-specific effects by first differencing and instrumenting the endogenous variables with their lags (see Narasimhan et al. 2006; Tuli and Bharadwaj 2009 for further information on this method).

\section{Results}

We outline the results of the models in Table 4. Because we used first differencing and the lagged values for conversion rate, the sample size for the models fell to 4,763 observations (591 books). The pooled augmented Dickey-Fuller test verified that our series in conversion rates was stationary $(p<.01)$; the conversion rate observations were independent of time (Levin et al. 2002). The Sargan/Hansen test to verify the joint validity of our moment 
instruments was insignificant, which indicates that the instruments in the estimation are valid (Tuli and Bharadwaj 2009). Furthermore, though it is to be expected that the full disturbance is auto correlated, because it contains fixed effects that the estimators were designed to eliminate, we checked for second-order autocorrelation in the residuals using Arellano and Bond's (1991) test for first differences. There was insufficient evidence to reject the assumption of no autocorrelation in the differences, so our generalized method estimators likely yielded unbiased and constituent estimates (Arellano and Bond 1991). The exogenous variables indicated frequency (percentages of affect-laden positive and negative content words in the review text; match percentage in function words), so we mean-centered the variables and calculated the interaction term by multiplying mean-centered variable scores. We constructed the squared term in a similar way. In the hierarchical approach to test our hypotheses, we first estimated Model 1 with just the time-varying covariates, price discount, quantity of reviews, perceived review helpfulness, star rating, and variance in star rating, as recorded from Amazon.com. Next, we assessed the main effects (and covariates) in Model 2, added interaction effects in Model 3, and included squared effects in Model 4. We compared the models by computing the chi-square difference test, which confirmed that the main, interaction, and squared effects added explanatory power to the original Model $1(p<.01)$. In Model 5, we additionally split up affective content into positive and negative affective content. We use the estimates reported from Model 4, including all hypothesized effects, to discuss our results. 
TABLE 4

Results

\begin{tabular}{|c|c|c|c|c|c|}
\hline \\
\hline Variables & Model 1 & Model 2 & Model 3 & Model 4 & Model 5 \\
\hline$\overline{\Delta(\text { Conversion rate })_{i(t-1)}}$ & $.917 * *$ & $.712 * *$ & $.725 * *$ & $.727 * *$ & $.763 * *$ \\
\hline$\Delta(\text { Conversion })_{\mathrm{i}(\mathrm{t}-2)}$ & $-.056 * *$ & $-.022 *$ & $-.021 *$ & $-.021 *$ & -.005 \\
\hline$\Delta(\mathrm{LSM})_{\mathrm{it}}$ & & $.004 * *$ & $.004 * *$ & $.004 * *$ & $.006 * *$ \\
\hline$\Delta(\text { Affective Content })_{\text {it }}$ & & $.051 * *$ & $.050 * *$ & $.050 * *$ & \\
\hline$\Delta(\text { LSM } \times \text { Affective Content })_{\text {it }}$ & & & $.002 * *$ & $.002 * *$ & \\
\hline$\Delta\left(\text { Affective content }^{2}\right)_{\text {it }}$ & & & & $-.004 * *$ & \\
\hline$\Delta(\text { Positive Affect })_{\text {it }}$ & & & & & $.055 * *$ \\
\hline$\Delta(\text { Negative Affect })_{\text {it }}$ & & & & & $.067 * *$ \\
\hline$\Delta\left(\text { Positive Affect }^{2}\right)_{\text {it }}$ & & & & & $-.007 * *$ \\
\hline$\Delta\left(\text { Negative Affect }{ }^{2}\right)_{\text {it }}$ & & & & & .005 \\
\hline$\Delta(\text { Review Quantity })_{\text {it }}$ & $.003 *$ & $.002 *$ & $.002 *$ & $.002 *$ & $.005 * *$ \\
\hline$\Delta(\text { Helpfulness })_{\mathrm{i}(\mathrm{t}-1)}$ & $.017 *$ & $.006 *$ & $.007 *$ & $.006 *$ & .004 \\
\hline$\Delta{\text { (Price Discount })_{\mathrm{i}(\mathrm{t}-1)}}$ & $.010 * *$ & $.009 *$ & $.009 * *$ & $.009 * *$ & $.007 * *$ \\
\hline$\Delta(\text { Star Rating })_{\text {it }}$ & .007 & -.002 & -.002 & -.004 & -.002 \\
\hline$\Delta(\text { Star Rating Variation })_{\text {it }}$ & $.005 *$ & $.005 *$ & $.005 * *$ & $.004 *$ & $.003 *$ \\
\hline$\Delta(\text { Affective Content Variation })_{\text {it }}$ & & & .003 & .002 & .002 \\
\hline$\Delta(\text { LSM } \times \text { Review Quantity })_{\text {it }}$ & & & $.002 * *$ & $.002 * *$ & $.003 * *$ \\
\hline Wald's chi-square & $899.93(7)^{* *}$ & $2128.68(9) * *$ & $2199.56(12)^{* *}$ & $2234.35(13) * *$ & $2033.87(14) * *$ \\
\hline $\mathrm{N}$ & 4763 & 4763 & 4763 & 4763 & 4763 \\
\hline
\end{tabular}

$* * p<.01$. 
In general, we found a strong, positive, significant effect of increasing levels of positive affective content on subsequent conversion rate changes $\left(\beta_{\text {Affective Content }}=.050, p<\right.$ .001 ), whereas extreme intensity changes in affective content exhibited a quadratic (taperingoff) relationship on product conversion rates $\left(\beta_{\text {Affective Content }}{ }=-.004, p<.001\right)$, in support of the nonlinear relationship between affective content changes and conversion rate changes.

To test whether these positive and negative changes in affective content were attenuated at the extremes, as hypothesized $\left(\mathrm{H}_{1 \mathrm{~A}}\right.$ and $\left.\mathrm{H}_{1 \mathrm{~B}}\right)$, we computed separate estimates for positive and negative changes (see Mittal et al. 1998 for a similar approach). We created two variables to reflect positive (negative) affective content changes by retaining all positive (negative) affective content changes and recoding all negative (positive) affective content changes and no affective content changes to equal 0 . We squared the newly created variables to capture changes in squared positive and squared negative affective content changes (see Model 5). As hypothesized, both changes towards positive affective content $\left(\beta_{\text {Positive Affect }}=\right.$ $.055, p<.001)$ and squared positive affective content $\left(\beta_{\text {Positive Affect }^{2}}=-.007, p<.001\right)$ had significant influences on conversion rate changes. The negative coefficient of the squared term for positive affective content indicates that the effect tapered off, so in line with $\mathrm{H}_{1 \mathrm{~A}}$, overtly positive changes in the affective content in customer reviews had a smaller positive impact on conversion rate, compared with moderate changes in positive affective tone. In the case of negative changes in conveyed affect, only changes in negative affective content $\left(\beta_{\text {Negative Affect }}=.067, p<.001\right)$, not squared negative affective content, related significantly to subsequent changes in conversion rate. Thus $\mathrm{H}_{1 \mathrm{~B}}$ is not supported. The coefficient of a negative affect change emerged as positive; as affective changes became increasingly negative, the subsequent conversion rate of the product's retail site decreased more. The coefficients of positive and negative changes in affective content differed significantly $(p<$ .001 ), and negative changes had stronger impacts on the conversion rate. Thus, our results 
indicated asymmetries in the relationship between changes in affective content conveyed in reviews and conversion rates: Negative changes in the affective content of customer reviews were more detrimental to a product site's conversion rate than were identical increases in the positive affective content.

The results in Table 4 support $\mathrm{H}_{2}$, in that an increasing degree of LSM in reviews related to increases in conversion rates $\left(\beta_{\mathrm{LSM}}=.004, p<.001\right)$. Finally, the interaction between the increasing degrees of LSM and positive changes in the affective content of reviews significantly predicted increases in conversion rates $\left(\beta_{\mathrm{LSM} \times \mathrm{Affective} \text { Content }}=.002, p<\right.$ .001), in support of $\mathrm{H}_{3}$. In Figure 1, we illustrate the predicted impact of changes to the affective content ( $\Delta$ Affective content) and LSM ( $\Delta$ LSM) in the customer reviews on the subsequent conversion rate change $(\Delta \hat{y})$. Based on the coefficients of Model 4 , we plot the regression lines of change in conversion rate $(\Delta \hat{y})$ on $\Delta$ LSM, $\Delta$ Affective content, $\Delta$ Affective content ${ }^{2}$ and the interaction term $\Delta \mathrm{LSM} \times$ Affective content. The following regression line is thus plotted: $\Delta \hat{\mathrm{y}}=.004 \Delta$ (LSM) $+.050 \Delta$ (Affective content) $-.004 \Delta$ $\left(\right.$ Affective content $\left.{ }^{2}\right)+.002 \Delta($ LSM $\times$ Affective content

For purpose of illustration, the overall regression equation was rearranged to show the regression of change in conversion rate on change in affective content at three levels of change in LSM. Values for LSM were chosen to be one standard deviation below the mean (low) at the mean (medium) and one standard deviation above the mean (high). The figure illustrates how a change in the reviews' content towards more positive affect leads to higher predicted changes in conversion rate, yet tappers off at extreme degrees of change. The impact is alleviated if this change towards more positive affective content is combined with an increase in LSM, and attenuated if the LSM of the reviews simultaneously decreases. 
Figure 1.

The Combined Impact of Changes to Affective Content and LSM on Conversion Rate

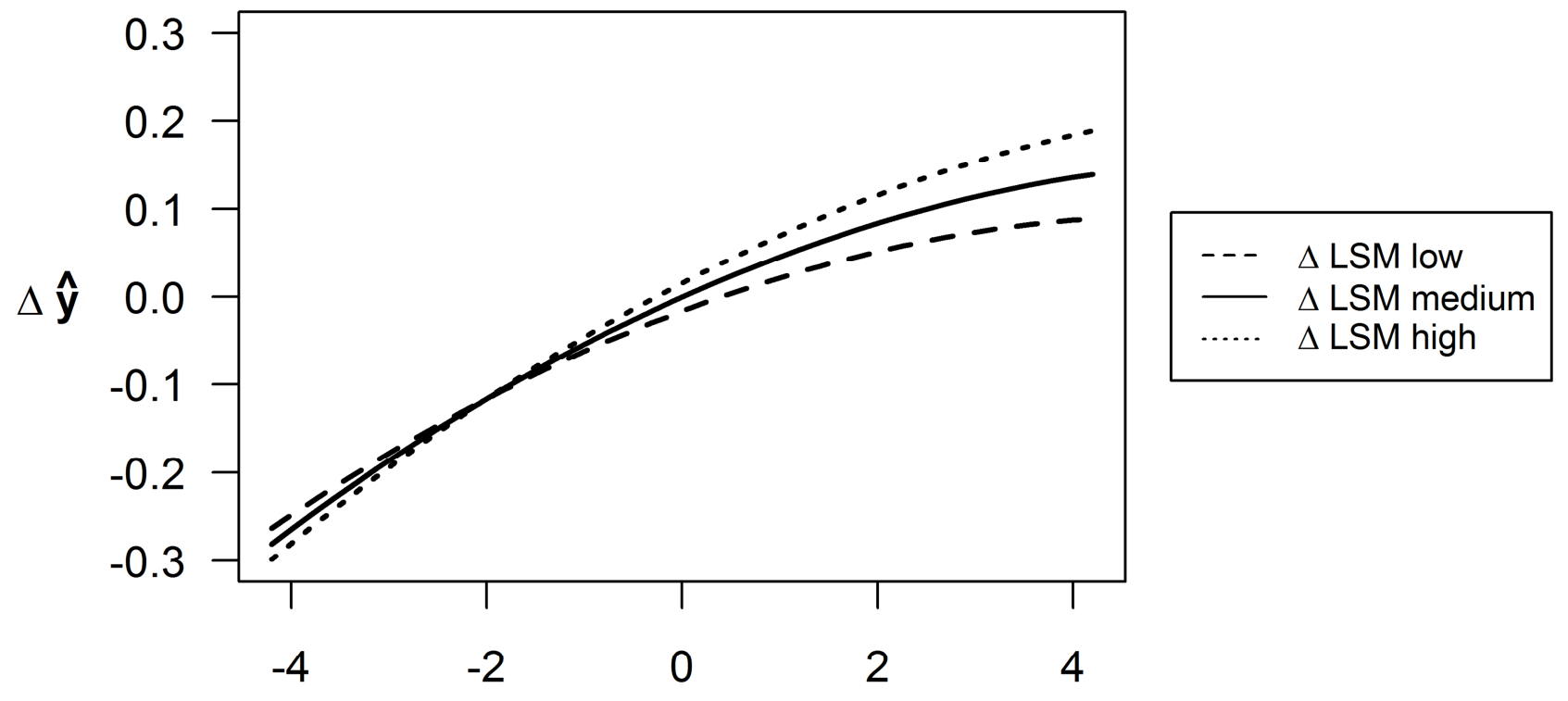

$\Delta$ Affective content 
The results of the control variables largely aligned with prior marketing research; increases in the lagged price discount significantly and positively drove future conversion rates $\left(\beta_{\text {Price Discount }}=.009, p<.001\right)$, so price remained a key determinant of purchase decisions. Changes in review quantity also had significant effects on changes in conversion rates $\left(\beta_{\text {Review Quantity }}=.002, p<.05\right)$, in line with prior studies that have indicated product sales can be explained by review volume (Godes and Mayzlin 2004). We found a significant, positive interaction effect of review quantity changes and increasing degrees of LSM on the subsequent conversion rate $\left(\beta_{\text {LSM }} \times\right.$ Review Quantity $\left.=.002, p<.001\right)$; that is, the more reviews with greater LSMs are posted, the greater the subsequent positive increase in conversion rate. Changes in helpfulness were weakly significant, positive predictors of subsequent conversion rate changes $\left(\beta_{\text {Helpfulness }}=.006, p<.10\right)$. We tested the effect of changes in star-ratings on subsequent conversion rate changes, yet, in line with Yong (2006), we found no significant relation. The descriptive information in Table 3 reveals that the average star rating for all products was mildly positive (4.15) and did not change much over time-in line with recent research that suggests star ratings converge to an average within a few weeks (Moe and Trusov 2011). Review texts are nuanced though and still provide new and relevant information over time that may color overall product evaluations more than the overall star rating dynamics. However, we found a significant relationship between changes in the variability of star ratings $\left(\beta_{\text {Star Rating Variation }}=.004, p<.05\right)$ and conversion rate changes, similar to Clemons, Gao, and Hitt (2006), In contrast, variance in the weekly changes of affective content were not significant related to subsequent conversion rate changes $\left(\beta_{\text {Affective Content }}\right.$ Variation $=.002, p<.411)$. 


\section{Discussion and Conclusion}

\section{Theoretical Implications}

Extending Extant Research: This study contributes to contemporary research on customer reviews by outlining a method to dissect customer review texts to reveal their semantic content and style properties, as well as demonstrating the dynamic influence of text properties on conversion rates in online retail sites. We thus extend extant research in three important ways.

First, most research on affect as a driver of consumer behavior assumes and tests linear relationships, such as the positive association between positive affect and marketing performance indicators. Our results extend some initial experimental research (Andrade 2005; Roehm and Roehm 2005) by demonstrating a quadratic relationship between changes in affective content and changes in conversion behavior in a dynamic, online field study. By taking into account a broader range of affective content and intensity, we assess the impact of extreme positive and negative changes in reviews, which is both theoretically and managerially relevant. Various concerns persist about the validity of reviews (Mudambi and Schuff 2010), and we confirm that in the case of sharp increases in positive affective content, the conversion rate increases are smaller than if the positive affective content increase were more moderate. Yet we fail to find a similar attenuating effect for extremely negative changes. Thus, a negative change in the affective content of customer reviews is more detrimental to conversion rates than is an increase of the same size in the reviews' positive affective content. This finding, though unexpected, is consistent with previous research that indicates negative affective cues can be more powerful than positive ones for driving judgment and behavior. This phenomenon may result from evolutionary processes, such that stronger evaluative and behavioral responses to negative stimuli (e.g., displays of negative 
emotions by others) provide a survival advantage by ensuring a rapid response to danger or threats (Baumeister et al. 2007; Cohen et al. 2008). Our research makes a theoretical contribution by demonstrating the nuanced relationship between affective content in online reviews and consumer behavior.

Second, communication accommodation theory (CAT) proposes that adaptations in communication style can elicit positive images among others (Pornpitakpan 2004), which suggests that LSM could be a good predictor of attitudes and behavior (Huffaker et al. 2011; Ireland and Pennebaker 2010). Yet the scope of extant research has been restricted to communication dyads or personal relationships; we extrapolate this research (Ireland and Pennebaker 2010) to derive the linguistic style commonalities across customer reviews embedded in a wide range of book genres. We thus show for the first time that in an anonymous customer review setting, the impact of linguistic style of reviews extends beyond their content, establishes source perceptions, and evokes a positive bias that subsequently shapes conversion rates.

Third, beyond the standalone influences of reviews' content or style, we underscore, in an online context, the importance of joint considerations of message and source characteristics (Pornpitakpan 2004). Reviews exert a greater influence on customer behavior when they convey affective content and match the typical linguistic style of the target audience. Online review settings remove the face-to-face contacts that traditionally have informed word-ofmouth recommendations, but our research reveals that the contents of reviews have significant effects when their linguistic style elicits source similarity perceptions. In line with experimental evidence about how the interaction between source and message elements shapes purchase intentions, we test and verify the joint influence of a review's content (particularly affective content) and its relative LSM on key outcomes. 
Corroborating Extant Research: Customer review phenomena have stimulated exceptional research studies aimed at uncovering relations between the information diagnostics provided in such settings and retail performance, yet the field still lacks a good synthesis and reconciliation of evidently divergent findings (Zhu and Zhang 2010). In the process of empirically validating our hypothesized relationships, we include key decisionmaking diagnostics from previous research and offer some corroboration of extant research findings. First, in line with previous research (Dodds et al. 1991), we find that changes in price discounts induce changes in conversion rates. Although surprisingly little research on customer review settings considers price or price discounts, our results highlight that price dynamics remain a decisive purchase criterion, irrespective of any other information.

Second, in accordance with Duan, Gu, and Whinston (2008) and Yong (2006) but in contrast with Dellarocas, Xiaoquan, and Awad (2007), we note that the consideration of dynamic, rather than static, relations reveals that changes in the volume of reviews posted on a particular product retail site significantly predicts subsequent conversion rates. If we include combined effects of increases in volume and LSM in reviews, we find that increases in review volume are even more effective for enhancing the subsequent conversion rate associated with the site if they match the linguistic style of the product interest group.

Third, in line with Mudambi and Schuff (2010), who argue that more helpful reviews increase the diagnosticity of an online retail page, we find that increases in helpfulness perceptions of featured customer reviews enhance subsequent conversion rates by enhancing site diagnosticity.

Fourth, we help reconcile equivocal prior findings regarding the influence of customer reviews' star ratings. By collecting longitudinal weekly data and converting our model into first differences, we statistically removed fixed product effects, such as inherent quality, which could account for previous mixed findings (Zhu and Zhang 2010). Similar to Chen, 
$\mathrm{Wu}$, and Jungsun (2004), we find no significant impact of changes in star ratings on the retail site's conversion rate for that product. Importantly, overall star ratings still contain useful and meaningful information about product quality for customers. Yet, the ratings tendency to quickly converge to a product-specific baseline level over time, which then becomes resistant to change (Moe and Trusov 2011), renders the incremental impact of new star-ratings negligible. The addition of another new 4-star rating thus has little additional effect on the conversion rate once the baseline score has been reached.

Fifth, in line with (Clemons et al. 2006), we find that greater variability (or dispersion) of star ratings increases the conversion rate. Clemons et al. (2006) discuss the benefits of hyperdifferentiation in ratings, but this positive variation effect might stem from enhanced objectivity perceptions evoked among readers who have been presented with both the pros and cons of a product. 


\section{Limitations and Further Research}

Our results are consistent with the proposition that customers read and rely on review text information in their purchase decision making (Chevalier and Mayzlin 2006). However, several limitations of our study provide worthwhile avenues for research. First, though we consider all function class categories, our empirical study featured only one content word category: affective content words. Affective content has a strong impact on behavior (LauGesk and Meyers-Levy 2009), but additional research should try to uncover other content word categories that offer readily accessible diagnostics for online customers.

Second, our modeling approach takes into account dynamic changes to a product's retail site, prominent purchase decision-making information (e.g., reviews, price), and fixed effects (e.g., product quality), yet in the online retail environment, the presence of substitute or complementary products also could affect the focal items' retail success. Online retailers, such as Amazon.com, increasingly prompt customers with complementary or alternative product choices to cross and up-sell, so ongoing research should investigate how these products might affect the conversion success of a focal product.

Third, we chose books as our sample product category—a relatively low-involvement product class. Because online information tends to be processed heuristically (Jones et al. 2004), peripheral cues such as affective content and LSM should be relevant and influential, whereas in higher involvement product categories (e.g., cars), the results may differ, because customers often read and process texts more carefully, and rely less on simple heuristics, to make these purchase decisions. Researchers should test different types of products, especially those for which a more central route to persuasion is likely.

Fourth, affective connotations in customer reviews are not always literal. Ironic connotations use subtleties to communicate the opposite of the actual word meaning. In our study setting, the detection of irony is less crucial, because heuristic processing often prevents 
consumers from perceiving irony, which instead requires extensive reading time and processing motivation (Jones et al. 2004). Nonetheless, further research might investigate linguistic properties that characterize ironic statements, especially in higher involvement purchase situations. Such insights could help identify the sentiment orientation of usergenerated content and enable companies to avoid erroneous opinion mining.

Fifth, following CAT (Giles 2009b) greater linguistic style matches reflect greater identification with a conversant (Ireland and Pennebaker 2010). Conversely a greater mismatch in linguistic style may indicate that a conversant derives a sense of self by distancing herself from the particular conversational partner or collective. Such dis-identification and its implications would present an interesting avenue for future research (Elsbach and Bhattacharya 2001).

Finally, our operationalization of LSM is based on research by Pennebaker and colleagues and quantifies the function word similarity between individual reviews and all other reviews in the product category. Although this approach offers a computationally simple tool for establishing linguistic synchrony by computing the differences between individuallevel and group-level function word usage, future research could develop and validate alternate computational means of deriving LSM in group-settings. 


\section{Managerial Implications}

Online feedback mechanisms have amplified and accelerated marketers' reach, to the point that nearly any customer comment about products and services can function as an influential product recommendation or dissuasion. The sheer volumes of qualitative customer reviews posted daily have intensified efforts to gauge their impact accurately. We illustrate the use of text analytics to systematically analyze specific aspects of customer reviews, a method that can be applied while monitoring customer opinions and subsequent impacts in real time. Text analytics is an emergent and growing field; Forrester (2009) predicts its value to increase from $\$ 499$ million in 2011 to $\$ 978$ million in 2014 . This tool enables marketers to analyze vast amounts of unstructured data and quantify information that is mostly qualitative in nature. Thus, it is ideal for retailers and product manufacturers that need to gather marketing intelligence from online customer reviews. Beyond collecting, categorizing, and monitoring customer sentiment, text analytics can help companies predict customer behavior and more effectively converse with customer target groups. Our results also suggest several ways online retailers can increase the effectiveness of their retail sites.

To improve conversion rates, online retailers should encourage customers to describe their product experiences in a way that reflects their emotions vividly and in a writing style that is consonant with a particular genre or product class. Because the alignment of style and affective content in customer review texts increases their impact on conversion rates, review writing guidelines could be invaluable. For example, retailers might prompt customers to express their emotions through questions such as "How did you feel about this book?" They also can provide examples of how other customers typically express their opinions about a product. Then the preferred content and style alignment should be reflected in the other types of textual communication on retailer websites, such as editorial comments or product descriptions. This study's insights into people's emotional states and their interaction with the 
development of a shared language, retrievable through function word usage, suggest that textbased sentiment analysis of customer reviews should incorporate these words. That is, for retailers, mining customers' particular use of affective content and function words may open up a trove of insights on their personal backgrounds, emotional states, and preferences.

Another means to improve conversion rates might entail changing the order in which the customer reviews appear. Instead of showing the most recent reviews first, online retailers might order customer reviews according to their projected impact on conversion rates, such that reviews with strong affective content and an aligned linguistic style appear first. Reviews perceived as most helpful also tend to display the highest degree of LSM with the target audience, which increases their positive impact on conversion rates. However, we also note a caveat for ranking customer reviews: Online retailers should ensure that the most visible reviews represent diverse viewpoints. Our findings of a negative squared effect of extremely positive review changes and a positive effect for changes in the variation of star ratings indicates that customers discount overtly positive and/or similar reviews as biased or fake.

Our results also offer important insights for producers, publishers, and other retail managers who buy customer reviews from Amazon.com or other sites and post them on their website (e.g., as testimonials) or add them to product descriptions (Mudambi and Schuff 2010). These purchasers could improve their return on the significant investments in customer reviews by selecting those reviews that are most impactful in terms of conversion rates, as determined by the elicited affective content and linguistic style convergence.

Conversion rates average around $2-3 \%$ across online retail sites, yet deceptively small increases of even $1 \%$ in conversion rate at retailers like Amazon.com can translate into millions of dollars in sales revenues (RedEye 2011). The rapid growth of narrative, usergenerated content and increased sharing of customer opinions and experiences across a wide variety of social media platforms makes the real-time analysis of customer sentiment an 
increasingly vital predictor of market trends and customer intent and behavior. This study emphasizes that developing insights into how customers express their views is crucial, because the linguistic properties of reviews ultimately influence purchase decisions. Furthermore, our study offers a glimpse of how customers talk among themselves, which can help companies fine-tune their dialogue with customers to participate in natural, authentic conversations with them. By establishing a common ground based on what customers say and how they say it, companies can establish a firm foundation for longer lasting relationships with customers. 


\section{4 \\ CONCLUSION}

\section{Synopsis}

Already in 1901, Freud's "slips of tongue" examples emphasized that word useage is diagnostic of peoples' mental, social, and even physical states. Accordingly, psychoanalysist Jacques Lacan (1968) and philosopher Paul Ricoeur (1976) posit, that the unconscious asserts itself through language use and that how people describe events define the meanings of these events. Such conceptualizations of the implications of people's language use for their own perceptions and behaviors have been the foundation for the work by sociolinguistics (e.g. Eckert 1999), narrative and discourse analyses (Schiffrin 1994), and communication research (Robinson and Giles 2001). Importantly, just as people's word use signifies their own realities, it also affects their audience. The way people communicate their experiences and viewpoints has direct implications for the accessibility and perceived diagnosticity of that information for their audience (Feldman and Lynch 1988).

These conceptualizations on language use gain ever more importance for companies in the age of the digital revolution. The rise of the internet has amplified and accelerated conversations among customers to the point where discussions on products and services are no longer just acts of intimate, one-on-one communication. Today, customers share their views and experiences on a one-to-many basis by writing product reviews on online retail sites or posting and disseminating opinions through user-communities. Facing thousands of text-based conversations, it becomes of critical importance for companies to efficiently determine customer perceptions and derive implications from these textual accounts. Where previous research in marketing has mainly focused on the content of online conversations, in 
this dissertation we consider of how online conversations are formulated at word level. We investigate how language use (in terms of content and function words) enables the assessment of conversants' perceptions and behaviors, as well as the impact they will have on their audience. Accordingly, two studies were conducted to focus on six main aspects of how words create realities, rather than merely being the product of them and the business implications thereof.

In study one we choose the setting of online user-communities, an increasingly popular channel for customer conversations, to adapt the dyadic-level principles of communication accommodation theory and study the implications of members' word uses for their community perceptions and behavior.

First, we contribute to research on communication accommodation and usercommunity research by conceptualizing members' linguistic style match with the conventional style of a user-community as symbolic action. We find that the degree of linguistic style match signals members' level of community identification and is predictive of their participation behavior in the community.

Second, following contemporary research, we view organizational members' social integration as a process rather than a time invariant status quo. We suggest two distinct temporal patterns in members' linguistic style matches (e.g. trend and reversals) and show their distinct influence on members' participation behaviors.

Third, given the plethora of user-communities nowadays, yet relative paucity on context implications for communication, we examine between-community differences in linguistic style cohesiveness on individual member's participation. We find that synchronicity in communicative behavior, or put differently cohesiveness across all members' linguistic styles, substantively explains individual members' participation behavior. 
The study two then turns towards the implications of word use for the behavior of the audience. We analyze the impact of affective content words and linguistic style matches in customer reviews on the conversion rate dynamics of online retail sites.

First, we examine the collective impact of affective content words from a dynamic perspective, showing how affective content influences conversion rates. Our results extend some initial experimental research (Andrade 2005; Roehm and Roehm 2005) by demonstrating a quadratic relationship between changes in affective content and changes in conversion behavior in a dynamic, online field study. We find that in the case of sharp increases in positive affective content, the conversion rate increases are smaller than if the positive affective content increases were more moderate. Yet, no such attenuating effect emerged for extremely negative changes to the affective content of the customer reviews describing the product.

Second, we enrich recent research by investigating the impact of linguistic style of customer reviews on online conversion rates. Recent research has shown that synchronization in conversational style, irrespective of content, increases rapport, credibility, and shared perceptions in communication dyads (Ireland and Pennebaker 2010). We extrapolate these research insights to derive the linguistic style commonalities across customer reviews embedded in a wide range of book genres. We find for the first time that in an anonymous customer review setting, the impact of linguistic style in reviews extends beyond their content, and shapes conversion rates.

Third, since content and function words are inherently inseparable we investigate their collective impact. We supplement prior research on customer reviews by showing how the interaction between source and message elements shapes purchase intentions, we find a joint influence of a review's content (particularly affective content) and its relative linguistic style match on conversion rate dynamics. 


\section{Further Research Suggestions}

Specific suggestions for future research have been discussed at the end of each study. However, I would like to point out some general directions for future research on language use in text-based conversations that may prove valuable to the marketing discipline and managers alike. In this dissertation, I have primarily investigated how word usage signals conversants' identification perceptions towards a collective, influences their participation behavior and finally increases (or diminishes) the impact their opinions have on the target audience. Text mining content- and function word use was an effective means by which these theoretically meaningful and practically important outcomes could be ascertained.

A key premise of my dissertation is that the ways people use language can serve as a window into basic social and psychological processes they undergo. Yet, simply counting words is an admittedly crude way to understand what people feel. Firstly, this method ignores the relational structure between words. Secondly, in English, content words often have different meanings in different contexts. For example, the adjective "mad" normally signifies anger and would be counted towards the negative affect word category which implies that phrases such as "I am mad about my lover" are simply miscoded. Thirdly, current best text mining methods are also unable to detect irony, sarcasm, and the use of metaphors.

In our studies, we focus only on the use of function words to explain conversants' own perceptions. We study the effect of content words on other conversants in a setting where it is arguably safe to assume that the audience is less likely to detect and hence react to sarcasm. Yet, future research, aiming to uncover how content words relate to the conversants' own perceptions need to develop more sophisticated ways to automatically ascertain such constructs from text. 
With this in mind, a whole range of managerially relevant insights (e.g. preferences and interests, demographics and personality aspects) could be derived, not only from the function-, but also the content words customers use.

First, we show how the alignment of function words can be used as marker of relationship between an individual and a collective. Particularly, we have focused on the relevance of function word uses for the assessment of user-community identification. There may be several other important characteristics of relationships (for example hierarchies within relationships) detectable through customers word use which could aid in identifying community leaders.

Third, at a community-level we show that the more in-sync the linguistic styles of members in a user-community are, the more do the individual members exert themselves on behalf of the collective. Future research could consider the longitudinal development of community-level linguistic style cohesiveness and the implications thereof, drawing on the temporal shape parameters we present and exploring additional ones.

Fourth, though we find a significant impact of affective content words and linguistic style matches on the rate by which visitors are convicted into purchase on an online retail site, the importance of such word use may vary across product types. For example, in case of car purchases an analytical presentation of the cars characteristics (e.g. speed, price etc.) may be more influential than the affective content words in the text-based customer reviews.

Finally text mining may enable us to also learn about the behavior of companies based on their past text-based communication. Google already makes predictions on the severity of illnesses based on the frequency with which relevant keywords (e.g. flue) are being used on the web (www.google.org/flutrends). Could critical turning points in companies' strategies similarly be detected via the words they used in their yearly statements or how their public statements towards stakeholders? Could we have known about the economic crisis based on 
the subtle word use, or changes therein, in the statements by bankers and the stock markets? Michel et al., (2011) gives a glimpse at the possibilities of using text mining methods to study word usage in historical data, by relating them to large scale phenomena and cultural changes. Word use may not only enable researchers to better understand perceptions and behaviors of individual customers, but also entire companies. 


\section{Managerial Implications}

As online text-based conversations are growing rapidly, business models are increasingly re-organized to incorporate and manage customers' online conversations. But managing online customers and their conversations is far from easy. We offer insights, how word uses relate to conversants' perceptions and behaviors but also impact the audience. We show that word uses are a key to understand and manage online customer conversations. Along these lines our study offers specific suggestions to managers involved in managing user-communities and online retail sites. Here we want to make two concluding suggestions for managing online customer conversations.

First, the assumption - "build it and they will participate"- is destined to fail. Just providing a platform where customers can share their views and experiences is not enough. In fact managers need to realize that there are thousands of online platforms (running from message boards to entire virtual worlds) in a battle for online customer attention. While a strong community identification is the primary reason for members to stay and participate, such identification perceptions evolve and need to be monitored continuously. By monitoring members' linguistic styles, community managers can automatically and unobtrusively assess the social integration of their members and react in-time to sustain their participation.

Second, while companies spend billions on enticing advertising campaigns, what really makes up a consumer's mind nowadays is a peer's word-of-mouth recommendation (Bughin et al. 2010). A starting point, to capture the impact of such conversations, has been to count the number of recommendations and dissuasions for a given product. Though there is an appealing power and simplicity in simply aggregating star-ratings or "Likes" for a given product, this approach does not account for variability in the power of such recommendations and dissuasions. The easier readers can grasp the content and the more they trust the author to really know about the product or service in question, the greater the impact will be. Following 
our findings, companies must assess the actual text-based customer conversations, in terms of their affective content cues and linguistic style match, to estimate their impact. 


\section{Final Thought}

Recent years have seen a sheer explosion of online text-based conversations. Not only acquaintances, friendships or romantic relationships are nowadays established and maintained online, there are also multiple online platforms for customers to share, in their own words, product and service experiences. The central premise of this dissertation suggests that, the particular word usage in these conversations tells far more than just a story. The words people use in text-based conversations, like linguistic fingerprints, are windows to their perceptions and behaviors. Word usage in conversations also defines their relative accessibility and diagonisticity, causing their impact on the audience to diverge. With these new insights I hope to have enhanced understanding into how perceptions and interpersonal relations manifest themselves in word usages and influence behaviors, in this new world in words. 


\section{REFERENCES}

Algesheimer, R., U.M. Dholakia, and A. Herrmann (2005), "The Social Influence of Brand Community: Evidence from European Car Clubs," Journal of Marketing, 69 (3), 19-34.

Allport, Gordon W. Ed. (1961), Pattern and Growth in Personality. New York, NY: Holt, Rinehart, \& Winston.

Andrade, Eduardo B. (2005), "Behavioral Consequences of Affect: Combining Evaluative and Regulatory Mechanisms," Journal of Consumer Research, 32 (3), 355-62.

Archak, N., A. Ghose, and P.G. Ipeirotis (2011), "Deriving the pricing power of product features by mining consumer reviews," Management Science, 57 (8), 1485-509.

Arellano, Manuel and Stephen Bond (1991), "Some Tests of Specification for Panel Data: Monte Carlo Evidence and an Application to Employment Equations," Review of Economic Studies, 58 (194), 277-97.

Bateson, Gregory (1972), Steps to an Ecology of Mind. London: Granada.

Baumeister, Roy F., Kathleen D. Vohs, C. Nathan Dewall, and Liqing Zhang (2007), "How Emotion Shapes Behavior:Feedback, Anticipation, and Reflection, Rather Than Direct Causation," Personality \& Social Psychology Review, 11 (2), 167-203.

Berger, Jonah, Alan T. Sorensen, and Scott J. Rasmussen (2010), "Positive Effects of Negative Publicity: When Negative Reviews Increase Sales," Marketing Science, 29 (5), 81527.

Berger, P. and T. Luckmann (1966), The Social Construction of Reality. London:: Penguin.

Bernoff, Josh and Ted Schadler (2010), "Empowered. (cover story)," Harvard Business Review, 88 (7/8), 94-101.

Bird, Helen, Sue Franklin, and David Howard (2002), "'Little words'--not really: Function and content words in normal and aphasic speech," Journal of Neurolinguistics, 15 (3-5), 209-37.

Bliese, Paul D. (2000), Within-Group Agreement, Non-Independence, and Reliability: Implications for Data Aggregation and Analysis: Jossey-Bass. 
Bock, K. and Z.M. Griffin (2000), "The Persistence of Structural Priming: Transient Activation or Implicit Learning?," Journal of Experimental Psychology: General, 129 (2), 177-92.

Bonnet, Didier and Priyank Nandan (2011), "Transform to the Power of Digital- Digital Transformation as a Driver of Corporate Performance. ," in Report: Capgemini Consulting

Bray, Mike and J.L. Martin (2011), Internet Rich: Your Blueprint to Book Sales. Missoula, Montana, USA: Wolfpack Publishing.

Brennan, Susan E. and Herbert H. Clark (1996), "Conceptual Pacts and Lexical Choice in Conversation," Journal of Experimental Psychology: Learning, Memory, and Cognition, 22 (6), 1482-93.

Brockman, B.K. and R.M. Morgan (2006), "The Moderating Effect of Organizational Cohesiveness in Knowledge Use and New Product Development," Journal of the Academy of Marketing Science, 34 (3), 295-307.

Bronto.com (2011), "Online Consumer Technology Retailer Lifts Conversions 20\% with Automated Product Review Messages," in CUSTOMER SUCCESS STORY, Bronto (Ed.). Durham, North Carolina.

Brown, James, Stephan Grzeskowiak, and Chekitan Dev (2009), "Using influence strategies to reduce marketing channel opportunism: The moderating effect of relational norms," Marketing Letters, 20 (2), 139-54.

Bughin, Jacques, Jonathan Doogan, and Ole J. Vetvik (2010), "A new Way to Measure Wordof-Mouth Marketing," in Marketing and Sales Practice: McKinsey Quarterly.

Cacioppo, J.T. and R.E. Petty (1981), "Social Psychological Procedures for Cognitive Response Assessment: The Thought-Listing Technique," in Cognitive Assessment, X V. Merluzzi and C. R. Glass and M. Genest, eds.: New York: Guilford Press.

Campbell, Marci K., Jay M. Bernhardt, Michael Waldmiller, Bethany Jackson, Dave Potenziani, Benita Weathers, and Seleshi Demissie (1999), "Varying the Message Source in Computer-Tailored Nutrition Education," Patient Education and Counseling, 36 (2), 157-69.

Cao, Qing, Wenjing Duan, and Qiwei Gan (2011), "Exploring Determinants of Voting for the "Helpfulness" of Online User Reviews: A Text Mining Approach," Decision Support Systems, 50 (2), 511-21. 
Chaiken, Shelly and Durairaj Maheswaran (1994), "Heuristic Processing Can Bias Systematic Processing: Effects of Source Credibility, Argument Ambiguity, and Task Importance on Attitude Judgment," Journal of Personality \& Social Psychology, 66 (3), 460-73.

ChannelAdvisor (2010), "Through the Eyes of the Consumer: 2010 Consumer Shopping Habits Survey," in: Morrisville, NC: ChannelAdvisor Corporation.

Chen, Pei-Yu, Shin-Yi Wu, and Yoon Jungsun (2004), "The Impact of Online Recommendations and Consumer Feedback on Sales," in Proceedings of the International Conference on Information Systems, ICIS 2004. Washington, D.C.

Chevalier, Judith A. and Dina Mayzlin (2006), "The Effect of Word of Mouth on Sales: Online Book Reviews," Journal of Marketing Research, 43 (3), 345-54.

Chidambaram, L. (1996), "Relational Development in Computer-Supported Groups," MIS Quarterly, 20 (2), 143-65.

Chung, C.K. and J.W. Pennebaker (2007), "The Psychological Function of Function Words," in Social Communication: Frontiers of Social Psychology, K. Fiedler, ed.: New York: Psychology Press.

Chung, Cindy, James Pennebaker, and Klaus Fiedler (2007), "The Psychological Functions of Function Words," in Social Communication. New York, NY US: Psychology Press.

Clark, Herbert H. and Susan E. Brennan (1991), "Grounding in Communication," Perspectives on socially shared cognition, 13 (1991), 127-49.

Clemons, Eric K., Guodong Gordon Gao, and Lorin M. Hitt (2006), "When Online Reviews Meet Hyperdifferentiation: A Study of the Craft Beer Industry," Journal of Management Information Systems, 23 (2), 149-71.

Cohen, Joel B., Michel T. Pham, Eduardo B. Andrade, Curtis P. Haugtvedt, Paul M. Herr, and Frank R. Kardes (2008), "The Nature and Role of Affect in Consumer Behavior," in Handbook of consumer psychology. New York, NY: Taylor \& Francis Group.

Cohn, Michael A., Matthias R. Mehl, and James W. Pennebaker (2004), "Linguistic Indicators of Psychological Change after September 11, 2001," Psychological Science, 15, 687-93.

Cole, M.S., A.G. Bedeian, R.R. Hirschfeld, and B. Vogel (2011), "Dispersion-Composition Models in Multilevel Research," Organizational Research Methods, 14 (4), 718-34. 
ComScore (2007), "Online Consumer-Generated Reviews Have Significant Impact on Offline Purchase Behavior," ComScore Company Report.

Corliss, R. (2009), "Box-Office Weekend: Brüno a One-Day Wonder?," (accessed June 5, 2011), [available at http://www.time.com/time/arts/article/0,8599,1910059,00.html].

Czapiski, Janusz and Maria Lewicka (1979), "Dynamics of Interpersonal Attitudes: PositiveNegative Asymmetry," Polish Psychological Bulletin, 10 (1), 31-40.

Dahlander, Linus and Lars Frederiksen (2012), "The Core and Cosmopolitans: A Relational View of Innovation in User Communities," Organization Science, 23 (4), 988-1007.

Das, Sanjiv, Asis Martinez-Jerez, and Peter Tufano (2005), "eInformation: A Clinical Study of Investor Discussion and Sentiment," Financial Management, 34 (3), 103-37.

De Ruyck, Tom, Niels Schillewaert, Martijn van Kesteren, and Stephan Ludwig (2010), "How Fans become Shapers of an Ice-cream Brand - Towards the Next Frontier in Conducting Insight Communities," in ESOMAR Qualitative Research Conference. Berlin.

DeKinder, Jade S. and Ajay K. Kohli (2008), "Flow Signals: How Patterns over Time Affect the Acceptance of Start-Up Firms," Journal of Marketing, 72 (5), 84-97.

Dellarocas, Chrysanthos, Zhang Xiaoquan, and Neveen F. Awad (2007), "Exploring the Value of Online Product Reviews in Forecasting Sales: The Case of Motion Pictures," Journal of Interactive Marketing, 21 (4), 23-45.

Dennis, A.R., R.M. Fuller, and J.S. Valacich (2008), "Media, Tasks, and Communication Processes: A Theory of Media Synchronicity," MIS Quarterly, 32 (3), 575-600.

DeSanctis, G. and P. Monge (1999), "Communication Processes for Virtual Organizations," Organization Science, 10 (6), 693-703.

Dholakia, Utpal, Richard Bagozzi, and Lisa Pearo (2004), "A Social Influence Model of Consumer Participation in Network- and Small-Group-Based Virtual Communities," International Journal of Research in Marketing, 21 (3), 241-63.

Di Gangi, P.M., MM Wasko, and RE Hooker (2010), "Getting Customers' Ideas to Work for You: Learning from Dell How to Succeed with Online User Innovation Communities," MIS Quarterly Executive, 9 (4), 213-28. 
Dino, Amanda, Stephen Reysen, and Nyla R. Branscombe (2009), "Online Interactions between Group Members who Differ in Status," Journal of Language and Social Psychology, $28(1), 85-93$.

Dodds, William B., Kent B. Monroe, and Dhruv Grewal (1991), "Effects of Price, Brand, and Store Information on Buyers' Product Evaluations," Journal of Marketing Research, 28 (3), 307-19.

Duan, Wenjing, Bin Gu, and Andrew B. Whinston (2008), "Do Online Reviews Matter? An Empirical Investigation of Panel Data," Decision Support Systems, 45 (4), 1007-16.

Duriau, Vincent J., Rhonda K. Reger, and Michael D. Pfarrer (2007), "A Content Analysis of the Content Analysis Literature in Organization Studies," Organizational Research Methods, $10(1), 5-34$.

Eckert, Penelope (1999), Language Variation as Social Practice: The Linguistic Construction of Identity in Belten High. NewYork: Blackwell.

Econsultancy (2011), "Reducing Customer Struggle." New York: Econsultancy.

Elsbach, K.D. and CB Bhattacharya (2001), "Defining Who You are by What You're Not: Organizational Disidentification and the National Rifle Association," Organization Science, $12(4), 393-413$.

eMarketer (2010), "What Makes Social Media Trustworthy?," (accessed May 15, 2011), [available

http://www.emarketer.com/(S(e23a5r33pvpzlojwfi4wzv45))/Article.aspx?R=1007863].

Fairclough, N. (1992), "Discourse and Text: Linguistic and Intertextual Analysis within Discourse Analysis," Discourse and Society, 3, 193-217.

Faraj, S., S.L. Jarvenpaa, and A. Majchrzak (2011), "Knowledge Collaboration in Online Communities," Organization Science, 22 (5), 1224-39.

Farnham, Shelly (2002), "Predicting Active Participation in MSN Communities: It's all in the Conversation," in Microsoft Research, Redmond, WA.

Farzan, R., R. Kraut, A. Pal, and J. Konstan (2012), "Socializing Volunteers in an Online Community: A Field Experiment," in Computer Supported Cooperative Work 2012: WA: Association for Computing Machinery. 
Fayard, Anne-Laure and Geraldine DeSanctis (2010), "Enacting Language Games: The Development of a Sense of 'We-ness' in Online Forums," Information Systems Journal, 20 (4), 383-416.

Feldman, J ack M. and John G. Lynch (1988), "Self-generated Validity and Other Effects of Measurement on Belief, Attitude, Intention, and Behavior," Journal of Applied Psychology, $73(3), 421$.

Feldman, Robert H. (1984), "The Influence of Communicator Characteristics on the Nutrition Attitudes and Behavior of High School Students," Journal of School Health, 54 (4), 149-51.

Forman, Chris, Anindya Ghose, and Batia Wiesenfeld (2008), "Examining the Relationship Between Reviews and Sales: The Role of Reviewer Identity Disclosure in Electronic Markets," Information Systems research, 19 (3), 291-313.

Forrester (2009), "Text Analytics Takes Business Insight To New Depths," Forrester Report.

Füller, Johann, Michael Bartl, Holger Ernst, and Hans Mühlbacher (2006), "Community Based Innovation: How to Integrate Members of Virtual Communities into New Product Development," Electronic Commerce Research, 6 (1), 57-73.

Gasper, Karen and Gerald L. Clore (1998), "The Persistent Use of Negative Affect by Anxious Individuals to Estimate Risk," Journal of Personality \& Social Psychology, 74 (5), $1350-63$.

Gergen, Kenneth J. and Tojo Joseph Thatchenkery (2004), "Organization Science as Social Construction," Journal of Applied Behavioral Science, 40 (2), 228-49.

Gibson, Cristina B. and Mary E. Zellmer-Bruhn (2001), "Metaphors and Meaning: An Intercultural Analysis of the Concept of Teamwork," Administrative Science Quarterly, 46 (2), 274-303.

Giles, H. (2009a), "The Process of Communication Accomodation " in The New Reader in Sociolinguistics, N. Coupland and A. Jaworski, eds. Basingstoke, England: Macmillan.

Giles, H., M. Willemyns, C. Gallois, and M.C. Anderson (2007), "Accommodating a New Frontier: The Context of Law Enforcement," in Social communication, K. Fiedler, ed.: Psychology Press.

Giles, Howard (2009b), "The Process of Communication Accommodation," in: In N. Coupland \& A. Jaworksi (Eds.), The new reader in sociolinguistics (pp. 276-286). Basingstoke, UK: Macmillan. 
Giles, Howard and Philip Smith (1979), Accommodation theory: Optimal levels of convergence Baltimore: University Park Press.

Giles, Howard and Nikolas Coupland Eds. (1991), Language: Contexts and consequences. Milton Keynes, England: Open University Press.

Gill, A.M. and K. Whedbee (1997), "Rhetoric," in Discourse Studies: A Multidisciplinary Introduction, T.A. van Dijk, ed. Vol. 1. Beverly Hills, CA: Sage.

Godes, David and Dina Mayzlin (2004), "Using Online Conversations to Study Word-ofMouth Communication," Marketing Science, 23 (4), 545-60.

Gonzales, Amy L., Jeffrey T. Hancock, and James W. Pennebaker (2010), "Language Style Matching as a Predictor of Social Dynamics in Small Groups," Communication Research, 37 (1), 3-19.

Gorn, Gerald, Michel T. Pham, and Leo Y. Sin (2001), "When Arousal Influences Ad Evaluation and Valence does not," Journal of Consumer Psychology, 11 (1), 43-55.

Gouran, D. S. (1990), "Exploiting the Predictive Potential of Structuration Theory," in Communication Yearbook, J. A. Anderson, ed. Vol. 13. Newbury Park, CA: Sage.

Greifender, Rainer, Herbert Bless, and Michel T. Pham (2011), "When Do People Rely on Affective and Cognitive Feelings in Judgment? A Review," Personality and Social Psychology Review, 15 (2), 107-41.

Gumperz, J.J. (1996), Rethinking Linguistic Relativity: Cambridge, UK.

Gurley, J. William (2000), "The One Internet Metric That Really Matters," Fortune, 141 (5), 392-92.

Hansen, Morten T. and Martine R. Haas (2001), "Competing for Attention in Knowledge Markets: Electronic Document Dissemination in a Management Consulting Company," Administrative Science Quarterly, 46 (1), 1-28.

Hardy, C., T.B. Lawrence, and D. Grant (2005), "Discourse and Collaboration: The Role of Conversations and Collective Identity," The Academy of Management Review, 30 (1), 58-77.

Harrison, D.A. and K.J. Klein (2007), "What's the Difference? Diversity Constructs as Separation, Variety, or Disparity in Organizations," The Academy of Management Review, 32 (4), 1199-228. 
Hart, Roderick P. (2001), Redeveloping DICTION: Theoretical Considerations: See West 2001.

Heracleous, L. and R.J. Marshak (2004), "Conceptualizing Organizational Discourse as Situated Symbolic Action," Human Relations, 57 (10), 1285-312.

Herring, S.C. (2001), "Computer-Mediated Discourse," in The Handbook of Discourse Analysis, D. Tannen and D. Schiffrin and H. Hamilton, eds. Vol. 612634: Oxford, UK: Blackwell.

Huffaker, D.A., R. Swaab, and D. Diermeier (2011), "The Language of Coalition Formation in Online Multiparty Negotiations," Journal of Language and Social Psychology, 30 (1), 6681.

Humphreys, A. (2010), "Megamarketing: The Creation of Markets as a Social Process," Journal of Marketing, 74 (2), 1-19.

Incite, NM (2011), "How Social Media Impacts Brand Marketing," NM Incite.

Ireland, M.E. and J.W. Pennebaker (2010), "Language Style Matching in Writing: Synchrony in Essays, Correspondence, and Poetry," Journal of Personality and Social Psychology, 99 (3), 549-71.

Iriberri, A. and G. Leroy (2009), "A Life-Cycle Perspective on Online Community Success," ACM Computing Surveys, 41 (2), 11-29.

James, L.R., R.G. Demaree, and G. Wolf (1984), "Estimating Within-Group Interrater Reliability with and without Response Bias," Journal of Applied Psychology, 69 (1), 85-98.

Jansen, Bernard J., Mimi Zhang, Kate Sobel, and Abdur Chowdury (2009), "Twitter power: Tweets as electronic word of mouth," Journal of the American Society for Information Science \& Technology, 60 (11), 2169-88.

Jokisaari, M. and J.E. Nurmi (2009), "Change in Newcomers' Supervisor Support and Socialization Outcomes after Organizational Entry," The Academy of Management Review, $52(3), 527-44$.

Jones, Quentin, Gilad Ravid, and Sheizaf Rafaeli (2004), "Information Overload and the Message Dynamics of Online Interaction Spaces: A Theoretical Model and Empirical Exploration," Information Systems research, 15 (2), 194-210. 
Joon, Koh, Kim Young-Gul, Brian Butler, and Bock Gee-Woo (2007), "Encouraging Participation in Virtual Communities," Communications of the ACM, 50 (2), 69-73.

Kabanoff, Boris, Robert Waldersee, and Marcus Cohen (1995), "ESPOUSED VALUES AND ORGANIZATIONAL CHANGE THEMES," Academy of Management Journal, 38 (4), 1075-104.

Kambil, Ajit, Patrick Conroy, and Ryan Alvanos (2005), "A View from the Glass House: How to Compete in the Transparent Marketplace," in Deloitte Review: Deloitte.

Kammeyer-Mueller, J.D., C.R. Wanberg, T.M. Glomb, and D. Ahlburg (2005), "The Role of Temporal Shifts in Turnover Processes: It's about Time," Journal of Applied Psychology, 90 (4), 644-58.

Katja, Klafka (2009), "Conrad's Review Programme Significantly Increases Conversion Rates," in Company Report: Bazaar Voice.

Kock, N. (2004), "The Psychobiological Model: Towards a New Theory of ComputerMediated Communication Based on Darwinian Evolution," Organization Science, 15 (3), $327-48$

Koh, J., Y.G. Kim, B. Butler, and G.W. Bock (2007), "Encouraging Participation in Virtual Communities," Communications of the ACM, 50 (2), 68-73.

Kohler, T., J. Fueller, K. Matzler, and D. Stieger (2011), "Co-creation in Virtual Worlds: The Design of the User Experience," MIS Quarterly, 35 (3), 773-88.

Kozlowski, S.W.J. and D.R. Ilgen (2006), "Enhancing the Effectiveness of Work Groups and Teams," Psychological Science in the Public Interest, 7 (3), 77-124.

Kreiner, G.E. and B.E. Ashforth (2004), "Evidence Toward an Expanded Model of Organizational Identification," Journal of Organizational Behavior, 25 (1), 1-27.

Krippendorff, Klaus (2004), Content Analysis: An Introduction to its Methodology: Sage Publications, Inc.

Lacan, Jacques (1968), The Language of the Self: The Function of Language in Psychoanalysis. Baltimore: Johns Hopkins Press.

Lau-Gesk, Loraine and Joan Meyers-Levy (2009), "Emotional Persuasion: When the Valence versus the Resource Demands of Emotions Influence Consumers' Attitudes," Journal of Consumer Research, 36 (4), 585-99. 
Lee, Thomas Y. and Eric T. Bradlow (2011), "Automated Marketing Research Using Online Customer Reviews," Journal of Marketing Research (JMR), 48 (5), 881-94.

Lench, Heather C., Sarah A. Flores, and Shane W. Bench (2011), "Discrete Emotions Predict Changes in Cognition, Judgment, Experience, Behavior, and Physiology: A Meta-Analysis of Experimental Emotion Elicitations," Psychological Bulletin, 137 (5), 834-55.

Levin, Andrew, Chien-Fu Lin, and Chia-Shang J. Chu (2002), "Unit Root Tests in Panel Data: Asymptotic and Finite-Sample Properties," Journal of Econometrics, 108 (1), 1-24.

Levine, J.M. and R.L. Moreland (1994), "Group Socialization: Theory and Research," European Review of Social Psychology, 5 (1), 305-36.

Levy, Benjamin (2010), "Facebook is World's Third Largest Country," Young Money.

Long, J. S. (1997), Regression Models for Categorical and Limited Dependent Variables. Thousand Oaks, CA:Sage Publications.

Ludwig, Stephan and Tom De Ruyck (2012), "Why 'function words' matter," Research-Live.

Ludwig, Stephan, Tom De Ruyck, and Niels Schillewaert (2011a), "Op Zoek Naar de Ideale Mix: Hoe de Deelname in Online Communities voor Marktonderzoek Stimuleren," MOA Jaarboek: ontwikkelingen in het marktonderzoek.

Ludwig, Stephan, Tom De Ruyck, Niels Schillewaert, and Moritz Mann (2011b), "The Darkside to Crowdsourcing in Online Research Communities," CASRO 2011 Journal.

Ludwig, Stephan and Paul Nola (2011), "Why it pays to get social in research communities," Research-live.

Ma, M. and R. Agarwal (2007), "Through a Glass Darkly: Information Technology Design, Identity Verification, and Knowledge Contribution in Online Communities," Information Systems Research, 18 (1), 42-67.

McCroskey, James C. and Virginia P. Richmond ( 2000), "Applying Reciprocity And Accommodation Theories To Supervisor/Subordinate Communication," Journal of Applied Communication Research, 28 (3), 278 -89.

Menon, Tanya and Sally Blount (2003), "The Messenger Bias: A Relational Model of Knowledge Valuation," in Research in Organizational Behavior: An Annual Series of 
Analytical Essays and Critical Reviews, Roderick M. Kramer and Barry M. Staw, eds. Vol. 25. Oxford, England: Elsevier Science Ltd.

Meyerson, Debra E. and Maureen A. Scully (1995), "Tempered Radicalism and the Politics of Ambivalence and Change," Organization Science, 6 (5), 585-600.

Michel, J.B., Y.K. Shen, A.P. Aiden, A. Veres, M.K. Gray, J.P. Pickett, D. Hoiberg, D. Clancy, P. Norvig, and J. Orwant (2011), "Quantitative Analysis of Culture using Millions of Digitized Books," Science, 331 (6014), 176.

Miller, Katherine (2005), Communication Theories: New York: McGraw Hill.

Mittal, Vikas, William T. Ross, and Patrick M. Baldasare (1998), "The Asymmetric Impact of Negative and Positive Attribute-Level Performance on Overall Satisfaction and Repurchase Intentions," Journal of Marketing, 62 (1), 33-47.

Moe, Wendy W. and Peter S. Fader (2004), "Dynamic Conversion Behavior at E-Commerce Sites," Management Science, 50 (3), 326-35.

Moe, Wendy W. and Michael Trusov (2011), "The Value of Social Dynamics in Online Product Ratings Forums," Journal of Marketing Research, 48 (3), 444-56.

Moran, E. and F. Gossieaux (2010), "Marketing in a Hyper-Social World: The Tribalization of Business Study and Characteristics of Successful Online Communities," Journal of Advertising Research, 50 (3), 232-40.

Mudambi, Susan M. and David Schuff (2010), "What Makes a Helpful Online Review? A Study of Customer Reviews on Amazon.com," MIS Quarterly, 34 (1), 185-200.

Muniz, Albert M. and Thomas C. O'Guinn (2001), "Brand Community," Journal of Consumer Research, 27 (4), 412-32.

Nambisan, Satish and Robert A. Baron (2009), "Virtual Customer Environments: Testing a Model of Voluntary Participation in Value Co-creation Activities," Journal of Product Innovation Management, 26 (4), 388-406.

Narasimhan, Om, Surendra Rajiv, and Shantanu Dutta (2006), "Absorptive Capacity in HighTechnology Markets: The Competitive Advantage of the Haves," Marketing Science, 25 (5), 510.

Neuendorf, Kimberly A. (2002), The Content Analysis Guidebook: Thousand Oaks, CA: Sage. 
Nickell, Stephen (1981), "Biases in Dynamic Models with Fixed Effects," Econometrica, 49 (6), 1417-26.

Niederhoffer, Kate G. and James W. Pennebaker (2002), "Linguistic Style Matching in Social Interaction," Journal of Language and Social Psychology, 21 (4), 337-60.

Nielsen (2010), "Global Trends in Online Shopping," in Nielsen Global Consumer Report.

Noriega, J. and E. Blair (2008), "Advertising to Bilinguals: Does the Language of Advertising Influence the Nature of Thoughts?," Journal of Marketing, 72 (5), 69-83.

Ortony, A., G.L. Clore, and M.A. Foss (1987), "The Referential Structure of the Affective Lexicon," Cognitive Science, 11 (3), 341-64.

Pavlou, Paul A. and Angelika Dimoka (2006), "The Nature and Role of Feedback Text Comments in Online Marketplaces: Implications for Trust Building, Price Premiums, and Seller Differentiation," Information Systems Research, 17 (4), 392-414.

Pennebaker, James W. (2011), "Your Use of Pronouns Reveals Your Personality," Vol. 89: Harvard Business School Publication Corp.

Pennebaker, James W., Cindy K. Chung, Molly Ireland, Amy Gonzales, and Roger J. Booth (2007), "The Development and Psychometric Properties of LIWC2007." Austin, Texas: LIWC.net.

Pennebaker, James W., Matthias R. Mehl, and Kate G. Niederhoffer (2003), "Psychological Aspects of Natural Language Use: Our Words, Our Selves," Annual Review of Psychology, 54 (1), 547-77.

Petty, Richard E., Leandre R. Fabrigar, and Duane T. Wegener (2003), "Emotional Factors in Attitudes and Persuasion," in Handbook of affective sciences, R. J. Davidson and K. R. Scherer and H. H. Goldsmith, eds.: Oxford: Oxford University Press.

Pham, Michel T., Joel B. Cohen, John W. Pracejus, and David G. Hughes (2001), "Affect Monitoring and the Primacy of Feelings in Judgment," Journal of Consumer Research, 28 (2), 167-88.

Pickering, Martin J. and Simon Garrod (2004), "Toward a Mechanistic Psychology of Dialogue," Behavioral and Brain Sciences, 27 (02), 169-90. 
Pollach, Irene (2012), "Taming Textual Data: The Contribution of Corpus Linguistics to Computer-Aided Text Analysis," Organizational Research Methods, 15 (2), 263-87.

Porac, Joseph F., James B. Wade, and Timothy G. Pollock (1999), "Industry Categories and the Politics of the Comparable Firm in CEO Compensation," Administrative Science Quarterly, 44 (1), 112-44.

Pornpitakpan, Chanthika (2004), "The Persuasiveness of Source Credibility: A Critical Review of Five Decades' Evidence," Journal of Applied Social Psychology, 34 (2), 243-81.

Postmes, T., R. Spears, and M. Lea (2000), "The Formation of Group Norms in ComputerMediated Communication," Human communication research, 26 (3), 341-71.

Prendergast, Gerard , David Ko, and Siu Y. V. Yuen (2010), "Online Word of Mouth and Consumer Purchase Intentions," International Journal of Advertising, 29 (5), 687-708.

Pulman-Jones, Simon (2012), "The Magical World of Online Co-creation, from Passive Consumers to Pioneering Co-creators," GFK Focus.

Ransbotham, Sam and Gerald C. Kane (2011), "Membership Turnover and Collaboration Success in Online Communities: Explaining Rises and Falls from Grace in Wikipedia," MIS Quarterly, 35 (3), 613-27.

Raudenbush, S.W. and A.S. Bryk (2002), Hierarchical Linear Models: Applications and Data Analysis Methods. Newbury Park, CA: Sage Publications.

RedEye (2011), "Conversion Rate Optimization Report 2011," Econsultancy \& RedEye.

Ricoeur, Paul (1976), Interpretation Theory: Discourse and the Surplus of Meaning. . Fort Worth: Texas Christian Univ. Press.

Robinson, W. P. and Howard Giles (2001), The New Handbook of Language and Social Psychology. Chichester, UK: Wiley.

Rochon, Elizabeth, Eleanor M. Saffran, Rita S. Berndt, and Myrna F. Schwartz (2000), "Quantitative Analysis of Aphasic Sentence Production: Further Development and New Data," Brain and Language, 72 (3), 193-218.

Roehm, Harper A. and Michelle L. Roehm (2005), "Revisiting the Effect of Positive Mood on Variety Seeking," Journal of Consumer Research, 32 (2), 330-36. 
Russell, James A. (2003), "Core Affect and the Psychological Construction of Emotion," Psychological Review, 110 (1), 145-72.

Schau, Hope Jensen, Albert M. Muniz, and Eric J. Arnould (2009), "How Brand Community Practices Create Value," Journal of Marketing, 73 (5), 30-51.

Schiffrin, Deborah (1994), Approaches to Discourse. Cambridge: Blackwell.

Schwarz, Norbert and Gerald L. Clore (1996), "Feelings and Phenomenal Experiences," Social psychology: Handbook of basic principles, 2, 385-400.

Searle, J. (1975), "Indirect Speech Acts," in Syntax and Semantics 3: Speech Acts, P. Cole and J. Morgan, ed. Vol. 3. New York: Academic Press.

Seibold, David R., Daisy R. Lemus, and Paul Kang (2010), "Extending the Conversational Argument Coding Scheme in Studies of Argument Quality in Group Deliberations," Communication Methods and Measures, 4 (1-2), 46-64.

Seibold, David R. and Renee A. Meyers (2007), "Group Argument : A Structuration Perspective and Research Program," Small Group Research, 38 (3), 312-36.

Short, Jeremy C., J. Christian Broberg, Claudia C. Cogliser, and Keith H. Brigham (2010), "Construct Validation Using Computer-Aided Text Analysis (CATA): An Illustration Using Entrepreneurial Orientation," Organizational Research Methods, 13 (2), 320-47.

Singh, Surendra N., Steve Hillmer, and Wang Ze (2011), "Efficient Methods for Sampling Responses from Large-Scale Qualitative Data," Marketing Science, 30 (3), 532-49.

Slatcher, Richard B. and James W. Pennebaker (2006), "How do I Love Thee? Let me Count the Words," Psychological Science, 17 (8), 660.

Spaulding, Trent J. (2009), "How can virtual communities create value for business?," Electronic Commerce Research \& Applications, 9 (1), 38-49.

Stonequist, E. (1937), The Marginal Man. New York: Russell and Russell.

Streitfeld, David (2011), "In a Race to Out-Rave, 5-Star Web Reviews go for 5\$," The New York Times. 
Tausczik, Yla R. and James W. Pennebaker (2010), "The Psychological Meaning of Words: LIWC and Computerized Text Analysis Methods," Journal of Language and Social Psychology, 29 (1), 24-54.

Tirunillai, Seshadri and Gerard J. Tellis (2012), "Does Chatter Really Matter? Dynamics of User-Generated Content and Stock Performance," Marketing Science, 31 (2), 198-215.

Tuli, Kapil R. and Sundar G. Bharadwaj (2009), "Customer Satisfaction and Stock Returns Risk," Journal of Marketing, 73 (6), 184-97.

Verhaeghe, Annelies, Tom De Ruyck, Niels Schillewaert, Carel Verijken, and Stephan Ludwig (2010), "Synergizing Natural and Research Communities," in ESOMAR Excellence Award Nominee - Best Paper 2010/2011.

Wasko, M.M. and S. Faraj (2005), "Why Should I Share? Examining Social Capital and Knowledge Contribution in Electronic Networks of Practice," MIS Quarterly, 29 (1), 35-57.

Weick, K.E. (1995), Sensemaking in Organizations. Newbury Park, CA: Sage Publications.

Xinxin, Li and Lorin M. Hitt (2010), "Price Effects in Online Product Reviews: An Analytical Model and Empirical Analysis," MIS Quarterly, 34 (4), 809-31.

Yong, Liu (2006), "Word of Mouth for Movies: Its Dynamics and Impact on Box Office Revenue," Journal of Marketing, 70 (3), 74-89.

Zajonc, R.B. (1980), "Feeling and Thinking: Preferences Need No Inferences," American Psychologist, 35 (2), 151.

Zhu, Feng and Xiaoquan Zhang (2010), "Impact of Online Consumer Reviews on Sales: The Moderating Role of Product and Consumer Characteristics," Journal of Marketing, 74 (2), $133-48$. 


\section{APPENDIX}

\section{Pilot Study}

Method: For the pilot study we solicited the cooperation of 230 Business students who were at least in their $3^{\text {rd }}$ year of study $(119$ women $(51.7 \%)$, mean age $=21$ years $(\mathrm{SD}=$ 2.32)), to ensure that they had substantial exposure to business jargon over the course of their studies. The self-reported mean number of business books read was $15(\mathrm{SD}=5)$.

Procedure: Participants were invited via email to an online experiment. After instructing them to picture themselves in a situation, in which they needed to buy a new business book, they were randomly assigned to one of 4 experimental groups and sequentially shown two typical Amazon pages featuring a business book with two customer reviews respectively, taken from our review sample. We used a $2 \times 2$ between-subjects factorial design, in which we manipulated LSM and affective content by showing (1) two positive reviews that closely matched the linguistic style of the business book genre (high LSM) (2) two positive reviews that did not match the linguistic style well, (low LSM) (3) two negative reviews with a high LSM or (4) two negative reviews with low LSM The dependent variables in our pilot study consisted of purchase intention and, identification with the reviewer. We employed a 5-point Likert-type scales to measure participants' purchase intentions using the scale: "The likelihood of purchasing this book is: (very low to very high)" (adapted from Dodds et al. 1991). Four multiple-item, 7-point Likert-type scales (Coefficient $\alpha=.952$ ) were used to measure participants perceived identification with the reviewers (Prendergast et al. 2010).

Results: The goal of the study was to determine the degree to which LSM influenced (1) participants' identification with the reviewers and (2) interacts with affective content to 
increase (or attenuate in the case of low LSM) the impact of the reviews on purchase intention. Analyses between conditions found high levels of LSM resulted in higher identification $(M=5.52, S D=1.45)$ than low levels of $\operatorname{LSM}(M=4.31, S D=1.41)$, irrespective of the valence of the reviews' affective content $(\mathrm{F}=40.55, \mathrm{p}<.001)$. The main effect of affective content and the interaction effect were not significant. Considering the results for the second part of the pilot study, positive affective content increased purchase intentions $(\mathrm{M}=3.39, \mathrm{SD}=1.20)$ as opposed to negative affective content $(\mathrm{M}=1.53, \mathrm{SD}=.74)(\mathrm{F}$ $=246.81, \mathrm{p}<.001) . \mathrm{LSM}$ also significantly influences purchase intention $(\mathrm{F}=7.16, \mathrm{p}<.05)$, where reviews with a high LSM increased purchase intentions. Finally, we found a significant positive interaction effect between affective content and the LSM of reviews ( $\mathrm{F}=27.39, p<$ .001 ), such that reviews that convey positive affective content had a significantly stronger positive influence on purchase likelihood if they matched the linguistic style of the business book target audience (high levels of LSM) $(\mathrm{M}=3.97, \mathrm{SD}=1.04)$ than if they diverged from it $(\mathrm{M}=3.00, \mathrm{SD}=1.19)$. Similarly, negative reviews were more detrimental to purchase likelihood if they used a matching linguistic style (high LSM $)(\mathrm{M}=1.39, \mathrm{SD}=.83)$ than if not $($ low LSM $)(\mathrm{M}=1.70, \mathrm{SD}=.62)$.

Discussion: The pilot study presents first evidence for our hypothesized effects in $\mathrm{H}_{2}$ and $\mathrm{H}_{3}$, in a controlled experimental setting. 


\section{SUMMARY}

\section{Our World in Words}

\section{The Business Implications of Word Use in Online Customer Conversations}

In two studies we show that by assessing the word use in online conversations, we can draw relevant theoretical and managerial insights regarding peoples' own realities as well as the extent to which an online communication affects the audience.

In study one, we show how word use can signify members' perceptions and participation behavior in user-communities. User-communities are increasingly becoming an essential element of companies' business processes. However, reaping the benefits of such social systems does not always prove to be effective. An important reason is that companies fail to continuously stimulate members' collaboration by neglecting members' social integration in these communities. Following communication accommodation theory, members' communication style alignment may symbolically reflect their community identification and impact subsequent participation behavior. This research uses text mining to extract linguistic style properties of 74,246 members' posts across 37 user-communities. Two mixed multilevel regression models show that the members' linguistic style matches with the conventional community style signal their community identification and impact their participation quantity and quality. Drawing on the expanded view on organizational identification, the dynamics in members' social identification are considered, by examining the trend and reversals in linguistic style match developments. Whereas a stronger trend of alignment leads to greater participation quantity and quality, frequent reversals in members' linguistic style match developments suggest lower participation quantity. At a community 
level, a greater synchronicity in the linguistic style across all community members fosters individual members' participation behavior.

In study 2 then we consider the recent online development where customers increasingly rely on other consumers' reviews to make purchase decisions online. We show how new insights into the customer review phenomenon can be derived from studying the semantic content and style properties of verbatim customer reviews to examine their influence online retail sites' conversion rates. The current research employs text mining to extract changes in affective content and linguistic style properties of customer book reviews on Amazon.com. A dynamic panel data model reveals the influence of positive affective content on conversion rates is asymmetrical, such that greater increases in positive affective content in customer reviews have a smaller effect on subsequent increases in conversion rate. No such tapering-off effect occurs for changes in negative affective content in reviews. Furthermore, positive changes in affective cues and increasing congruence with the product interest group's typical linguistic style directly and conjointly increase conversion rates. These findings suggest that managers should identify and promote the most influential reviews in a given product category, provide instructions to stimulate reviewers to write powerful reviews, and adapt the style of their own editorial reviews to the relevant product category. 


\section{SAMENVATTING}

\section{Onze Wereld in Woorden}

\section{De bedrijfsmatige gevolgen van Online Klantenconversaties}

In twee studies laten wij zien dat het beoordelen van woordgebruik in online conversaties, tot relevante theoretische en praktische inzichten kan leiden over over consumenten en de manier waarop ze tegen de wereld aankijken en hoe de wijze waarop zij zich uiten medeconsumenten beinvloedt. In een eerste studie wordt duidelijk wat woordgebruik kan betekenen voor de percepties en het deelnamegedrag van deelnemers in online communities. Deze gemeenschappen worden een steeds essentiëler onderdeel van het contact dat bedrijven onderhouden met hun markten. Echter, het behalen van concurrentiele voordelen uit deze z.g., gebruikersgroepen blijkt niet altijd effectief. Een belangrijke reden is dat bedrijven er niet in lijken te slagen de samenwerking tussen deelnemers op continue wijze te stimuleren, omdat ze te weinig aandacht hebben voor de mate van sociale integratie van de deelnemers. De Communicatie Accomodatie theorie stelt dat het aanpassen van de communicatiestijl symbool staat voor identificatie met een collectief en dat dit zal leiden tot een verhoogde participatie in de discussie. In onze eerste stuidie passen we tekst-mining toe om de kenmerken van de taalkundige stijl van bijdragen van 74.246 deelnemers in 37 gebruikersgroepen te analyseren. Twee mixed-multilevel regressie modellen laten zien dat wanneer de taalkundige stijl van de deelnemers overeen komt met de gemeenschappelijke wijze van communiceren in de groep, de deelnamefrequentie en -kwaliteit wordt verhoogd. We houden bovendien ook rekening met de dynamiek in de wijze waarop deelnemers zich identificeren met de community door na te gaan wat het effect is van trends en patronen in de manier waarop deelnemers hun stijl aanpassen. Een dominantere wijze van afstemming leidt 
tot een hogere deelnamefrequentie en -kwaliteit. Eengrotere mate van fluctuaties in de ontwikkeling van de match in taalkundige stijl van de deelnemers daarentegen leidt tot een lagere deelnamefrequentie. Op gebruikersgroepsniveau leidt een hogere synchroniciteit van de taalkundige stijl van alle deelnemers tot een hogere individuele deelnamefrequentie.

In Studie 2 onderzoeken we een belangrijke recente trend die inhoudt dat consumenten in toenemende mate hun aankopen laten afhangen van de mening van mede-consumenten. We laten zien hoe nieuwe inzichten kunnen worden afgeleid uit het bestuderen van de semantische inhoud en de stijleigenschappen van reviews door klanten met het oog op het voorspellen van aankoopgedrag. Het onderzoek maakt gebruik van tekst mining technieken om fluctuaties in in affectieve inhoud en taalkundige stijleigenschappen van reviews over boeken door klanten van Amazon.com te analyseren. Een dynamisch panel data-model laat zien dat de invloed van positieve affectieve inhoud op verkopen asymmetrisch is, zodanig dat een grotere toename van positieve affectieve inhoud in klantbeoordelingen een kleiner effect op een daaropvolgende toename van verkopen zal hebben. Een dergelijk afbouwend effect treedt niet op voor veranderingen in negatieve affectieve inhoud van beoordelingen. Bovendien verhogen positieve veranderingen in affectieve signalen en het verhogen van de congruentie met de typische taalkundige stijl van het klantsegment van het product direct en gezamenlijk de verkopen. Deze bevindingen suggereren dat managers de meest invloedrijke beoordelingen in een bepaalde productcategorie moeten identificeren en promoten, beoordelaars moeten instruëeren expliciete reviews te schrijven en de stijl van hun eigen redactionele besprekingen van de relevante productcategorie moeten aanpassen. 


\section{Research @ InSites Consulting}

In many ways this dissertation can be seen as a co-creation between Maastricht University and InSites Consulting. Not only was my PhD sponsored by InSites Consulting, this cooperation enabled me to conduct and publish a number of research studies together with my colleagues from InSites Consulting. Although, these studies are not core to this dissertation, they should be viewed as valuable spin-offs, some of which I outline here:

"How fans become shapers of an ice-cream brand - Towards the next frontier in conducting insight communities" (De Ruyck et al. 2010). In this study we outline how conversational marketing' techniques have gained importance and can be used to revise marketing plans, by describing the case of Ben \& Jerry's market research online community (MROC).

In our study, titled “op zoek naar de ideale mix: hoe de deelname in online communities voor marktonderzoek stimuleren" (Ludwig et al. 2011a), we then consider members' long term participation behavior within MROCs. Drawing on extant marketing community literature, a range of participation drivers are proposed and empirically validated to influence members' likelihood to actively contribute to on-topic content. Following these findings, we advise facilitators of research communities to balance the on-topic, co-creational interaction with the off-topic more social interaction.

"Why it pays to get social in research communities" (Ludwig and Nola 2011), similarly shows the benefits of social interaction between participants of online research communities for both facilitator and members.

In a follow up study we examine "The Darkside to Crowdsourcing in Online Research Communities" (Ludwig et al. 2011b). We show a longitudinal decline in the quality of individual contributions over the course of the crowd discussions and offer potential remedies 
to counter the quality depletion phenomenon drawing on identification- and engagement theories.

In our article on "Synergizing natural and research communities" we illustrate how the fusion between listening into conversations on natural communities and asking questions on research communities' leads to a substantial increase in the research insights gained (Verhaeghe et al. 2010).

Finally we demonstrate "Why 'function words' matter" (Ludwig and De Ruyck 2012), in determining the happiness of members in market research online communities purely on their text-based community posts. 


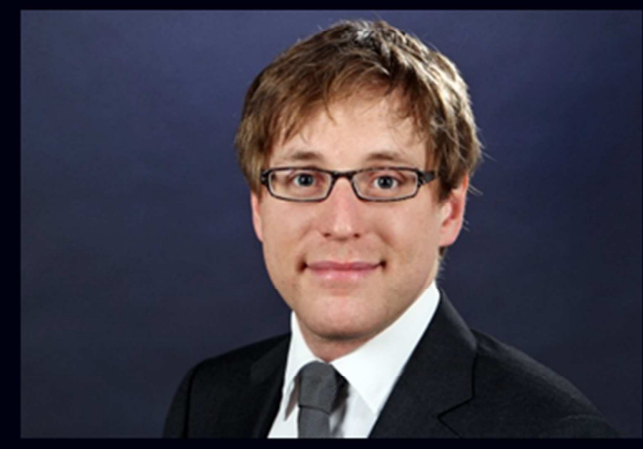

ABOUT THE AUTHOR

Stephan Ludwig was born in Bernkastel-Kues, Germany, on the 15. April 1983. From 1993 to 1999, he went to the Peter-Wust Gymnasium Wittlich, Germany, before emigrating to South Africa in January 1999. He received his final years of school education at the Deutsche Internationale Schule Kapstadt, in Cape Town, from 1999 to 2002. Having graduated with Honours in the Bachelor of Business Science at the University Cape Town, he completed his studies with a Master of Science in strategic Marketing at the University Maastricht. Stephan received a position as a $\mathrm{PhD}$ candidate at the Marketing and Supply Chain Management Department of the University Maastricht in 2008. Under the supervision of Promoters Prof. dr. Ko de Ruyter, Prof. dr. Martin Wetzels and Prof. dr. Gerard Pfann, Stephan's work centered around the creation of realities through word use in online conversations and the resulting business implications. The PhD position was fully sponsored by InSites Consulting where Stephan worked part-time as a Research Consultant for the FowaRD Lab. In many ways, this resulting dissertation represents the real-life proof for the opportunities innate to collaborations between practice and academia. The studies of this dissertation have appeared in various market research magazines, conferences and the Journal of Marketing.

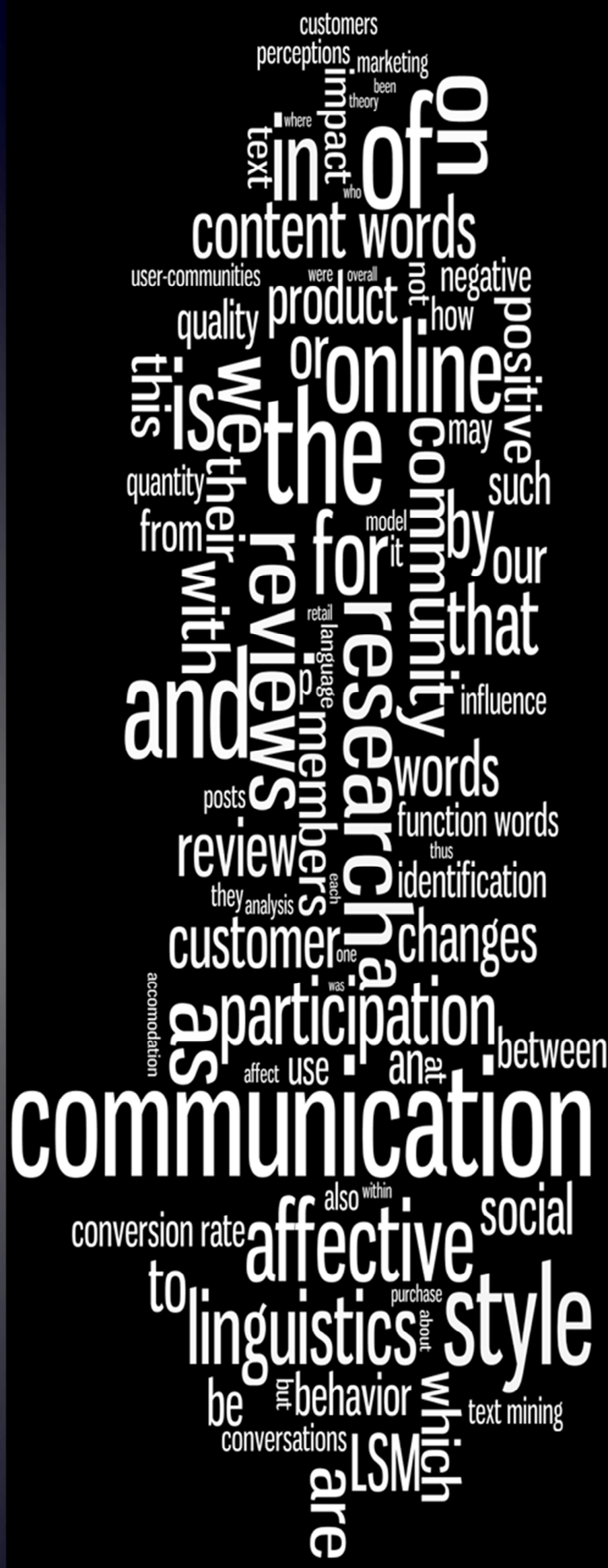

Most frequent words in this dissertation 